\title{
Temporal Bisection and Effects of d-Amphetamine Administration in Lewis and Fischer 344 Rats
}

\author{
Marissa Turturici
}

Follow this and additional works at: https://researchrepository.wvu.edu/etd

\section{Recommended Citation}

Turturici, Marissa, "Temporal Bisection and Effects of d-Amphetamine Administration in Lewis and Fischer 344 Rats" (2018). Graduate Theses, Dissertations, and Problem Reports. 6842.

https://researchrepository.wvu.edu/etd/6842

This Dissertation is protected by copyright and/or related rights. It has been brought to you by the The Research Repository @ WVU with permission from the rights-holder(s). You are free to use this Dissertation in any way that is permitted by the copyright and related rights legislation that applies to your use. For other uses you must obtain permission from the rights-holder(s) directly, unless additional rights are indicated by a Creative Commons license in the record and/ or on the work itself. This Dissertation has been accepted for inclusion in WVU Graduate Theses, Dissertations, and Problem Reports collection by an authorized administrator of The Research Repository @ WVU.

For more information, please contact researchrepository@mail.wvu.edu. 
Temporal Bisection and Effects of $d$-Amphetamine Administration in Lewis and Fischer 344 Rats

\author{
Marissa Turturici, M.S. \\ Dissertation submitted \\ to the Eberly College of Arts and Sciences \\ at West Virginia University \\ in partial fulfillment of the requirements for the degree of \\ Doctor of Philosophy in \\ Psychology
}

Karen G. Anderson, PhD., Chair

Kathryn Kestner, Ph.D.

Steven G. Kinsey, Ph.D.

JoNell Strough, Ph.D.

Stanley M. Hileman, Ph.D.

Department of Psychology

Morgantown, West Virginia

2018

Keywords: rat, temporal, discrimination, $d$-amphetamine, temporal bisection, Lewis, Fischer 344

Copyright 2018 Marissa Turturici 


\begin{abstract}
Temporal Bisection and Effects of $d$-Amphetamine Administration in Lewis and Fischer 344 Rats

Marissa Turturici

Temporal control concerns the discrimination of intervals of time. Individuals with various psychological disorders have shown differences in temporal control when compared to control populations. It is unknown whether and how temporal control might be linked with impulsivity, another measure that predicts problem behavior such as attention-deficit/hyperactivity disorder. Because Lewis (LEW) rats reliably show greater impulsive choice relative to Fischer 344 (F344) rats, the present study examined responding in these two strains under a temporal-bisection procedure that assesses temporal control. In the temporal-bisection procedure, rats are trained to discriminate between two durations. Intermediate durations are subsequently presented to determine the duration at which responding is nearly equally distributed between the original training durations. This duration is the bisection point. Because LEW rats show greater impulsive choice, it was hypothesized that LEW rats would show overestimation of duration (shorter bisection points). This effect would indicate that the subjective experience of duration, or delay, is longer for LEW rats. Results indicated that LEW rats' bisection points were shorter on average than F344 rats' bisection points in the baseline phase of the experiment. The baseline difference between LEW and F344 was not replicated during a subsequent phase of the experiment, but LEW and F344 rats did show differential effects of $d$-amphetamine on behavior during select conditions and doses. Effects of $d$-amphetamine replicated previous studies that showed apparent loss of stimulus control with increasing $d$-amphetamine doses, as opposed to underestimation or overestimation of temporal duration. The results generally add to the evidence supporting a link between impulsivity and temporal control.
\end{abstract}




\section{Acknowledgments}

First, I would like to express sincere gratitude to my advisor, Karen G. Anderson, for her guidance and mentorship throughout my time in graduate school. Karen has always encouraged my passion for behavioral pharmacology and motivated me to continue pursuing my graduate studies. I also thank Katie Kestner, Steve Kinsey, JoNell Strough, and Stan Hileman for serving on my dissertation committee and providing their thoughtful comments on the project. I am very grateful to Liz Kyonka for the classes she taught that sparked my interest in temporal control, for providing helpful comments on the proposed version of the project, and for teaching me how to conduct many of the analyses. Thank you to Regina Carroll for also providing helpful comments on the proposed version of this project. I am tremendously grateful to my parents, Frank and Diane Turturici, who have provided me with an enormous amount of love and support in all of my academic pursuits. I am also so grateful to Trisha Hopkins, who has been a true friend, trusted confidant, and amazing roommate. Finally, I would like to thank several other people who have supported me throughout this process: Jenny Ozga, for being an amazing friend and partner in the lab; Matt Eckard, Devin Galdieri, Josh Tost, Ashley Shultz, and Chris Iames for running portions of the experiment; Tyler Nighbor and Shrinidhi Subramaniam for helping me create log-survivor plots; Erin McClure for providing helpful comments on the analyses; Ryan Smith for his support and encouragement while I began a new position and finished this project during the same year; and Apral Foreman, Elizabeth Edens, Paul Enlow, and Chris Krebs for their advice and friendship. 
Table of Contents

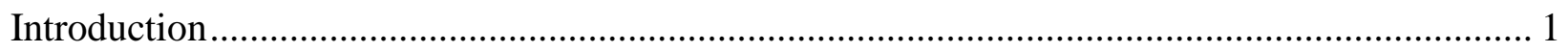

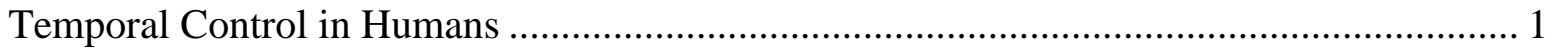

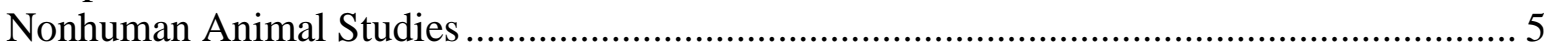

Procedural Variations in Temporal Bisection .................................................................. 9

The Role of Dopamine in Temporal Control ................................................................. 10

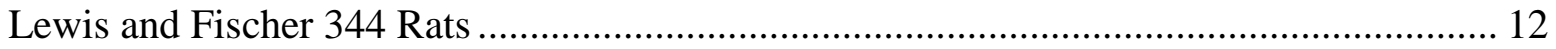

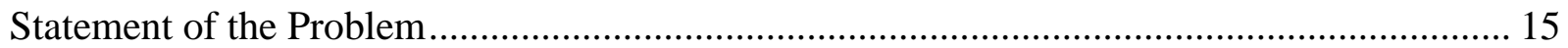

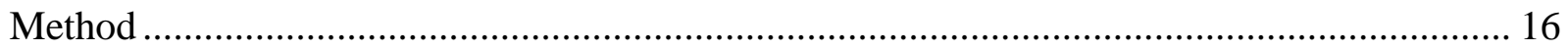

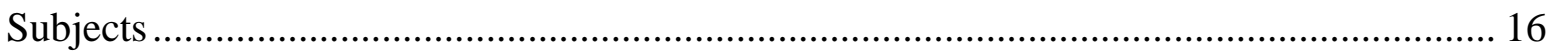

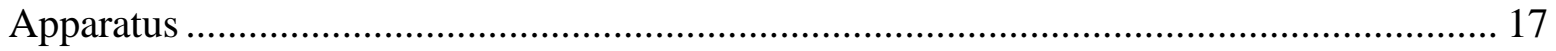

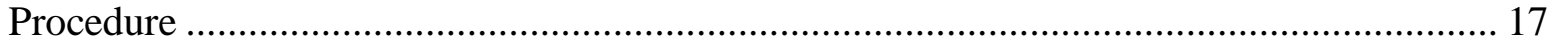

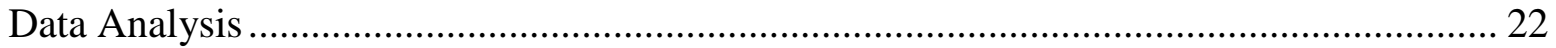

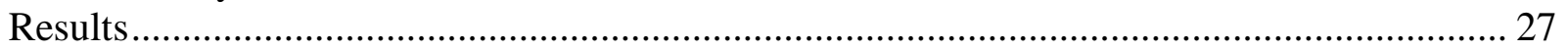

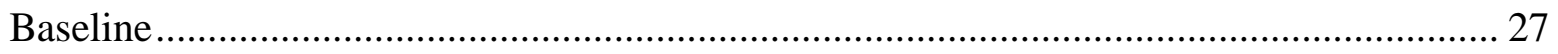

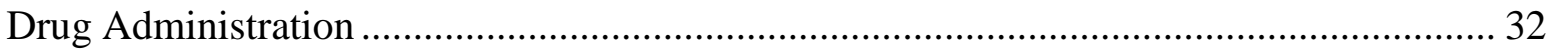

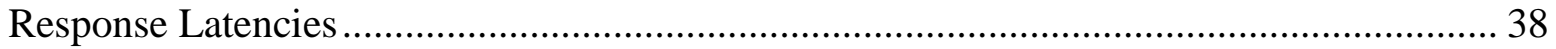

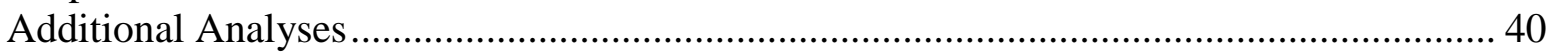

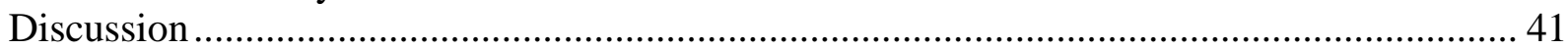

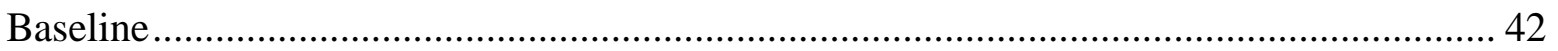

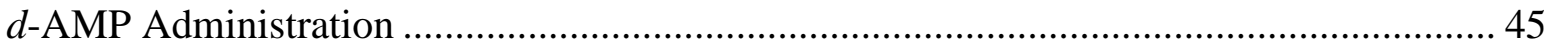

Comparisons Across Data Analysis Methods ..................................................................... 48

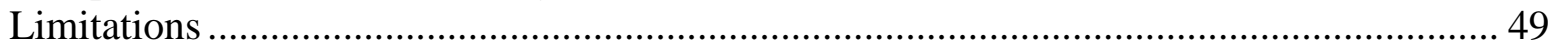

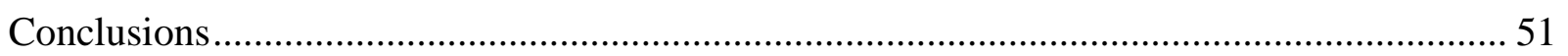

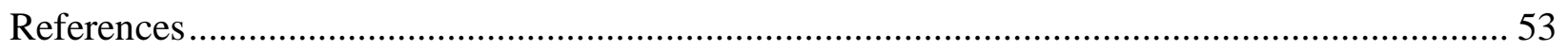

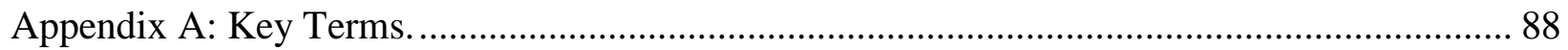

Appendix B: Method and Data from Original Analyses. ............................................................ 90

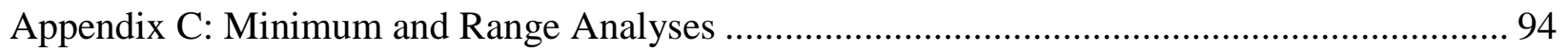

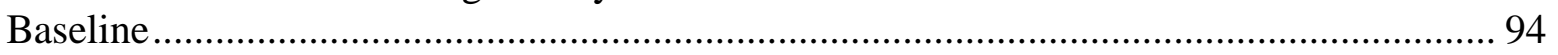

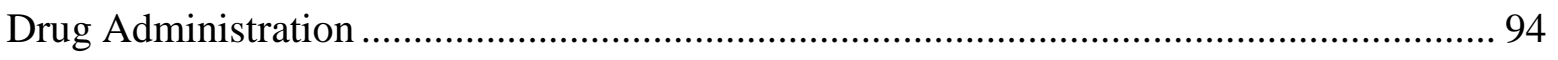

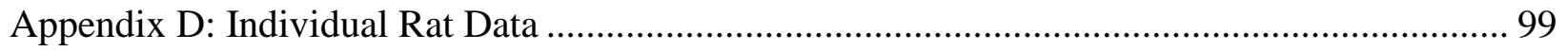

Appendix E: Log-Survivor Plots of Latencies....................................................................... 111 


\section{List of Tables}

Table 1. Duration values (in seconds) that comprise each series.

Table 2. Baseline results summary. Arrows represent significant increases or decreases that occurred with increasing series.

Table 3. Drug administration results summary.

Table 4. Average omissions per session and number of sessions excluded 64

Table 5. Average omissions per session for each rat (included sessions only) 65

Table 6. Bisection point (BP), difference limen (DL), Weber fraction (WF), and coefficient of determination $\left(\mathrm{R}^{2}\right)$ for each series of the baseline phase.

Table 7. Minimum (Min), range, bisection point ( $\mathrm{Mu}$ ), standard deviation (Sigma), and coefficient of determination $\left(\mathrm{R}^{2}\right)$ for baseline phase.

Table 8. Bisection point (BP), difference limen (DL), Weber fraction (WF), and coefficient of determination $\left(\mathrm{R}^{2}\right)$ for the 2-s-vs.-8-s duration series of the drug administration phase. 68

Table 9. Minimum (Min), range, bisection point $(\mathrm{Mu})$, standard deviation (Sigma), and coefficient of determination $\left(\mathrm{R}^{2}\right)$ for the 2-s-vs.-8-s duration series of the drug administration phase.

Table 10. Bisection point (BP), difference limen (DL), Weber fraction (WF), and coefficient of determination $\left(\mathrm{R}^{2}\right)$ for the 15 -s-vs.-60-s duration series of the drug administration phase.

Table 11. Minimum (Min), range, bisection point (Mu), standard deviation (Sigma), and coefficient of determination $\left(\mathrm{R}^{2}\right)$ for the 15 -s-vs.-60-s duration series of the drug administration phase. 


\section{List of Figures}

Figure 1. Hypothetical psychophysical function.

72

Figure 2. Proportion correct across correction and regular training sessions for the initial temporal discrimination. 73

Figure 3. Proportion correct across correction and regular training sessions for the initial temporal discrimination.

Figure 4. Results from two-duration training for each series (x-axes) during the baseline phase.75

Figure 5. Baseline proportion long response across durations presented in baseline test sessions,

averaged by each rat. 76

Figure 6. Boxplot of average proportion long response for each series of the baseline phase ..... 77

Figure 7. Mean bisection points, difference limen values, and Weber fractions by strain and series for the baseline phase (linear results)

Figure 8. Mean, minimum, range, standard deviation (sigma), and bisection points of Gaussian functions across strains and series for the baseline phase.

Figure 9. Proportion long response across durations from test sessions averaged by drug dose and strain for the 2-s-vs.8-s duration series. 80

Figure 10. Boxplot of average proportion long response for each dose of the 2-s-vs.-8-s series of the drug administration phase.....

Figure 11. Mean bisection points, difference limen values, and Weber fractions from the linear analyses of the 2-s-vs.-8-s series across drug doses

Figure 12. Mean Gaussian parameters across drug doses for LEW and F344 rats from the 2-s-vs.8-s series.

Figure 13. Proportion long response across durations from test sessions averaged by drug dose and strain for the 15-s-vs.-60-s duration series.

Figure 14. Boxplot of average proportion long response for each dose of the 15-s-vs.-60-s series of the drug administration phase.

Figure 15. Mean bisection points, difference limen values, and Weber fractions from the linear analyses of the 15-s-vs.-60-s series across drug doses

Figure 16. Mean Gaussian parameters across drug doses for LEW and F344 rats from the 15-svs.-60-s series. 
Temporal Bisection and Effects of $d$-Amphetamine Administration in Lewis and Fischer 344

$$
\text { Rats }
$$

Stimulus discrimination occurs when an organism responds differentially in the presence of one environmental context over another. Operant-conditioning chambers illustrate this process when they are arranged to produce reinforcement when a rat presses a lever. Constraints can then be added to this contingency to further specify the conditions under which reinforcement occurs. One example constraint might specify that lever presses produce reinforcement only when a light above the lever is lit. Conversely, when this light is off, lever presses would have no consequences. Initial exposure to these conditions will result in undifferentiated lever pressing regardless of the light's status, but eventually, lever pressing will cease when the light is turned off and resume when the light is turned on. When such responding occurs reliably, stimulus discrimination has occurred between the light-on and light-off stimuli, and the behavior is under stimulus control. Organisms discriminate between wide arrays of stimuli across multiple dimensions. When the stimuli discriminated are durations of time, behavior is said to be under temporal control.

\section{Temporal Control in Humans}

Temporal control can be categorized according to the length of the interval controlling behavior. Most commonly, this categorization comprises two types of timing: circadian and interval. Circadian timing concerns durations approximately $24 \mathrm{hr}$ in length, around which mammals usually exhibit cyclical behavioral patterns (Golombek \& Rosenstein, 2010; Hinton \& Meck, 1997). In contrast, interval timing concerns temporal control that occurs in the seconds-tominutes range. Deficits in either type of temporal control are associated with various psychological disorders in humans. 
There is evidence to suggest that poor temporal control is implicated in bipolar disorder. Although most studies have focused on the role of circadian intervals in bipolar disorder, there is evidence that interval timing may also be disrupted. Compared to control participants, Tysk (1984) demonstrated that manic participants overestimated interval durations, whereas underestimation was evident in subsets of depressed participants. In contrast, another study found that both depressed and manic individuals overestimated temporal intervals compared to control participants (Bschor, Ising, Bauer, Lewitzka, Skerstupeit, Müller-Oerlinghausen, Baethge, 2004). These results conflicted with self-reports that showed a subjective lengthening of time in depressed participants and a subjective shortening in manic participants. Therefore, deficits in temporal control may not necessarily be in line with the subjective experience of time. It is also possible that temporal control deficits result in increased variability of temporal estimates in both directions (overestimation and underestimation), as bipolar participants have also shown higher variability in reproduction of temporal intervals compared to control participants (Bolbecker, Hong, Kent, Forsyth, Klaunig, Lazar...\& Hetrick, 2011).

Other neurological and psychological disorders exist that correlate with deficits in temporal control. These disorders have also manifested with overestimation, underestimation, or increased variability in temporal estimates. Reviews of the role of temporal control in several disorders, including Parkinson's disease and schizophrenia, have been outlined in Teixeira et al. (2013), and Buhusi and Meck (2005). Children with attention-deficit/hyperactivity disorder (ADHD; Smith, Taylor, Warner Rogers, Newman, \& Rubia, 2002) have shown impaired discrimination of temporal intervals that differ by 100-300 milliseconds, compared to control children. Children with ADHD are also prone to underestimation on tasks that assess temporal control (Smith et al., 2002), as are children with hyperactive behavior in general (Sonuga Barke, 
Saxton, \& Hall, 1998). Dyslexia, which is highly comorbid with ADHD, also correlates with lower accuracy on a temporal estimation task in both children (Nicholson, Fawcett, \& Dean, 1996) and adults (Hari \& Kiesilä, 1996).

Many of the neurological and psychological disorders above are either directly rooted in dopamine dysfunction (as in Parkinson's disease, see Dauer \& Przedborski, 2003) or carry strong evidence to suggest that they relate to dopamine transmission (for schizophrenia, see Ross, Margolis, Reading, Pletnikov, \& Coyle, 2006; for bipolar disorder, see Ashok et al., 2017; for ADHD, see Hulst et al., 2017). Dopaminergic drugs are commonly used as therapeutic agents in these disorders. Therefore, it is possible that dopaminergic drugs alter or improve temporal control, which in turn may affect other symptoms. Such other symptoms can include behavioral problems such as impulsivity, which is quite common in individuals with ADHD.

The Diagnostic and Statistical Manual of Mental Disorders (DSM-V) includes "hyperactivity-impulsivity" as one of the criteria for diagnosis in ADHD (American Psychiatric Association, 2013). Hyperactivity/impulsivity symptoms in the DSM-V include those such as fidgeting, inability to remain still, talking excessively, or responding out of turn. Thus, responding too early, which is termed "motor impulsivity," "behavioral disinhibition," or “impulsive action," is often present in these individuals (Schachar, \& Logan, 1990, see Winstanley, Eagle, \& Robbins, 2006, for a review). Impulsivity of a second kind, often termed "impulsive choice," or "delay discounting" tends to occur more often in individuals with ADHD as well. That is, individuals with ADHD choose smaller, sooner reinforcers over larger, more delayed reinforcers more so than individuals without ADHD (Sonuga-Barke, Taylor, Sembi, \& Smith, 1992; see Winstanley et al., 2006, for a review). Because individuals with ADHD exhibit 
poor temporal control, impulsivity, and likely dopaminergic dysregulation, it is quite possible that these three characteristics are somehow linked.

It has been hypothesized that both motor impulsivity and impulsive choice involve poor temporal control (Rubia, Halari, Christakou, \& Taylor, 2009). In motor impulsivity, a response is made before a specified interval has elapsed, perhaps due to perception of the interval as longer, which may be in the range of milliseconds. Assessment of impulsive choice involves the presentation of two response alternatives: a small, immediate reinforcer and a larger, delayed reinforcer. Thus, intolerance to long delays, or an impaired estimation of the length of delays has been proposed to account for impulsive choice (Winstanley et al., 2006).

Assessments of the relation between temporal control and impulsive choice in humans have shown mixed results. Baumann and Odum (2012) found that shorter judgments of duration correlated with fewer impulsive choices, and longer judgments correlated with more impulsive choices. Thus, individuals who overestimate the duration of stimuli may be more likely to make impulsive choices. While this explanation is most intuitive (the duration seems longer, so an individual is less likely to wait for a larger reward), others have shown different results. Reynolds \& Schiffbauer (2004) demonstrated that sleep-deprived individuals made more impulsive choices compared to control participants, and they underrepresented intervals when they were required to reproduce them. Barkley, Edwards, Laneri, Fletcher, \& Metevia (2001) demonstrated that while adolescents with ADHD made more impulsive choices and made more errors on a temporal-reproduction task than control adolescents, their errors were not systematically classified as errors of overestimation or underestimation. Adolescents with ADHD in this study were simply less accurate. In addition, these adolescents did not differ from control adolescents in a temporal-estimation task, which required participants to report an 
estimate of the duration immediately after it has elapsed, rather than to reproduce it. Toplak, Dockstader, \& Tannock (2006) provide a review of several studies that show differences between individuals with ADHD and those without on timing tasks which echoes these mixed results. Therefore, it is unclear whether underestimation, overestimation, or a lack of control by temporal intervals, predicts impulsive choice or any given disorder associated with it.

\section{Nonhuman Animal Studies}

The study of temporal control in nonhuman animals provides a robust way to assess how temporal control relates to genetic and environmental factors. Several procedures have been developed to assess accuracy and precision of temporal control in nonhuman animals.

Fixed-interval schedules. One of the first demonstrations of temporal control occurred when Skinner (1938) examined behavior on fixed-interval (FI) schedules. An FI schedule presents a reinforcer contingent on the first response that occurs following a specified interval of time. Responses before this time interval elapses are counted, but do not have any other programmed consequences. Skinner demonstrated that response rate on FI schedules increases as the time to reinforcement approaches. Schneider (1969) went on to show that quarter-life, or the point at which $25 \%$ of responses on a given trial are made, is proportional to the length of the fixed interval. These were among the first studies to demonstrate that organisms vary behavior according to time, and that behavior under temporal control is proportional to the relevant interval of the controlling contingency.

Peak-interval procedure. The peak-interval procedure presents sessions composed of a majority of FI trials, but with random, non-reinforced trials inserted (Catania, 1970; Roberts, 1981). These "peak trials" are double in length to the fixed-interval trials. Typical response patterns on peak trials first show the characteristic FI pattern of responding, in which response 
rate increases until the point at which reinforcement is usually delivered. Then, response rate peaks around the value of the fixed-interval length, and subsequently decreases, forming an inverted-u-shaped curve, or "low-high-low" pattern. Like quarter-life, this "peak time" is proportional to the length of the FI. The quarter-life also denotes the start of responding during both peak- and fixed-interval trials. Peak spread, a measure of the width of the peak, increases in proportion to the length of the FI (multiplicatively), rather than in absolute value to it. Thus, the FI and peak procedures provide evidence that responding is governed by relative, rather than absolute differences in temporal stimuli.

Temporal bisection. In another procedure using pigeons, Stubbs (1968; Experiment 1) presented discrete trials in which two keys were available concurrently. Pecks to a key of one color (red or green) were considered correct if the duration of the light was between 1 and $5 \mathrm{~s}$ (short) while pecks to the other colored key were considered correct if the duration of the light was between 6 and $10 \mathrm{~s}$ (long). Every correct response produced a conditioned reinforcer $(0.5 \mathrm{~s}$ illumination of the feeder light), while every sixth correct response also produced food. Each of the ten durations (1-10 s) had an equal probability of occurrence on any given trial throughout the session. This procedure is called the temporal-bisection procedure, which will henceforth be referred to as the bisection procedure throughout the text. Using the bisection procedure, Stubbs found that the point at which the probability of a long response was $50 \%$ was approximately $3 \mathrm{~s}$. This measure of temporal control is called the bisection point (Church \& Deluty, 1977), or point of subjective equality. In other words, the bisection point shows the duration at which responding on either alternative (short or long) was equally probable. The bisection point of $3 \mathrm{~s}$ found in Stubbs (1968; Experiment 1) was near the geometric mean of the shortest (1 s) and longest (10 s) stimulus durations (3.16). The geometric mean is determined by multiplying a set of values and 
taking the $n$th root, where $n$ is the sample size of the set of values. In contrast to the arithmetic mean, (determined by summing the set of values and dividing by their sample size), the geometric mean may be preferred for its multiplicative aspect that results in a reduction of the influence of outliers on the mean. To translate its relevance to temporal control, the correspondence of the bisection point to the geometric mean indicates that temporal control depends on the relative (multiplicative) differences between stimuli, rather than the absolute (additive) differences. Therefore, Stubbs (1968; Experiment 1) corroborated the finding that temporal discrimination is governed by the relative, rather than absolute differences between temporal stimuli.

In another variation of the bisection procedure, Stubbs (1976) used a free-operant procedure involving a response key and a changeover key rather than two response keys. When the response key was green, a response made to that key was considered a "short" response, and when the response key was red, a response made to that key was considered a "long" response. The changeover key changed the color of the response key when pecked. Responses could be made throughout the trial. However, reinforcement was scheduled only for responses occurring at either one of two intervals: short (e.g., 2-4 s) or long (e.g., 60-64 s). The length of the intervals and the trials varied across conditions. The time at which responding was equally distributed between red and green keys (the bisection point) fell again near the geometric mean.

The bisection point was also shown to occur at the geometric mean of two intervals in rats (Church \& Deluty, 1977). During training, responses on the left lever were reinforced if the sample duration was long, while responses on the right lever were reinforced if the sample duration was short. Intermediate durations were then introduced in the testing phase of the experiment. In testing, the original sample durations occurred $25 \%$ of the time, while the 
remaining durations were intermediate. Only responses to the original sample durations produced reinforcement. Church and Deluty (1977) then compared bisection points to the arithmetic, harmonic, and geometric means. The geometric mean again accounted for the most variance in the bisection point.

None of the temporal-bisection experiments listed thus far demonstrated that behavior was controlled by both the short and the long intervals, though the interpretation of the results rested on this assumption. In a similar procedure to Stubbs (1976), Platt and Davis (1983) ruled out the possibility that the short interval alone was controlling the change in responding by varying the length of the short interval while holding the long interval constant and vice versa. Similar results were obtained in which the bisection point was found to lie at or near the geometric mean, demonstrating that both intervals acquire temporal control over behavior in the bisection procedure. Thus, in each of the bisection experiments noted above, the probability of the "long" response increased as a sigmoidal function of the sample duration, with 50\% probability of a "long" response (the bisection point) corresponding with the geometric mean of the sample duration. This sigmoidal function is also referred to as the psychophysical function.

A hypothetical psychophysical function is presented in Figure 1. In the present study, a cumulative Gaussian function was used to fit the data with two free parameters. The mean, or bisection point $(\mu)$, shows the point of subjective equality between the two durations, when responding on the long and short alternatives is equally probable. Shifts of the bisection point to the left represent faster timing, and potential overestimation of stimulus duration. Shifts of the bisection point to the right represent slower timing, and potential underestimation of stimulus duration. The second free parameter, the standard deviation, represents the slope of the function $(\sigma)$, and is considered a measure of stimulus control or sensitivity. For example, functions with 
shorter standard deviations display data from less varied responses across stimulus durations, thus reflecting more precise stimulus control.

\section{Procedural Variations in Temporal Bisection}

Intertrial intervals (ITIs). There is evidence that temporal control may be affected by small procedural variations. For example, Raslear, Shurtleff, and Simmons (1992) found that increases in the ITI, which co-occurred with decreases in reinforcement rate, altered sensitivity of the temporal discrimination on a bisection task. Sensitivity was a quantitative measure of accuracy ranging from complete accuracy to responding at chance levels or below. Sensitivity was greatest at a 5-s ITI and lowest at a 20-s ITI. Decreasing the ITI below $5 \mathrm{~s}$ lowered sensitivity. Raslear et al. (1992) also examined effects of ITI length on bias to respond on the short or long alternative. Bias toward the long response was more apparent with longer ITIs. The bias for each rat appeared to coincide with the lever that produced more reinforcement, but when analyzed statistically, the trend was not significant. That is, the larger bias to respond on the long-duration lever when ITIs were also long could not fully be explained by a higher obtained relative reinforcement rate associated with that lever. Because each trial length was fixed at $100 \mathrm{~s}$ in the current study, there was no potential effect of the ITI on the rate of reinforcement. In addition, trials were randomly distributed throughout the session, eliminating any potential possibility that any given ITI duration might act as a cue for the upcoming stimulus duration. It is possible that responses on trials following long ITIs differed from responses on trials following short ITIs, but the random distribution of trial types ensured that any effect on the results was not systematic.

Correction for inattention. The time between the start of a trial and the response is known as the latency to the response. Maricq, Roberts and Church (1981) and Maricq and 
Church (1983) corrected for responses with long latencies (longer than the mean, and longer than $5 \mathrm{~s}$, respectively) by omitting them from the psychophysical functions. Church \& Deluty (1977) also corrected data by using the error responses on the stimulus anchors (long and short) to estimate the total errors that might be attributed to a side bias or inattention. Other authors (e.g., Odum, Lieving \& Shaal, 2002) have questioned whether or not these types of corrections account for the leftward shifts in the psychophysical functions observed when dopaminergic drugs are administered. The rationale for removing responses with longer latencies is that they may be associated with errors, inattention, or both. Thus, uncorrected data may result in flatter functions due to more errors represented in the function. For example, for a procedure that trains discrimination between 2-s and 8-s, a "long" response to a 2-s stimulus would be considered incorrect. Should this response also have a long latency, it would only be represented in the function if it were not corrected. Compared to corrected data, inclusion of this error would result in an increase in the left tail, and a flattening of the function. Because it is unclear whether correcting data could alter results, both uncorrected and corrected data were calculated in the present study.

\section{The Role of Dopamine in Temporal Control}

As noted above, dopamine is involved in both temporal control and impulsive choice. Dopaminergic agonists, such as $d$-amphetamine ( $d$-AMP) and methamphetamine increase the availability of extracellular dopamine (Kuczenski \& Segal, 1997). $d$-AMP decreases impulsive behavior in humans (de Wit, Engasser, \& Richards, 2002) and rats (Huskinson \& Anderson, 2012; Huskinson, Krebs, \& Anderson, 2012; Cardinal, Robbins, \& Everitt, 2000; Wade, deWit, \& Richards, 2000). $d$-AMP and related compounds are often prescribed to individuals with ADHD. 
There have been some mixed results on the role of dopaminergic drugs in choice and timing. In rats, when the peak procedure is used, studies have generally shown that peak response rates shift to the left when dopaminergic agonists are administered (Chiang et al., 2000, Experiment 1; Maricq, et al., 1981, Experiments 1 \& 2; but see Bayley, Bentley, \& Dawson, 1998). A peak shift to the left indicates an overestimation of the length of time that has passed since the trial began.

In the bisection procedure, some studies have shown that the psychophysical function and bisection point shift to the left when dopaminergic agonists are administered to rats (Cheng, MacDonald, \& Meck, 2006; Maricq et al., 1981, Experiment 3; Maricq \& Church, 1983). A shift to the left indicates that dopaminergic agonists produce a subjective increase in the speed of time resulting in overestimation of the length of time that has passed. However, other studies have shown a flattening of the psychophysical function following administration of dopaminergic agonists that was not accompanied by a shift in the function (McClure et al., 2005; McClure, Saulsgiver, \& Wynne, 2009; Odum \& Ward, 2007), although these studies used pigeons as subjects. A flattened function without a change in the bisection point typically indicates a general unsystematic pattern of behavior, or the loss of control by temporal stimuli, rather than underestimation or overestimation of time. Administration of dopaminergic antagonists, which reduce the availability of dopamine, has produced a shift to the right in the psychophysical function (Maricq \& Church, 1983; Meck, 1986).

Çevik (2003) demonstrated that methamphetamine's effect on the bisection point was dependent upon on the time that the bisection procedure began. Longer wait times between drug administration and the start of the bisection procedure altered results. When the procedure occurred 20-100 min after injection, the psychophysical function was flattened without a shift, 
but when the procedure occurred 100-180 min following the same dose, the function shifted to the left. One limitation of this study is that it did not employ a parametric design testing several doses of the drug. Thus, the results are likely due to pharmacokinetic effects. That is, a large amount of methamphetamine was likely eliminated after $100 \mathrm{~min}$ due to the relatively short halflife of methamphetamine in the rat (approximately 70 min; Cho, Melega, Kuczenski, \& Segal, 2001).

Similar to studies that have examined effects of dopaminergic drugs on temporal control, some studies have shown mixed results regarding the efficacy of dopamine agonists at reducing impulsive choice. For example, Huskinson et al. (2012) found that $d$-AMP's effects on impulsive choice depended on rat strain. If impulsivity stems from poor temporal control, it may be the case that $d$-AMP's effects on temporal control also depend on genetic factors, which can be studied using different rat strains.

\section{Lewis and Fischer 344 Rats}

The Lewis (LEW) and Fischer 344 (F344) rat strains are often used to study impulsivity. These genetically different strains also tend to display differences in impulsivity. For example, LEW rats make more impulsive choices than F344 rats in a delay-discounting procedure (Anderson \& Diller, 2010; Anderson \& Woolverton, 2005; Huskinson et al., 2012; Stein, Pinkston, Brewer, Francisco, \& Madden, 2012), and also make more premature responses in a procedure measuring motor impulsivity (the Five Choice Serial Reaction Time Task; Hamilton, Potenza, \& Grunberg, 2014). LEW rats also have less extracellular dopamine and fewer dopamine transporters in several brain areas than F344 rats (Flores, Wood, Barbeau, Quirion, \& Srivastava 1998). These behavioral and physiological differences have prompted research concerning the LEW rat as a potential animal model of ADHD (Garcia \& Kirkpatrick, 2013). 
Studies involving humans have shown that more impulsive choices on a delaydiscounting procedure correlate with shorter judgments of interval length (Baumann \& Odum, 2012; Reynolds \& Shiffbauer, 2004). This result has also been shown in individuals with ADHD, who more commonly show impulsive choice and inaccurate temporal control. For example, some studies comparing children with ADHD to children without ADHD have shown greater delay discounting correlates with inaccurate temporal control either by underestimation or overestimation (e.g., Barkley et al., 2001; Smith et al., 2002). Thus, it is unclear whether altered temporal control in ADHD necessarily manifests as underestimation of intervals or a general lack of stimulus control or precision.

A similar question has been raised in animal research, where the LEW rat has shown wider peak times (less precise temporal control) than the Sprague-Dawley rat, but has not necessarily shown underestimation or overestimation (Smith, Marshall, \& Kirkpatrick, 2015; Experiment 3). Still, impulsive choice was evident in LEW rats in Smith et al. (2015), where LEW rats made more impulsive choices in Experiment 3 compared to Sprague-Dawley rats used in Experiment 1 and 2. Procedures were also implemented to reduce impulsive choice across all strains. The procedure used in both Sprague-Dawley and LEW rats involved 30 sessions of training on FI or variable-interval (VI) schedules. Following this training, impulsive choice was significantly reduced overall in Sprague-Dawley, but not LEW rats. LEW rats only showed a reduction in impulsive choice when data were analyzed by components of the experiment (for example, effects were only evident at certain delay values). Accuracy of temporal control was increased in all rats, shown by decreased standard deviation of peak times. However, the effect was less robust for the LEW rat in Experiment 3 than the two previous experiments using Sprague-Dawley rats. A similar relation was also shown in Heilbronner and Meck (2014), but 
peak time, rather than spread, was negatively correlated with impulsive choice in SpragueDawley rats.

Although rats that make more impulsive choices show less accurate temporal control, research has yet to demonstrate differences between LEW and F344 rats on the bisection procedure. A study using spontaneously hypertensive rats (SHRs), which have been used as a rat analog of ADHD, did not find differences in temporal control on a bisection procedure compared to control rats (Orduña, Hong, \& Bouzas, 2007).

One study conducted in the same laboratory as the present study used a peak-interval procedure to assess temporal control in LEW and F344 rats before and after $d$-AMP administration (Follett, 2014). Results showed no differences in peak time between the two strains, though LEW rats showed higher response rates and larger peak spread in certain conditions of the experiment. The higher peak spread in LEW rats reflects the results of Smith et al. (2015). In Follett (2014), it is possible that the larger spread may have reflected impulsive behavior in the LEW rat in the form of premature responding, as latencies to begin responding were shorter in this strain. For most rats, the shift to the left in the peak time (indicating an earlier peak time) was observed after $d$-AMP administration, but the extent of the shift did not differ between the LEW and F344 strains. The larger peak spread may point to potential differences in the precision of temporal control in LEW rats, which may be the mechanism of impulsive choice in this strain, rather than overestimation or underestimation of duration length.

It may be useful to determine if temporal control differs between these strains when behavior is constrained to a single response. Using a procedure that relies on a discrete, rather than continuous, measure of behavior may control for variation in response rate and for some (but not all) impulsive responding. As Follett (2014) noted, the bisection procedure provides 
such a discrete measure while still allowing for a precise measurement of temporal control that can be compared between the two strains.

Considering that LEW rats make more impulsive choices than F344 rats in delaydiscounting procedures, it is possible that overestimation of the length of the delay to the larger reinforcer results in LEW rats choosing the small, immediate reinforcer more often. If that is the case then their bisection points should be shifted to the left in comparison to F344 rats' bisection points. It is also possible that LEW rats' lower dopamine levels results in two independent processes: underestimation and impulsive choice, under which shifts to the right relative to F344 would be observed. A third possibility is that LEW rats differ from F344 rats only in precision of temporal control. In that case, LEW rats should take longer to acquire the original temporal discrimination in the bisection procedure, and they should show flatter psychophysical functions compared to F344 rats.

\section{Statement of the Problem}

If impulsivity stems from a "timing disturbance," as some have suggested (Rubia et al., 2009), then temporal control is expected to differ in LEW and F344 rats. Specifically, the more impulsive strain of the two (typically LEW) may be prone to inaccurate or imprecise temporal control. On a bisection procedure, overestimation in LEW rats would manifest as shorter bisection points relative to the F344 rats and possibly also relative to the geometric mean. Underestimation in the LEW rat would show the converse: longer bisection points relative to the F344 rats' values. Though LEW and F344 did not differ in temporal control on a peak procedure, the bisection procedure may offer a larger degree of experimental control by reducing erroneous responding and restricting the number of responses allowed. If the parameters of the psychophysical function obtained from the bisection procedure for LEW and F344 do not differ, 
such evidence would call into question whether impulsivity and temporal control stem from the same process. While it is clear that poor temporal control and impulsive behavior can co-occur, it is unknown whether the two outcomes stem from a single process. The present study was not designed to unequivocally answer this question, but to provide further evidence in either direction.

A second goal stemmed from the differential effects on impulsive choice under $d$-AMP that LEW and F344 strains show, particularly in delay-discounting procedures. It is possible that effects of $d$-AMP depend on baseline levels of impulsive choice. If the LEW and F344 strains differ in temporal control in the bisection procedure, they may also demonstrate differential effects of $d$-AMP on the psychophysical function.

\section{Method}

The present study consisted of a multi-phase assessment of temporal control in LEW and F344 rats. Data were analyzed using two methods, a linear analysis and a Gaussian analysis. Because the terms used may vary between procedures and analyses, a list of key terms is provided in Appendix A.

\section{Subjects}

Six experimentally naïve LEW and six experimentally naïve F344 rats served as subjects. Rats were obtained from Envigo, Inc. (Indianapolis, IN), and were approximately 6 weeks old when shipped. Rats were housed singly with continuous access to water for the duration of the experiment. The colony room temperature was maintained at approximately 20 degrees $\mathrm{C}$ and a 12-hour reversed light-dark cycle was in effect. All sessions were conducted during the dark portion of the light-dark cycle. 
For the first week, food and water were provided ad libitum in the home cage and there were no experimental sessions. Following this period, rats were restricted from access to food for $22 \mathrm{hr}$ prior to experimental sessions and were fed approximately 12-15 g of standard rat chow 30 min after each session. Rats were weighed at least once per week. All procedures were approved by West Virginia University's Animal Care and Use Committee.

\section{Apparatus}

Eight operant-conditioning chambers for rats were used for the duration of the experiment (Med Associates, VT). Each chamber was enclosed in a melamine sound-attenuating cubicle and contained a working area of $30.5 \mathrm{~cm}$ by $24.5 \mathrm{~cm}$ by $21.0 \mathrm{~cm}$, a grid floor, and a $45-$ mg pellet dispenser with a pellet receptacle centered between two retractable response levers. The levers were $11.5 \mathrm{~cm}$ apart from each other and required a force of $0.25 \mathrm{~N}$ for a response to be recorded. The levers were $4.8 \mathrm{~cm}$ wide, were elevated $8 \mathrm{~cm}$ from the grid floor, and protruded $1.9 \mathrm{~cm}$ into the chamber. A $28-\mathrm{V}$ houselight was attached to the wall opposite the wall containing the operanda. A ventilation fan circulated air and masked extraneous noise. Data collection and programmed consequences were controlled by a personal computer equipped with Med-PC software (Med Associates, VT).

\section{Procedure}

Feeder training. The first experimental session served as feeder training. Both levers in each chamber were retracted for the duration of the 1-h session. One food pellet was delivered on a variable-time 60 -s schedule, for a total of 60 food pellet deliveries. At the end of the session, any uneaten food pellets were counted and recorded. As no uneaten food pellets remained, only one session of feeder training was required for all rats. 
Acquisition training. Acquisition of lever pressing was trained using a tandem fixedratio (FR) 1, differential-reinforcement-of-other-behavior 10-s schedule. Both levers were extended into the chamber, but only one produced food pellets for the duration of this 8-h session. If lever pressing was not acquired by the end of this session, it was shaped using differential reinforcement of successive approximations. On the day following acquisition training, completion of an alternating FR schedule was used to confirm acquisition of the response and to train responses on the other lever. The alternating FR schedule first presented one lever into the chamber with its cue-light lit. One response on this active lever produced a food pellet while responses on the other lever had no programmed consequences. When five responses were completed on one lever, the cue-light above it turned off, the cue light above the other lever turned on, and the other lever produced a food pellet following a lever press. This contingency operated until 40 pellets were delivered or two hours elapsed. If the alternating FR schedule procedure lasted over an hour, it was in effect the following day. No more than three alternating FR sessions were required for any rat.

Baseline. When acquisition training was complete, a two-duration discrimination procedure was implemented. The following values constituted the short and long durations for each duration pair: $2 \mathrm{~s}$ and $8 \mathrm{~s}, 4 \mathrm{~s}$ and $16 \mathrm{~s}, 10 \mathrm{~s}$ and $40 \mathrm{~s}$, and $15 \mathrm{~s}$ and $60 \mathrm{~s}$. For each duration pair, the long stimulus was four times the length of the short stimulus. The 2-s vs. 8-s duration pair was chosen to replicate previous research using a bisection procedure (e.g., Church \& Deluty, 1977; Maricq et al., 1981). The remaining values were chosen because each of the long durations was equal to the terminal delay value in the delay-discounting procedure used by Huskinson et al. (2012) and other studies from the same laboratory. That is, any differences in 
timing that were influencing choice on the delay-discounting procedure would be most likely to emerge when responding to durations within the same range as those used in that procedure.

Temporal-bisection training. Sessions began with a 10-min blackout period. On any given trial, the houselight illuminated for either the short or the long duration (probability $=0.5$; Table 1 lists the probability of a given duration during training and testing of the experiment). When the duration elapsed, the houselight turned off and both levers were inserted into the chamber, each with their cue-lights lit. One lever produced a food pellet if it was pressed following the short stimulus duration (on "short" trials), while the other lever produced a food pellet if it was pressed following the long stimulus duration (on "long" trials). The position of the levers associated with the short and long stimulus durations were counterbalanced across rats. If a correct response was made within $30 \mathrm{~s}$ of insertion, the levers retracted, their cue lights turned off, and a food pellet was delivered. If an incorrect response was made, the levers retracted, their cue-lights turned off, and the response was counted as an error.

To keep conditions as similar as possible to the delay-discounting procedure used in Huskinson et al., 2012 and other studies, trials began every 100 s. Thus, the ITIs following food pellet delivery or an incorrect response varied. Variable ITIs ensure the same session length and the same potential rate of reinforcement across all pairs of durations. The disadvantage to using variable ITIs is that longer ITIs will occur when testing shorter duration series. This is a limitation of the study. Previous research (Raslear et al., 1992) showed that ITI length altered temporal discrimination, but the rate of reinforcement also varied with the ITI length in this study. Future studies should assess whether the ITI has a systematic effect on temporal discrimination when rate of reinforcement is held constant across ITIs. As noted, duration length 
presentation varied pseudo-randomly to ensure that the preceding ITI was not a predictor of the upcoming duration length.

If $30 \mathrm{~s}$ elapsed before a response was made, the levers retracted, a 70-s ITI began, and the trial was counted as an omission. This 30-s limited hold was also implemented in Huskinson et al. (2012). Training sessions ended after 20 reinforced trials occurred following each duration (short and long), with a maximum session length of 66 trials. This criterion constituted a further step taken to ensure a similar rate of reinforcement between short and long durations for all rats throughout the study.

For the first five sessions of training, a correction procedure was in effect such that incorrect responses produced the same stimulus duration on the next trial. This procedure prevented or minimized lever biases from forming. Following the first five sessions of training, the correction procedure was removed if the disparity between correct responses to the long and short durations was less than $25 \%$ (i.e., a lever bias was not present). A lever bias was operationally defined as such because greater than $25 \%$ disparity between the percentage correct on short and long trials would result in failure to meet the criterion required for advancement to the testing phase. The correction procedure was reintroduced if percent correct showed this disparity in subsequent sessions. Correction sessions ended when the same criterion was met as regular training sessions (20 reinforced trials to each duration, with a maximum of 66 total trials).

During the initial training using the 2-s and 8-s duration pair, at least 10 consecutive sessions of training without correction were required to advance to the testing phase. In addition, the last five sessions were required to show an average of $75 \%$ correct responses to each (short 
and long) duration. For all other duration pairs, the same criteria were in effect except only five consecutive sessions of training without correction were required.

Temporal-bisection testing. The two-duration training procedure was conducted each Monday, Wednesday, and Thursday (control days). On Tuesdays and Fridays, a testing procedure was employed in which five intermediate durations (see Table 1) were intermixed with the largest and smallest durations (the training duration pairs). Thus, there were four duration series of seven durations each. All test sessions were comprised of 40 trials and thus lasted 66.67 minutes (following the 10-min blackout period). Each of the two training durations (long and short) were presented with a probability of 0.25 on each trial. The remaining trials presented the intermediate, or "test" durations (probability of 0.1 for any given intermediate duration on any given trial). Thus, the duration presented on any trial was pseudo-random. That is, durations were chosen at random without replacement with the following constraints: exactly half of the trials presented original training durations and half of the trials presented intermediate durations, and the same duration was not presented on more than three consecutive trials. Responses to intermediate durations were recorded, but had no other programmed consequences. Correct responses to training durations were followed by food presentation. In the event that accuracy fell below $75 \%$ on short or long trials on the previous control day for a given rat, or if the disparity between percent correct responses to the short and long duration exceeded $25 \%$, an additional training session (without the correction procedure) was conducted for that rat and testing was omitted until responding met the above criteria. When four testing sessions had been completed, the psychophysical function was determined for that rat on the current duration pair, and training with the next duration pair began the following day. Each duration pair/series were 
trained and tested once across all rats in an ascending order of duration length prior to drug administration.

$\boldsymbol{d}$-Amphetamine administration. The 2-s vs. 8-s duration pair was re-trained to $75 \%$ accuracy on both levers before drug testing. One session of testing without any injection, or a control test, was conducted prior to beginning the injection sequence. The injection sequence began with a saline injection prior to drug injections. Additional tests with saline administration occurred if there was considerable variability from the control test on the 2-s vs. 8-s duration pair. Then, $d$-AMP (Sigma-Aldrich, St. Louis, MO; 0.1, 0.3, 1.0, and $1.8 \mathrm{mg} / \mathrm{kg}$ ) was administered on Tuesdays and Fridays prior to the testing procedure. Doses of $d$-AMP were prepared in a saline vehicle and administered intraperitoneally. Doses were administered in an ascending and then descending sequence. An additional saline administration and an additional control test followed the descending sequence. Additional $d$-AMP doses were administered on subsequent testing sessions if data showed considerable variability. Mondays and Thursdays served as control days on which training sessions (i.e., with only two durations presented) occurred.

Once a dose-response curve was established for the 2-s vs. 8-s duration pair for a given rat, the 15 -s vs. 60 -s duration pair was retrained. The shortest and longest duration pairs were chosen for drug administration because in the baseline condition over $75 \%$ accuracy on both levers was reached for all rats. Following replication of $75 \%$ accuracy on both levers, the $d$-AMP administration procedure described above was implemented.

\section{Data Analysis}

Training. For training sessions, the number of sessions required to reach $75 \%$ accuracy on both long and short trials were counted for each rat. The total number of training sessions and 
the total number of correction sessions required at each duration pair were also counted. These variables were compared across LEW and F344 rats using a 2 x 4 repeated-measures ANOVA with strain as the between-subjects factor and duration series as the within-subjects factor.

Testing. For each test session, the proportion of trials in which a long response occurred was plotted as a function of the duration length. For all test session analyses, omitted responses were not included in the calculation of the proportion of long responses. For example, on four hypothetical trials, if three responses to a given duration occurred on the lever associated with the long response, and one response was omitted, the proportion of long responses to that duration equals 1 (three of three responses that occurred were long). When many omitted responses occurred, sessions were excluded if there were no responses made in the presence of any given duration within the series. For example, a hypothetical session would be excluded if all trials during which the $3.2 \mathrm{~s}$ stimulus was presented were omitted. This criterion only became relevant during drug administration, as there were no omitted responses during baseline.

Two methods were used to analyze proportion long response across test-session durations: linear and Gaussian. Throughout both linear and Gaussian analyses, averages across each set of test sessions in a series (baseline phase) or across each drug dose and series (drug administration phase) were used for fitting functions, rather than calculating these parameters for each individual session.

Linear analyses. Bisection points were first calculated using the method described in Church \& Deluty (1977), in which a straight line is fit to the proportion of long responses at the three most central durations in each series. This method (henceforth called "the linear method," also allows calculation of the difference limen, which is the distance between the points at which 25 and $75 \%$ of long responses occur, divided by two. The difference limen provides an 
indication of the precision of temporal control, with higher values indicating less precision. The difference limen also represents the "just-noticeable difference" between temporal stimuli. The Weber fraction, which is the ratio of the difference limen to the bisection point, was also calculated. Any negative bisection points were converted to absolute value prior to calculating Weber fractions to maintain that decreased Weber fractions indicate finer discrimination.

Gaussian analyses. The second method used to analyze the data was the Gaussian method, which was developed from and modified based on Blough (1996), McClure et al. (2005) and McClure et al. (2009). The Gaussian method used in the present study involved fitting a cumulative Gaussian function to proportion long response at each duration. Two free parameters were used that represented the mean (the bisection point; $\mu$ ) and the standard deviation (the slope of the function; $\sigma$ ), The final Gaussian functions were completed using CurveExpert Pro, Version 2.6.0 (Hyams Development). The cumulative Gaussian equation used to fit the data was:

$$
y=\frac{1}{2}\left[1+\operatorname{erf}\left(\frac{x-\mu}{\sigma \sqrt{2}}\right)\right]
$$

The originally proposed hypothetical psychophysical function was based on Blough (1996) and McClure, Saulsgiver, and Wynne (2005) and had two other free parameters: the minimum of the function (the distance from the $\mathrm{x}$-asymptote to the $\mathrm{x}$-axis), and the range of the function (the difference between the asymptotes). The minimum and the range are also measures of stimulus control. Due to difficulty in obtaining fits during drug administration, analyses were subsequently modified to include only the mean and standard deviation as free parameters. A diagram of the original function and its parameters is presented in Figure B of Appendix B.

In the present study, the minimum and range were not free to vary but were calculated based on the fitted equation. The minimum and maximum were interpolated as the y values lying on the function that corresponded to the shortest and longest durations (x values) in the series. 
The minimum was then subtracted from the maximum to obtain the range of the function. As these values were not free parameters, they were affected by changes in the mean and standard deviation of the function. Thus, the statistical analyses of these variables are somewhat redundant. The values are presented in the tables that follow for clarity, while the statistical analyses and figures are presented in Appendix C.

Statistical tests. ANOVA tests were conducted to test for differences between LEW and F344 rats for each of the measures from the linear method (Church \& Deluty, 1977), as well as the Gaussian method (Blough, 1996; McClure et al., 2005) between the two strains at baseline. This resulted in a $2 \times 4$ repeated-measures ANOVA with strain as the between-subjects factor and series as the within-subjects factor for each dependent measure. All pairwise comparisons used the Bonferroni procedure.

During drug administration, results were analyzed in a similar manner, but separately for the 2-s-vs.-8-s and 15-s-vs.-60-s duration series. That is, repeated-measures ANOVA tests were conducted to test for differences in each of the four free parameters following drug administration. Strain (LEW or F344) served as the between-subjects factor and dose $(0,0.1,0.3$, 1.0 and $1.8 \mathrm{mg} / \mathrm{kg}$ ) served as the within-subjects factor.

Mauchly's test of sphericity determined whether the unequal variance was found between one or more possible combinations of the levels of the independent variables (i.e., strain, series, or dose). Levene's test additionally provided evidence of the equality of variances between strains. If Mauchly's test of sphericity was significant, but Levene's test was not, then the Greenhouse-Geisser corrected degrees of freedom were used to determine significance in the ANOVA test. If both tests were significant, and the differences in homogeneity of variance between groups could not be corrected by transforming the data, nonparametric tests were used. 
Nonparametric analyses involved the use of Friedman's rank test to determine a significant effect of dose, with follow-up Wilcoxon signed-rank tests to test for pairwise comparisons amongst doses. Mann-Whitney $U$ tests were used to determine significance for strain differences. The Bonferroni correction was used to control for multiple tests in the latter two procedures. Due to the lack of normality and linearity in much of the data, any correlations performed used either the nonparametric Spearman's rho or Kendall's tau-b.

Additional analyses. The proportion of long responses was also averaged across all durations within test sessions to obtain a general measure of response allocation. Because short and long trial durations were always equally distributed throughout test sessions, the expected average proportion of long responses is always 0.5 . As average proportion long responses increase, bisection points derived from either the linear or Gaussian method tend to decrease.

As noted previously, Maricq et al. (1981) and Maricq \& Church (1983) corrected for responses that may have occurred when responses were not controlled by the duration stimuli (i.e., due to inattention) by omitting data with long latencies. In the present study, latencies across each phase of the experiment were analyzed by obtaining the mean of the median latency, as well as the mean of the standard deviation of latencies, for each rat, series, and dose (where applicable). The mean of the median latency was used because it is not skewed by the latency to the first response, which was often much longer than latencies on other trials. Overall latency data were compared using a $t$ test to determine if differences existed between LEW and F344 rats. Then, repeated-measures ANOVA tests were also conducted to determine series differences at baseline with strain as the between-subjects factor and series as the within-subjects factor. For the drug administration phase of the experiment, there were no differences in latency between the two series ( 2 vs. 8 and 15 vs. 60). Therefore, latency data during this phase were not grouped 
by series. A repeated-measures ANOVA test served to determine whether $d$-AMP differentially affected latency between the LEW and F344 strains with strain as the between-subjects factor and dose as the within-subjects factor.

Data were then analyzed with and without a correction for long latencies to determine if responses with long latencies affected the outcome of the analyses. In Maricq \& Church (1983), latencies longer than $5 \mathrm{~s}$ were removed from the data and functions were re-determined. In the present study, log-survivor plots were used to determine a cutoff point at which latencies of a given length were unlikely to occur. For all baseline conditions and drug doses, this cutoff was at or near $4 \mathrm{~s}$, so responses associated with latencies above this criterion were removed from the data.

\section{Results}

For ease of interpretation, results in the text are often presented with duration series' names abbreviated using a hyphen between their respective short and long durations. For example, "the 2-s-vs.-8-s series" is presented in the text as "the $2-8$ series."

\section{Baseline}

Training. Individual training graphs are presented in Figures 2 and 3. These figures delineate percent correct for each rat across each day (session) of the initial training phase (2-8 series). Figure 4 presents the aggregated data from the training phase of each series, comprising average total training sessions, correction sessions, and sessions to meet the criterion of $75 \%$ correct responses to both durations.

Overall, LEW and F344 did not differ from one another in any aspect of acquiring the temporal discrimination. This was confirmed by the ANOVA, which showed no effect of strain or series, and no strain x series interaction on total training sessions required to meet both criteria 
necessary to move to the testing phase (see Figure 4, top panel). There were also no differences in total correction sessions required between strains or series, and there was no interaction between these variables (see Figure 4, middle panel). While total sessions to reach the criterion of $75 \%$ correct to both durations on any given day also did not show an effect of strain, there was a significant effect of series on this variable, $F(2.03,20.28)=40.42$, p <.001 (see Figure 4, bottom panel). There was no strain $\mathrm{x}$ series interaction. Post hoc tests indicated differences between the 2-8 duration series and the 4-16 series $(\mathrm{p}<.001)$, the $2-8$ and the $15-60$ series $(\mathrm{p}<.001)$, the $4-16$ series and the 10-40 duration series ( $\mathrm{p}<.01)$, and finally, the 10-40 and 15-60 duration series $(\mathrm{p}<.01)$. These post hoc tests indicated that the transition from the $2-8$ to the $4-16$ series required significantly fewer sessions to complete than the transition from the 4-16 to the 10-40 series, and that the transition from the 10-40 to the 15-60 series required significantly fewer sessions than the previous transition. Importantly, these effects were seen in both strains and reflect the effect of the differences in relative distance between the longest durations in each series. That is, 40 is 2.5 times greater than 16 . This distance is greater than the relative distance between 8 and 16 (2 times) or 40 and 60 (1.5 times). As shown in Figure 4, rats met the criterion of $75 \%$ correct to both durations in 1-2 days on the last transition (10-40 to 15-60). Importantly, this does not indicate testing was conducted the following day, as the last five regular training sessions were required to show $75 \%$ correct on average.

Testing. A summary of results from the baseline testing phase of the present study is presented in Table 2. There were no omitted responses during any baseline test session. Average obtained proportion long response across rats for baseline test sessions is presented in Figure 5. Psychophysical functions obtained from individual rats are presented in Appendix D, in Figures D1-D8. Each duration series is presented in its own panel with separate lines for LEW and F344 
rats. For both strains and in all series, proportion of long responses increased as durations increased. This indicated that behavior was under temporal control.

Overall, LEW rats allocated more responses to the lever associated with the long duration than F344 rats throughout the baseline phase. This was supported by a significant effect of strain on the average proportion of long responses across all durations throughout the baseline phase, $F(1,10)=6.95, \mathrm{p}<.05$. This analysis represents the main effect when collapsed across all four series/panels of Figure 5. F344 rats showed a mean proportion of $0.45(S E M=0.03)$, and LEW rats showed a mean proportion of 0.51 long responses throughout the baseline phase $(S E M=$ 0.03). This difference throughout the baseline phase is shown in more detail in Figure 6, where average proportion long response is presented in boxplots clustered by strain and series. There was no effect of series, and no interaction between strain and series on the overall proportion of long responses.

Linear results. The functions in Figure 5 were analyzed using the linear method described in Church and Deluty, 1977. Individual bisection points, Weber fraction values (standardized measure of sensitivity to changes in stimuli), and difference limen values (measure of precision) are presented in Table 6. Means of each of these dependent variables are presented in Figure 7 and organized by strain and series.

Mauchly’s test of sphericity (see Methods: Statistical tests and Appendix A: Key Terms) was significant for bisection points $\chi^{2}(5)=16.77, \mathrm{p}<.01$ as well as the difference limen $\chi^{2}(5)=$ $12.55, \mathrm{p}<.05$. Levene's test was not significant for bisection points, so an ANOVA test was used with the corrected degrees of freedom. Series presenting longer durations resulted in longer bisection points, confirming that responses were under temporal control. LEW and F344 showed similar bisection points when analyzed with the linear method, indicating that the average 
temporal estimate was similar between strains. These results were determined by the ANOVA test, which showed a significant effect of series on bisection points, $F(1.42,14.22)=41.17$, $\mathrm{p}<.05$, but no effect of strain or strain $\mathrm{x}$ series interaction. Pairwise comparisons indicated differences between all combinations of series (all $p<.05$ ), except for the 10-40 series and the 1560 series. These pairwise comparisons are represented by corresponding letters within Figure 7 (e.g., the two series labeled "a" are significantly different from one another, the two series labeled "b" are significantly different from one another, and so forth). Additional figures showing pairwise comparisons between series are also labeled in this manner.

Duration series did not affect the Weber fraction for either strain, which indicated that temporal control maintained proportionality to the duration stimuli. That is, the differences in duration stimuli were judged in a similar manner (by multiplicative difference) regardless of the series. LEW and F344 rats also had similar Weber fractions. This was confirmed by the ANOVA, which showed no strain or series effect on the Weber fraction and no interaction between these variables.

Longer duration series resulted in increased difference limen values, again indicating that behavior was under temporal control. This was determined by a significant effect of series on the difference limen $F(1.97,19.69)=15.84, \mathrm{p}<.01$. There was no effect of strain or strain $\mathrm{x}$ series interaction. Pairwise comparisons indicated differences between the 2-8 series and the 10-40 series $(\mathrm{p}<.001)$, the $2-8$ series and the $15-60$ series $(\mathrm{p}=.001)$, and between the $4-16$ series and the 15-60 series $(\mathrm{p}<.05)$. There was no difference in the amount of variance accounted for $\left(R^{2}\right)$ by the linear method for any of the measures across strains or series, and no interaction between these variables. 
Gaussian results. Individual parameters from the average Gaussian functions for each series are presented in Table 7. Average parameters by strain and series are presented in Figure 8. Mauchly's test of sphericity (see Methods: Statistical tests and Appendix A: Key Terms) was significant for the standard deviation of the functions $\chi 2(5)=12.25, \mathrm{p}<.05$. Because Levene's test of the equality of error variances was not significant across any of the parameters or $R^{2}$ values, ANOVAs were used with the corrected degrees of freedom for the standard deviation.

There was a significant effect of series for the bisection point and standard deviation of the function, but not $R^{2}$ values for functions. This indicates that the increasing durations across series affected the bisection point and standard deviation, while the goodness of fit of the Gaussian function remained similar. As behavior did show temporal control (proportion of long responses increased as duration values increased in each series), this pattern of responding resulted in larger standard deviations, $F(2.14,21.41)=59.87, \mathrm{p}<.001$, and longer bisection points, $F(3,30)=319.52, \mathrm{p}<.001$, as series increased. Pairwise comparisons were significant between all series combinations for bisection points (all $\mathrm{p}<.001)$ and standard deviations. Pairwise comparisons along the standard deviation showed the following levels of significance: the 2-8 and $4-16$ series showed $p<.05$; the $2-8$ and $10-40$ series showed $p<.001$; the $2-8$ and $15-60$ series showed $\mathrm{p}<.001$; the $4-16$ and $10-40$ series showed $\mathrm{p}<.05$; the $10-40$ and $15-60$ series showed $\mathrm{p}<.05$. Figure 8 also denotes significant pairwise comparisons between series.

There was a significant main effect of strain on bisection points $F(1,10)=9.02, \mathrm{p}<.05$, with LEW rats showing shorter bisection points throughout the baseline phase $(M=15.31, S E M$ $=4.15)$, or overestimation of temporal duration relative to F344 $(M=17.79, S E M=5.06)$. There was a significant series $\mathrm{x}$ strain interaction on bisection points $F(3,30)=3.30, \mathrm{p}<.05)$, indicating that bisection points increased across each series to a greater degree in F344 rats. Follow-up 
tests using simple effects indicated no significant pair-wise comparisons. There were no significant strain differences along $R^{2}$ values or standard deviations of Gaussian functions. These results conflict somewhat with the analyses obtained using the linear method, which found no strain differences in average temporal estimates (bisection points) or variability in these estimates. In contrast, the Gaussian results indicated that LEW and F344 did differ in temporal estimates (LEW overestimated durations compared to F344) but did not differ in variability of these estimates.

\section{Drug Administration}

Paired-samples $t$-tests across parameters and $R^{2}$ values of both the linear and Gaussian methods indicated no differences between control sessions (without injections) and sessions with saline vehicle injections, with one exception. Saline sessions resulted in a reduction in $R^{2}$ for the linear analysis. This may have been the result of a slight disruption resulting from the injection procedure. Because this was the only difference between saline and control sessions, and because saline administration controls for any such disruptions related to the injection procedure, results from saline sessions are presented throughout the study and used in all analyses. At 1.8-mg/kg, functions for several rats could not be determined under either analysis, in part due to the large number of omissions. Therefore, figures present only those functions that were obtained. Data from $1.8 \mathrm{mg} / \mathrm{kg}$ were not included in statistical analyses (except for analyses of the number of omissions at each dose). A summary of results from the drug administration phase of the present study is presented in Table 3.

\section{2-s-vs.-8-s series.}

Figure 9 displays obtained data (prior to fitting functions) from the 2-s-vs.-8-s series of drug administration. Psychophysical functions from individual rats are presented in Appendix D, 
in Figures D9 and D10. Eleven sessions were excluded from the analysis due to omitted responses on every trial for a given duration for F344 rats. Six sessions were excluded for LEW rats. Each excluded session was at the 1.0 or $1.8 \mathrm{mg} / \mathrm{kg} d$-AMP dose, with the exception of excluded sessions with saline administration for one F344 rat and one LEW rat each (the first injection). Data on excluded sessions are included in Table 4. Omissions data from included sessions can be found in Table 5. At $1.8 \mathrm{mg} / \mathrm{kg}$, data from three F344 rats and one LEW rat were excluded entirely due to a large number of omissions.

Mauchly's test of sphericity was significant for average proportion long response, $\chi 2(5)=$ $14.85, \mathrm{p}<.05$, and Levene's test was not significant. Therefore, the corrected degrees of freedom were used to determine significance of the ANOVA. There was a significant effect of strain on the average proportion of long responses throughout the 2-s-vs.-8-s series of drug administration, indicating that LEW rats made more long responses than F344 throughout this phase of the experiment, $F(1,10)=16.75, \mathrm{p}<.01$. This result was consistent with the baseline results, which also showed that LEW rats made more long responses throughout the entire baseline phase. The average proportion of long responses by strain and dose is displayed in Figure 10. There was no effect of dose or dose $\mathrm{x}$ strain interaction along this variable.

Linear results. For one $\mathrm{F} 344$ rat at $0.3 \mathrm{mg} / \mathrm{kg}$, one $\mathrm{LEW}$ rat at $1.0 \mathrm{mg} / \mathrm{kg}$, linear functions could not be determined. This occurred because proportion long response at the three central signal durations did not conform to a linear pattern. Means were imputed in these cases. In addition, because Levene's test of the equality of error variances was significant along multiple variables, the linear parameters were log-transformed prior to statistical analyses. Following log transformations, Levene's test remained significant for bisection points and Weber fractions 
under saline administration $(\mathrm{p}<.05)$. Therefore, nonparametric analyses were used to determine significance for dose.

Table 8 displays individual values, and Figure 11 displays summarized results from linear analyses. There were no effects of dose or strain on bisection points or $R^{2}$ values, indicating that $d$-AMP did not result in temporal overestimation or underestimation for either strain. Additionally, linear functions fit the data equally well for both strains and at all doses.

$d$-AMP resulted in larger difference limen values (less precision) at increasing doses. This was confirmed by a significant effect of dose on the difference limen, $\chi^{2}(3)=9.15, p<.05$, though there were no significant pairwise comparisons across doses. F344 rats also showed longer difference limen values than LEW rats, indicated by a significant effect of strain on the difference limen at the $0.3 \mathrm{mg} / \mathrm{kg} d$-AMP dose $(Z=-2.73, \mathrm{p}=.006)$. At this dose, LEW rats showed slightly lower difference limen values when compared with saline vehicle sessions, whereas F344 rats showed slightly larger difference limen values when compared with saline vehicle sessions. This indicates that $d$-AMP may have improved temporal precision for LEW rats and disrupted temporal precision for F344 rats at $0.3 \mathrm{mg} / \mathrm{kg}$.

There was a significant effect of dose on the Weber fraction $\chi^{2}(3)=9.69, p<.05$, but no significant pairwise comparisons. That is, $d$-AMP resulted in larger Weber fractions, or a larger ratio between the difference limen and the bisection point, across trials. There was no effect of strain on the Weber fraction.

Gaussian results. A Gaussian function could not be obtained for one LEW rat at the 1.0$\mathrm{mg} / \mathrm{kg} d$-AMP dose. Parameter means for LEW rats were imputed for this rat and dose. Figure 9 displays average obtained functions across each $d$-AMP dose. Mauchly's test of sphericity was significant for the bisection point, $\left.\chi^{2}(5)=17.76, \mathrm{p}<.01\right)$, and $R^{2}$ values, $\chi^{2}(5)=14.73, \mathrm{p}<.05$. 
Levene's test was not significant for the bisection point or standard deviation. Therefore, ANOVA tests were used with corrected degrees of freedom for the bisection point.

Figure 12 displays average parameter values across doses, and Table 9 displays individual values for each parameter. There was a significant effect of dose on the standard deviation, $F(3,30)=3.26, \mathrm{p}<.05) . d$-AMP dose dependently increased the standard deviation across both strains of rats. These results indicate that at all durations response variability increased and functions appeared flatter. Pairwise comparisons indicated significant differences between standard deviations of functions for saline and $1.0 \mathrm{mg} / \mathrm{kg} d-\mathrm{AMP}(\mathrm{p}<.05)$. Although there was no main effect of strain on the standard deviation, the dose effect on the standard deviation was qualified by significant dose $\mathrm{x}$ strain interaction $F(3,30)=4.17, \mathrm{p}<.05)$. This interaction indicated that $d$-AMP had differential effects on response variability for LEW and F344 rats. The standard deviation increased to a greater extent in F344 rats, reaching a significant difference from LEW rats at $1.0 \mathrm{mg} / \mathrm{kg} d$-AMP. This effect indicated that response variability, or precision, decreased to a greater extent in F344 rats. This effect was revealed by planned comparisons using simple effects with the Bonferroni correction, which showed larger standard deviations for F344 at this dose $(M=2.43, S E M=0.24)$ compared to LEW $(M=1.37$, $S E M=0.60 ; F(1,10)=9.92, \mathrm{p}=0.01)$. No other doses showed significant planned comparisons between LEW and F344 for the standard deviation.

There was also a significant main effect of strain on bisection points $F(1,10)=21.60$, $\mathrm{p}=.001)$, with LEW rats showing shorter bisection points $(M=3.71, S E M=0.28)$ than F344 rats $(M=4.45, S E M=0.30)$ in this phase of the experiment. That is, regardless of dose, LEW rats made more long responses at shorter durations (estimated durations to be longer) compared to F344 rats. There was no effect of dose or dose $\mathrm{x}$ strain interaction on bisection points. 


\section{5-s-vs.-60-s Series.}

Figure 13 displays obtained data (prior to fitting functions) from the 15 -s-vs.-60-s series of drug administration. Psychophysical functions from individual rats are presented in Appendix D, in Figures D11 and D12. Seven sessions were excluded from the data due to omitted responses on every trial for a given duration for F344 rats. No sessions were excluded for LEW rats. Data on excluded sessions are included in Table 4Table 4. Omissions data from included sessions can be found in Table 5.

Mauchly's test of sphericity was significant for average proportion long response, $\chi 2(5)=$ $25.45, \mathrm{p}<.001$, and Levene's test was not significant. Therefore, the corrected degrees of freedom were used to determine significance of the ANOVA. As in the previous series, there was a significant effect of strain on the average proportion of long responses throughout the 15-s-vs.60-s series of drug administration, indicating that LEW rats made more long responses than F344 throughout this phase of the experiment, $F(1,10)=14.65, \mathrm{p}<.01$. This result was consistent with both the previous series, as well as the baseline results. The average proportion of long responses by strain and dose is displayed in the boxplot in Figure 14. There was no significant effect of dose or dose $\mathrm{x}$ strain interaction seen for this variable.

Linear results. Levene's test of the equality of variances was significant for the difference limen and Weber fraction at multiple doses. Levene's test remained significant for both of these variables following log transformations, so nonparametric analyses were used for the difference limen and Weber fraction. Neither Mauchly's test of sphericity nor Levene's test of the equality of error variances were significant for bisection points and $R^{2}$ values. Thus, these variables were analyzed using repeated-measures ANOVA. 
Table 10 displays individual values, and Figure 15 displays summarized results from the linear analyses. As in the previous series (2-s vs. 8-s), $d$-AMP increased the difference limen. The ANOVA showed a significant effect of dose on the difference limen, $\chi^{2}(3)=17.50, p=.001$, but no significant pairwise comparisons. There were no significant effects of strain on the difference limen, indicating less precision for both strains of rats. Similar to the previous series, there was a significant effect of dose on the Weber fraction, $\chi^{2}(3)=13.90, p=.001$. Pairwise comparisons indicated a significant difference between saline and $1.0 \mathrm{mg} / \mathrm{kg} d$-AMP ( $\mathrm{p}=.002)$. There were no effects of strain on the Weber fraction.

There were no effects of strain or dose, and no interactions observed for bisection points or $R^{2}$ values. Thus, the $1.0 \mathrm{mg} / \mathrm{kg}$ dose resulted in behavior that was less sensitive to changes in duration across both strains, and this decrease in sensitivity was not due to a change in the average temporal estimate (the bisection point).

Gaussian results. Levene's test of the equality of variances was significant for the standard deviation at multiple doses. Levene's test remained significant after log-transforming the data. Therefore, due to the differences in variance between groups, nonparametric tests were used for the standard deviation. Bisection points and $R^{2}$ values were analyzed using repeatedmeasures ANOVA, as Levene's test was not significant for these variables. Mauchly's test of sphericity was significant for both bisection points $\chi^{2}(5)=76.64, \mathrm{p}<.001$, and $R^{2}$ values, $\chi^{2}(5)=$ 19.67, $\mathrm{p}<.01$. The corrected degrees of freedom were used to determine significance for these variables.

Table 11 displays individual values, and Figure 16 displays summarized results from the Gaussian analyses. There was a significant effect of dose on the standard deviation, $\chi^{2}(3)=19.90$, $\mathrm{p}<.001$. Significant differences were found between saline and $1.0 \mathrm{mg} / \mathrm{kg} d$-AMP $(Z=-2.98$, 
$\mathrm{p}=.003)$ as well as between 0.1 and $1.0 \mathrm{mg} / \mathrm{kg} d-\mathrm{AMP}(Z=-3.06, \mathrm{p}=.002)$. There was no effect of strain on the standard deviation at any dose, indicating that temporal precision was disrupted by $d$-AMP similarly for both strains.

There were no significant effects of strain or dose on bisection points. There was a significant main effect of dose on $R^{2}$ values $\left.F(1.83,18.26)=17.73, \mathrm{p}<.01\right)$, indicating that $d$-AMP dose dependently decreased the goodness-of-fit of the Gaussian functions. There was no effect of strain or dose $\mathrm{x}$ strain interaction. Pairwise comparisons revealed significant differences between saline and $1.0 \mathrm{mg} / \mathrm{kg} d$-AMP (p<.001), and between 0.1 and $1.0 \mathrm{mg} / \mathrm{kg} d-\mathrm{AMP}(\mathrm{p}=.001)$, with the higher dose resulting in poorer fit in both cases.

\section{Response Latencies}

\section{Baseline.}

Analysis of medians and standard deviations of latencies across baseline sessions using $t$ tests did not reveal differences between LEW and F344 rats. Thus, the time between stimulus offset and the lever press was similar for LEW and F344 rats. Longer series resulted in longer latencies to respond, evidenced by the significant effect of series on median latency, $F(3,30)=$ $6.89, \mathrm{p}=.001$. Pairwise comparisons revealed differences between the $2-8$ series $(M=0.48 \mathrm{~s}$, $S E M=0.05)$ and the $15-60$ series $(M=0.76 \mathrm{~s}, S E M=0.10, \mathrm{p}<.05)$.

\section{Drug administration.}

For sessions in the 2-s-vs.-8-s series of drug administration, Levene's test of the equality of error variances was significant for both the median and standard deviation of latencies. Logtransformations resulted in Levene's test remaining significant only at the $0.1 \mathrm{mg} / \mathrm{kg}$ dose for median latency. Therefore, repeated-measures ANOVA was still used for this series along the log-transformed data. 
LEW and F344 differed in the latency to the lever press, but only at certain doses. This effect was likely due to F344 rats omitting many more responses than LEW rats with increasing doses. There was a lack of main effect of strain or dose on median latency, but a significant dose $\mathrm{x}$ strain interaction on median latency, $F(4,40)=2.77, \mathrm{p}<.05$. Pairwise comparisons for dose indicated significant differences between the 0.1 and $1.8 \mathrm{mg} / \mathrm{kg}$ doses $(\mathrm{p}<.05)$, but this result should be interpreted with caution due to the increased number of omissions for F344 compared to LEW at the $1.8 \mathrm{mg} / \mathrm{kg}$ dose. This is likely the reason for the significant Levene's test at this dose. Importantly, both the main effect and the interaction effect were no longer significant when the $1.8 \mathrm{mg} / \mathrm{kg}$ dose was removed from the analysis.

As dose increased, the variability in latencies increased. This was in part due to a larger number of long latencies. This was shown by a significant effect of dose on the standard deviation of latencies, $F(4,40)=3.17, \mathrm{p}<.05$. This result was qualified by a significant dose $\mathrm{x}$ strain interaction, $F(4,40)=2.91, \mathrm{p}<.05$. Pairwise comparisons again indicated differences in standard deviation of latencies between the 0.1 and $1.8 \mathrm{mg} / \mathrm{kg}$ doses $(\mathrm{p}=.001)$. As with the previous analysis, these results should be interpreted with caution due to more omissions at $1.8 \mathrm{mg} / \mathrm{kg} d$-AMP. Again, both the main effect and interaction were no longer significant when the $1.8 \mathrm{mg} / \mathrm{kg}$ dose was removed from the analysis.

Data were also log-transformed for the 15-s-vs.60-s series of drug administration due to significant Levene's tests at the $1.8 \mathrm{mg} / \mathrm{kg}$ dose for median latencies, and for multiple doses for standard deviation of latencies. Levene's tests were not significant following logtransformations, but Mauchly's test of sphericity was significant for median latency, $\chi^{2}(9)=22.11, p=.01$. The corrected degrees of freedom were used for these analyses. 
Increasing doses again increased the time between stimulus offset and the lever press. This was shown by a significant effect of dose on median latency $F(1.7,17.03)=7.87, \mathrm{p}<.01$. There was no effect of strain or dose $\mathrm{x}$ strain interaction. Pairwise comparisons indicated significant differences between the 0.3 and $1.8 \mathrm{mg} / \mathrm{kg}$ doses $(\mathrm{p}<.05)$. Increasing doses of d-AMP also resulted in more variability between latencies, evidenced by a significant effect of dose on standard deviation of latencies $F(4,40)=8.50, \mathrm{p}<.001$. This effect was qualified by a significant dose $\mathrm{x}$ strain interaction $F(4,40)=3.18, \mathrm{p}<.05$. Similar to the dose $\mathrm{x}$ strain interaction that was found in the previous series, there was no main effect of strain. Pairwise comparisons indicated significant differences between the 0.3 and $1.8 \mathrm{mg} / \mathrm{kg}$ doses. Unlike the previous analyses, when the $1.8 \mathrm{mg} / \mathrm{kg}$ dose was removed from analyses, these effects persisted for both median and standard deviation of latencies, with the exception of the significant pairwise comparisons.

Although Maricq \& Church (1983) removed latencies longer than 5 s, log-survivor plots indicated that $4 \mathrm{~s}$ was a more reasonable cutoff for the present study. In addition, the use of a 5-s cutoff would have removed very few responses from the dataset. (For example, only 16 responses met this criterion across all baseline test sessions.) Log-survivor plots indicated a 4-s threshold for latency length, and corresponding responses were removed from the dataset for reanalysis. The log-survivor plots are presented in Appendix E. There were no significant differences in proportion long response in the originally obtained dataset and the adjusted dataset at any phase or series of the experiment, so no further analyses were conducted on the adjusted data.

\section{Additional Analyses}

At baseline, both LEW and F344 rats tended to show a larger latency between the trial offset and the response when the trial stimulus was longer. This was determined based on the 
significant correlations between latency and duration of the trial for F344 rats, $\rho(3839)=0.074$, $\mathrm{p}<.001$, and for LEW rats, $\rho(3839)=0.12, \mathrm{p}<.001$. However, it must be noted that these effects are overpowered due to the fact that this analysis was trial-based and did not take into account individual subjects.

Although there were no differences between LEW and F344 during the training phases of each series, inaccurate responding at training may have been indicative of disrupted temporal control for individual rats. There was a significant correlation between average number of correction sessions required throughout the baseline training phase and average bisection points using the Gaussian procedure $\left(\tau_{\mathrm{b}}=0.49, \mathrm{p}<.05\right)$, as well as the linear procedure $\left(\tau_{\mathrm{b}}=0.59\right.$, $\mathrm{p}<.01$ ), indicating that more correction sessions were associated with longer bisection points. For individual rats, requiring more correction sessions also co-occurred with less precise or differentiated responding across durations. This was shown by correlations between the average number of correction sessions and two other parameters: higher Weber fractions, $\rho(12)=0.60$, $\mathrm{p}<.05$, and longer difference limen values $\rho(12)=0.71, \mathrm{p}=01$. There were no other notable correlations.

\section{Discussion}

In the present study, two strains of rats (LEW and F344) were trained to discriminate four pairs of temporal durations. Once discrimination was established between the two training durations (long and short), rats responded in the presence of intermediate values between the two training durations. This bisection procedure with LEW and F344 rats demonstrated strain differences in temporal control, with LEW rats showing longer temporal estimates than F344 rats. Subsequent $d$-AMP administration resulted in strain differences in response to $d$-AMP under certain conditions and at certain doses. Similar strain differences have been observed in 
LEW and F344 in delay-discounting procedures, which measure impulsive choice (e.g., Huskinson et al., 2012, Huskinson \& Anderson, 2012). The results provide further insight into the relation between temporal control and impulsivity. Because impulsive choice involves delay to reinforcement, responses depend, in part, on temporal control. The study of temporal control in strains that differ in these processes can inform the understanding of problem behavior like impulsivity. The development of interventions should consider that individuals who choose smaller-sooner reinforcers may perceive the duration of the delay to the larger-later reinforcer as longer than others. Importantly, the present study echoed the results of McClure et al. (2005) and McClure et al. (2009), which showed that temporal control was not improved, but disrupted, by $d$-AMP administration. Because amphetamine and amphetamine-like stimulants are common pharmaceutical interventions for impulsivity in humans with ADHD, more insight is needed into the mechanism of this therapeutic effect. It is possible that the therapeutic effect lies in the reduction of attention to temporal stimuli, rather than a lengthening or shortening of the perception of time. The present results supported this possibility.

\section{Baseline}

There were no strain differences in the number of correction sessions required, number of sessions required to meet testing criteria, or the total number of training sessions during the initial training of each of the four duration series. This lack of difference indicated that LEW and F344 are similarly accurate when learning temporal discriminations. Whereas some transitions from one series to another appeared to result in more sessions required to meet testing criteria, this result was consistent for both strains. In addition, this result corroborates previous research that has shown that temporal discrimination relies on relative, rather than absolute duration (Church \& Deluty, 1977). Because of this finding, transitions presenting a larger change in the 
relative distance between learned temporal stimuli should more difficult to acquire than those that are more similar in relative distance to a previously learned temporal discrimination.

There were no strain differences in acquisition of the temporal discrimination, indicating that LEW and F344 were similarly adept at learning differences in duration length. Similarly, LEW and F344 rats did not differ in the various measures of stimulus control during baseline test sessions (minimum, range, standard deviation, Weber fraction, and difference limen), indicating that both strains maintained their similar accuracy in responding to the trained durations (or anchors).

In contrast, at baseline there was a main effect of strain under the Gaussian analyses that indicated shorter bisection points for LEW compared to F344. This also indicated that LEW rats made more responses on the lever associated with the long duration than F344 rats. LEW rats, which make more impulsive choices, were expected to show shorter bisection points (longer temporal estimates) if delay discounting was a result of an overestimation of the duration of delays. Therefore, this result was in line with studies that have shown overestimation of duration in impulsive individuals (e.g., Baumann \& Odum, 2012).

LEW and F344 rats show differences in delay discounting at delays that were similar to the durations used in the present study. For example, in Huskinson et al. (2012), LEW and F344 rats responded in a delay-discounting procedure, in which choice is between a small reinforcer available immediately, and a larger reinforcer available after a delay. When delays ranged from 0 to $60 \mathrm{~s}$, LEW rats showed a mean indifference point of $10 \mathrm{~s}$, whereas the mean for F344 rats was $20.5 \mathrm{~s}$. Due to the magnitude of average indifference points (approximately $10-20 \mathrm{~s}$ ), it expected that differences between strains in the present study would only become apparent at sufficiently long durations. Indeed, there was a significant main effect of strain on Gaussian 
bisection points at baseline, indicating that LEW rats showed shorter bisection points, but there was also a significant interaction with series. The interaction with series demonstrated that LEW rats' longer temporal estimates (relative to F344 rats) were more apparent at the longer durations. It is possible that these larger differences in temporal judgments at long durations are responsible for the shorter indifference points generated by LEW rats in previous studies.

One important caveat to LEW rats' shorter bisection points is that LEW rats' bisection points approximated the geometric mean more closely than F344 rats. Geometric means of each series were 4, 8, 20, and 30, in order of increasing series. In both linear and Gaussian analyses at baseline, LEW rats' average bisection points were always closer to the geometric mean than F344 rats' average bisection points (see Table 6 and 7). Therefore, when considering the significant strain difference for the Gaussian bisection points, results might be better framed as stating that F344 overestimate duration length, whereas LEW rats are timing accurately. As noted above, there were no differences in the measures of stimulus control (standard deviation, range, and minimum) between strains, so the differences in bisection points were not due to inaccuracy at the trained durations, nor were they due to the variability in estimates of tested durations. Rather, the difference reflects a left shift of the function for LEW when compared to F344, indicating a difference in the speed of timing itself. This result conflicts somewhat with Follett (2014) and Smith et al. (2015), in which LEW rats showed wider peak spread without mean shifts in the peak time, which is indicative of greater timing variability rather than differences in mean duration estimates. However, because the peak procedure does not constrain responding to a single response per trial, it may not capture the differences between LEW and F344 rats. Indeed, the differences in mean bisection points between strains were between 4 and 5 
$\mathrm{s}$ at their greatest (in the two longest series). This difference might be masked by additional responses around the peak time.

Correction sessions, in which the same duration was repeated following an incorrect trial, were implemented when rats showed more than $25 \%$ disparity between levers (potential bias for a given lever). More of these correction sessions required during training was associated with longer bisection points. Whether the correction sessions resulted in changes to temporal control or whether a tendency toward inaccuracy resulted in both more correction sessions and longer bisection points was not examined in the present study. It is possible, but unlikely, that correction sessions induced a bias in responding. The lack of a difference between strains in the number of correction sessions required indicates that this variable was approximately equally distributed across strains. In addition, correction sessions maintained the same approximate rate of reinforcement by ending sessions only when 20 reinforcers had been earned by pressing each lever (i.e., 20 on the left and 20 on the right). Although sessions also ended if they required over 66 trials, it was rare for this to occur.

\section{$d$-AMP Administration}

Generally, results replicated McClure et al. (2005 \& 2009), in which dose-dependent decreases in the range, increases in the minimum, and increases in the standard deviation of the functions were seen. The decrease in range and increase in minimum indicate a decrease in accuracy to both training durations, whereas the increase in the standard deviation indicates an increase in response variability across all durations. In addition, bisection points changed less than these measures, indicating that functions did not shift to the left when $d$-AMP was administered, but instead flattened. These flat functions are indicative of a loss of stimulus control, and were more dramatic at higher doses. 
There were a large number of omissions at $1.8 \mathrm{mg} / \mathrm{kg}$, particularly for F344 rats. This greater effect of $d$-AMP in F344 rats compared to LEW rats at the same dose is in line with the greater density of dopamine receptors and transporters in F344 rats (Flores et al., 1998). In order to achieve the same effect (here, the same number of omissions), a greater amount of $d$-AMP had to be administered to LEW rats because there are fewer available receptors and transporters on which $d$-AMP can exert its effects.

For both strains, the highest doses of $d$-AMP often induced a lever bias, in which stimulus control at the originally trained durations was lost. Figures displaying individual data in Appendix D demonstrate these lever biases more clearly, as near-exclusive responding can be observed (i.e., near-exclusive responding to either the short or long duration). When present, lever biases did not occur consistently on the same lever. This bias was more commonly seen on the lever associated with the shorter duration, but there are insufficient data to determine whether this is a meaningful trend. The lever for which this bias occurred often varied within individual rats, which makes interpretation difficult, though it is likely unrelated to temporal control. Considering the variation within individual rats, relatively larger doses of $d$-AMP may have resulted in perseverative responding on whichever lever resulted in the delivery of a food pellet first, though data have not been examined to this end. Alternatively, temporal perception may have been affected to such a degree that rats showing lever biases no longer detected one or both of the original stimulus anchors.

The present results conflict slightly with Maricq and Church (1983) and Maricq et al. (1981), which showed clear left shifts in the psychophysical function with methamphetamine. However, Maricq and Church (1983) did also show concurrent changes in the standard deviation, indicating some loss of stimulus control was also apparent. Considering that the 4-s latency 
adjustment in the present study did not change the results, it is highly unlikely that the 5-s latency adjustment in that study was responsible for the slight difference. Two other differences in Maricq and Church (1983) were the use of a different rat strain from either of the two used in the present study, and the use of 40 rats, which provided a much larger sample size. Maricq et al., (1981) also had similar differences in subjects from the present study. These differences may have accounted for the shifts to the left that were seen in those studies compared to the present one.

Again, the present results are similar to McClure et al. (2005) and McClure et al. (2009), in which a flattening of functions with $d$-AMP was apparent without changes in the bisection point. Although the present study demonstrated changes in the bisection point at some doses and conditions, the flattening of functions evidenced by increases in the minimum, decreases in the range, and increases in the standard deviation were more reliable than shifts in the bisection point. In the 15 -s-vs. 60 -s series at the $0.3 \mathrm{mg} / \mathrm{kg} d$-AMP dose (Figures 13 - 16) it appeared that bisection points may have decreased for LEW and increased for F344, but this result was not supported by the statistical analyses, perhaps as a result of low power. However, visual inspection of both the average and individual functions does indicate a larger effect of $d$-AMP on overall stimulus control than the bisection point itself. There were also no changes in the bisection point without concurrent changes in the measures of stimulus control. Therefore, it is possible that under $d$-AMP, temporal perception is unchanged, but reinforcer value has decreased such that maximization of reinforcer earnings fails to occur. Results in the delay-discounting procedure differ somewhat, as $d$-AMP tends to result in an increase in the maximization of reinforcement by increasing choice for the larger-later reinforcer. However, reinforcement in the 
current bisection procedure always occurred immediately following a correct response, so it is possible that $d$-AMP results in a decrease in the value of immediate reinforcers specifically.

\section{Comparisons Across Data Analysis Methods}

The originally proposed analyses used a Gaussian function with four free parameters as in McClure et al. (2005) and McClure et al. (2009). This analysis was feasible during the baseline phase, but became more difficult to fit with the increasingly flat functions during drug administration. In addition, the use of four free parameters resulted in parameter values that were unnecessarily variable due to what appeared to be a push of the function by the computer program in an extreme direction of any given parameter in order to achieve fit. The twoparameter Gaussian in the final analyses provided more interpretable results, though it generally resulted in less variance accounted for. It remained difficult to fit flat functions with the twoparameter Gaussian.

Linear analyses were also performed using the method of Church and Deluty (1977). At times, proportion long response at the three central signal durations did not conform to a linear pattern, the slope of the line was negative, or proportion long response at the three central signal durations caused the line to extrapolate outside the range of durations presented. Each of these occurrences resulted in an increase in the variability of the data and a decrease in the interpretability of results. Others have fit a straight line to the three steepest data points (e.g., Meck, 1986), used a logistic equation (Çevik, 2003; Chiang et al., 2000), or a mixture gammaexponential model (Laude, Daniels, Wade, \& Zentall, 2016). Therefore, data analyses in temporal-bisection studies have evolved quite a bit since the procedure was developed and vary widely. A complete evaluation of each method is not possible here. 
The most efficient way to analyze data in the bisection procedure may involve fitting different functions based upon the amount of variance accounted for. For example, bisection points can be determined using Gaussian functions at baseline, when responding conforms to this pattern, whereas linear analyses can be used when this method shows better fits (e.g., during drug administration at high doses). Of course, there is a broader rationale for fitting Gaussian functions to temporal control data that involves its proportional nature. In addition, it is not considered good practice to use different analyses in different conditions of an experiment. However, when Gaussian functions result in very poor fits to data from drug administration, there is a question of whether temporal control is truly occurring at all or if the data reflect another behavioral process (such as perseveration). Therefore, when the equations fitting the data best vary between conditions, the use of multiple analysis techniques may provide important details about the results.

\section{Limitations}

The results add to the literature supporting the idea that impulsivity and temporal control are related processes, but there are limitations to the procedures used. Most notably, the most robust experimental arrangement would allow the measurement of both impulsivity and temporal control in the same individual rats (similar to Smith et al., 2015). Though it was not possible due to the scope of the present project, use of this arrangement in future studies would allow a more fine-tuned analysis via correlation of temporal-control measures with impulsive-choice measures in individual rats.

Another limitation concerns the failure to replicate strain differences in bisection points under saline administration at either drug-administration phase of the experiment. Mean bisection points during the 2-s-vs.-8-s phase were different from one another in the same 
direction as baseline (the mean for LEW rats was less than the mean for F344 rats), though not significant. Bisection points during the 15-s-vs.-60-s series also differed in the same direction for Gaussian analyses only, and neither analysis showed significant results. However, the linear and Gaussian analyses showed quite different mean bisection points for LEW during this phase. It may be the case that saline injections slightly disrupted behavior and resulted in poorer linear fits. It is also possible that the second iteration of testing differs slightly from the first, when rats are naïve to testing durations. Thus, the differences in temporal control between LEW and F344 may be most evident when stimuli are relatively novel.

One advantage of the use of the small sample size in the present study was the ability to closely examine data within individual subjects (e.g., Appendix D). A disadvantage to this approach is that small sample sizes reduce the power of statistical analyses. The analyses used here still uncovered strain differences between LEW and F344 along certain variables. Previous studies have also found significant strain differences between LEW and F344 using ANOVA tests with similar sample sizes (e.g., Follett, 2014; Huskinson et al., 2012). Still, it is possible that strain differences would have emerged along additional variables with a larger sample size. For example, there are a few cases in which visual inspection shows non-overlapping standard error values, but analyses were not significant (e.g., bisection points in Figure 15). A larger sample size may also have been useful for examining variability within, rather than between each strain. For example, it was difficult to determine if a case represented a "true" outlier using the current sample size.

Despite these limitations, significant strain differences were found in temporal control and response to $d$-AMP in certain conditions, and these results call for more research in this area. Specifically, additional studies are needed to determine whether training accurate temporal 
control can result in related decreases in impulsivity. Although Smith et al. (2015) did not show decreases in impulsive choice in LEW rats following one such intervention, other procedures might show different results. For example, it may be interesting to determine whether chronic $d$ AMP administration would result in the development of tolerance to the disruptive effects on temporal control. This development of tolerance could result in two potential outcomes: chronic $d$-AMP could alter temporal control without the flattening effect seen here, or chronic $d$-AMP could elicit similar temporal control to baseline measures. The former possibility, where temporal control is altered without disruptions in stimulus control, could in turn reduce impulsive choice. If such an effect on temporal control occurs with $d$-AMP, it could be responsible for the reductions in impulsive choice seen in those prescribed amphetamines. In addition, other dopaminergic drugs that are administered chronically, such as bupropion, may be of interest to investigate in terms of their effects on temporal control. In any case, the use of different strains of rats can provide insight into whether the therapeutic efficacy of such pharmacological interventions have the potential to depend on genetic factors.

\section{Conclusions}

The differences in temporal control between LEW and F344 rats in the present study further implicate interval timing as a mechanism underlying the differences in impulsivity that also occur between these two strains. LEW rats, which show more impulsive choice, overestimated temporal intervals compared to F344 rats. This may indicate that LEW rats perceive delays to reinforcement to be longer than F344 rats, and in turn, choose smaller-sooner reinforcers more often. A similar mechanism may also underlie impulsivity in humans, where intolerance to long delays may be related to a difference in perception of durations of time. 
Administration of $d$-AMP in the present study yielded results that warrant further research. It is unclear whether the value in dopaminergic agonists as therapies for impulsivity stems from their amelioration of deficits in temporal control. The genetic differences between LEW and F344 include differences in dopaminergic regulation. While these differences in dopaminergic regulation are likely responsible for behavioral differences in both temporal control and impulsivity, the administration of the dopaminergic agonist $d$-AMP (which increases extracellular dopamine levels), resulted in somewhat different effects on temporal control from the differences seen at baseline between LEW and F344 rats. That is, $d$-AMP did not necessarily change behavior such that temporal control in LEW rats was similar to that of F344 rats, or vice versa. While effects of $d$-AMP on impulsivity may still relate to its alteration of temporal control, the present study showed that it likely affects other behaviors simultaneously, such as perseverative responding. Future research in this area is valuable for understanding problem behavior resulting from impulsivity and poor temporal control. Such research has potential to shed light on the processes underlying these problem behaviors to inform the development and improvement of interventions. 


\section{References}

American Psychiatric Association. (2013). Diagnostic and statistical manual of mental disorders (5 $5^{\text {th }}$ ed.). Arlington, VA: American Psychiatric Publishing.

Anderson, K. G., \& Diller, J. W. (2010). Effects of acute and repeated nicotine administration on delay discounting in Lewis and Fischer 344 rats. Behavioural Pharmacology, 21(8), 754 764.

Anderson K.G., \& Woolverton W.L. (2005). Effects of clomipramine on self-control choice in Lewis and Fischer 344 rats. Pharmacology, Biochemistry, \& Behavior, 80, 387-393.

Ashok, A. H., Marques, T. R., Jauhar, S., Nour, M. M., Goodwin, G. M., Young, A. H., \& Howes, O. D. (2017). The dopamine hypothesis of bipolar affective disorder: the state of the art and implications for treatment. Molecular Psychiatry, 22(5), 666-679.

Barkley, R. A., Edwards, G., Laneri, M., Fletcher, K., \& Metevia, L. (2001). Executive functioning, temporal discounting, and sense of time in adolescents with attention deficit hyperactivity disorder (ADHD) and oppositional defiant disorder (ODD). Journal of Abnormal Child Psychology, 29(6), 541-556.

Baumann, A.A., \& Odum, A. L. (2012). Impulsivity, risk taking, and timing. Behavioural Processes, 90(3), 408-414.

Bayley, P. J., Bentley, G. D., \& Dawson, G. R. (1998). The effects of selected antidepressant drugs on timing behaviour in rats. Psychopharmacology, 136(2), 114-122.

Blough, D.S. (1996). Error factors in pigeon discrimination and delayed matching. Journal of Experimental Psychology: Animal Behavior Processes, 22(1), 118-131. 
Bolbecker, A. R., Hong, S. L., Kent, J. S., Forsyth, J. K., Klaunig, M. J., Lazar, E. K., ... \& Hetrick, W.P. (2011). Paced finger-tapping abnormalities in bipolar disorder indicate timing dysfunction. Bipolar Disorders, 13(1), 99-110.

Bschor, T., Ising, M., Bauer, M., Lewitzka, U., Skerstupeit, M., Müller-Oerlinghausen, B., \& Baethge, C. (2004). Time experience and time judgment in major depression, mania, and healthy subjects. A controlled study of 93 subjects. Acta Psychiatrica Scandinavica, 109(3), 222-229.

Buhusi, C. V., \& Meck, W. H. (2005). What makes us tick? Functional and neural mechanisms of interval timing. Nature Reviews Neuroscience, 6(10), 755-765.

Cardinal, R.N., Robbins, T.W., \& Everitt, B.J. (2000). The effects of $d$-amphetamine, chlordiazepoxide, $\alpha$-flupenthixol and behavioural manipulations on choice of signaled and unsignalled delayed reinforcement in rats. Psychopharmacology, 152, 362-375.

Catania, A. C. (1970). Reinforcement schedules and psychophysical judgments: A study of some temporal properties of behavior. In W. N. Schoenfeld (Ed.), The theory of reinforcement schedules, (1-42). New York: Appleton-Century-Crofts.

Çevik, M. Ö. (2003). Effects of methamphetamine on duration discrimination. Behavioral Neuroscience, 117(4), 774-784.

Cheng, R. K., MacDonald, C. J., \& Meck, W. H. (2006). Differential effects of cocaine and ketamine on time estimation: implications for neurobiological models of interval timing. Pharmacology, Biochemistry and Behavior, 85(1), 114-122.

Chiang, T. J., Al-Ruwaitea, A. S. A., Mobini, S., Ho, M. Y., Bradshaw, C. M., \& Szabadi, E. (2000). The effect of $d$-amphetamine on performance on two operant timing schedules. Psychopharmacology, 150(2), 170-184. 
Cho, A. K., Melega, W. P., Kuczenski, R., \& Segal, D. S. (2001). Relevance of pharmacokinetic parameters in animal models of methamphetamine abuse. Synapse, 39(2), 161-166.

Church, R. M., \& Deluty, M. Z. (1977). Bisection of temporal intervals. Journal of Experimental Psychology: Animal Behavior Processes, 3(3), 216-228.

de Wit, H., Enggasser, J. L., \& Richards, J. B. (2002). Acute administration of $d$-amphetamine decreases impulsivity in healthy volunteers. Neuropsychopharmacology, 27(5), 813-825.

Dauer, W., \& Przedborski, S. (2003). Parkinson's disease: mechanisms and models. Neuron, 39(6), 889-909.

Flores, G., Wood, G. K., Barbeau, D., Quirion, R., \& Srivastava, L. K. (1998). Lewis and Fischer rats: A comparison of dopamine transporter and receptor levels. Brain Research, 814, 34-40.

Follett, M. E., \& West Virginia University. (2014). Effects of $d$-amphetamine on temporal control in a peak-interval procedure in Lewis and Fischer 344 rats. Morgantown, West Virginia: West Virginia University.

Garcia, A., \& Kirkpatrick, K. (2013). Impulsive choice behavior in four strains of rats: Evaluation of possible models of Attention-Deficit/Hyperactivity Disorder. Behavioural Brain Research, 238, 10-22.

Golombek, D. A., \& Rosenstein, R. E. (2010). Physiology of circadian entrainment. Physiological Reviews, 90(3), 1063-1102.

Hamilton, K. R., Potenza, M. N., \& Grunberg, N. E. (2014). Lewis rats have greater response impulsivity than Fischer rats. Addictive Behaviors, 39(11), 1565-1572.

Hari, R., \& Kiesila, P. (1996). Deficit of temporal auditory processing in dyslexic adults. Neuroscience Letters, 205, 138-140. 
Heilbronner, S. R., \& Meck, W. H. (2014). Dissociations between interval timing and intertemporal choice following administration of fluoxetine, cocaine, or methamphetamine. Behavioural Processes, 101, 123-134.

Hinton, S. C., \& Meck, W. H. (1997). The 'internal clocks' of circadian and interval timing (erratum). Endeavour, 21(2), 82-87.

Hulst, B. M., Zeeuw, P., Bos, D. J., Rijks, Y., Neggers, S. F., \& Durston, S. (2017). Children with ADHD symptoms show decreased activity in ventral striatum during the anticipation of reward, irrespective of ADHD diagnosis. Journal of Child Psychology and Psychiatry, 58(2), 206-214.

Huskinson, S. L., Krebs, C. A., \& Anderson, K. G. (2012). Strain differences in delay discounting between Lewis and Fischer 344 rats at baseline and following acute and chronic administration of d-amphetamine. Pharmacology Biochemistry and Behavior, 101, 403-416.

Huskinson, S.L., \& Anderson, K.G. (2012). Effects of acute and chronic administration of diazepam on delay discounting in Lewis and Fischer 344 rats. Behavioural Pharmacology, 23, 315-330.

Kuczenski, R., \& Segal, D. S. (1997). Effects of methylphenidate on extracellular dopamine, serotonin, and norepinephrine: comparison with amphetamine. Journal of Neurochemistry, 68(5), 2032-2037.

Laude, J. R., Daniels, C. W., Wade, J. C., \& Zentall, T. R. (2016). I can time with a little help from my friends: effect of social enrichment on timing processes in Pigeons (Columba livia). Animal Cognition, 19(6), 1205-1213. 
Maricq, A. V., \& Church, R. M. (1983). The differential effects of haloperidol and methamphetamine on time estimation in the rat. Psychopharmacology, 79(1), 10-15.

Maricq, A. V., Roberts, S., \& Church, R. M. (1981). Methamphetamine and time estimation. Journal of Experimental Psychology: Animal Behavior Processes, 7(1) 18-30.

McClure, E. A., Saulsgiver, K. A., \& Wynne, C. D. L. (2005). Effects of $d$-amphetamine on temporal discrimination in pigeons. Behavioural Pharmacology, 16(4), 193-208.

McClure, E. A., Saulsgiver, K. A., \& Wynne, C. D. (2009). Effects of acute and chronic damphetamine on two variations of a temporal discrimination procedure. Behavioural Pharmacology, 20(7), 668-672.

Meck, W. H. (1986). Affinity for the dopamine D 2 receptor predicts neuroleptic potency in decreasing the speed of an internal clock. Pharmacology Biochemistry and Behavior, 25(6), 1185-1189.

Nicolson, R.I., Fawcett, A.J., \& Dean, P. (1995). Time estimation deficits in developmental dyslexia: Evidence of cerebellar involvement. Proceedings of the Royal Society London: Brain and Biological Science, 259, 43-47.

Odum, A. L., Lieving, L. M., \& Schaal, D. W. (2002). Effects of $d$-amphetamine in a temporal discrimination procedure: Selective changes in timing or rate dependency? Journal of the Experimental Analysis of Behavior, 78(2), 195-214.

Odum, A. L., \& Ward, R. D. (2007). Characterizing the effects of $d$-amphetamine on temporal discrimination. Behavioural Processes, 75(2), 156-166.

Orduña, V., Hong, E., \& Bouzas, A. (2007). Interval bisection in spontaneously hypertensive rats. Behavioural Processes, 74, 107-111. 
Platt, J. R., \& Davis, E. R. (1983). Bisection of temporal intervals by pigeons. Journal of Experimental Psychology: Animal Behavior Processes, 9(2), 160-170.

Raslear, T. G., Shurtleff, D., \& Simmons, L. (1992). Intertrial-interval effects on sensitivity (A') and response bias ( $\mathrm{B} ")$ in a temporal discrimination by rats. Journal of the Experimental Analysis of Behavior, 58(3), 527-535.

Reynolds, B., \& Schiffbauer, R. (2004). Measuring state changes in human delay discounting: an experiential discounting task. Behavioural Processes, 67(3), 343-356.

Roberts, S. (1981). Isolation of an internal clock. Journal of Experimental Psychology: Animal Behavior Processes, 7(3), 242-268.

Ross, C. A., Margolis, R. L., Reading, S. A., Pletnikov, M., \& Coyle, J. T. (2006). Neurobiology of schizophrenia. Neuron, 52(1), 139-153.

Rubia, K., Halari, R., Christakou, A., \& Taylor, E. (2009). Impulsiveness as a timing disturbance: neurocognitive abnormalities in attention-deficit hyperactivity disorder during temporal processes and normalization with methylphenidate. Philosophical Transactions of the Royal Society B: Biological Sciences, 364(1525), 1919-1931.

Schachar, R., \& Logan, G. D. (1990). Impulsivity and inhibitory control in normal development and childhood psychopathology. Developmental Psychology, 26(5), 710-720.

Schneider, B. A. (1969). A two-state analysis of fixed-interval responding in the pigeon. Journal of the Experimental Analysis of Behavior, 12(5), 677-687.

Skinner, B.F. (1938). The Behavior of Organisms. New York, NY: D. Appelton-Century Company, Inc.

Smith, A. P., Marshall, A. T., \& Kirkpatrick, K. (2015). Mechanisms of impulsive choice: II. Time-based interventions to improve self-control. Behavioural Processes, 112, 29-42. 
Smith, A., Taylor, E., Warner Rogers, J., Newman, S., \& Rubia, K. (2002). Evidence for a pure time perception deficit in children with ADHD. Journal of Child Psychology and Psychiatry, 43(4), 529-542.

Sonuga-Barke, E. J. S., Taylor, E., Sembi, S., \& Smith, J. (1992). Hyperactivity and delay aversion-I. The effect of delay on choice. Journal of Child Psychology and Psychiatry, 33(2), 387-398.

Sonuga-Barke, E.J., Saxton, T., \& Hall, M. (1998). The role of interval underestimation in hyperactive children's failure to suppress responses over time. Behavioural Brain Research, 94, 45-50.

Stein, J. S., Pinkston, J. W., Brewer, A. T., Francisco, M. T., \& Madden, G. J. (2012). Delay Discounting in Lewis and Fischer 344 Rats: Steady-state and Rapid-determination Adjusting-amount Procedures. Journal of the Experimental Analysis of Behavior, 97(3), $305-321$.

Stubbs, A. (1968). The discrimination of stimulus duration by pigeons. Journal of the Experimental Analysis of Behavior, 11, 223-258.

Stubbs, A. (1976). Scaling of stimulus duration by pigeons. Journal of the Experimental Analysis of Behavior, 26, 15-23.

Teixeira, S., Machado, S., Paes, F., Velasques, B., Guilherme Silva, J., L Sanfim, A., ... \& AriasCarrion, O. (2013). Time perception distortion in neuropsychiatric and neurological disorders. CNS \& Neurological Disorders-Drug Targets (Formerly Current Drug Targets-CNS \& Neurological Disorders),12(5), 567-582. 
Toplak, M. E., Dockstader, C., \& Tannock, R. (2006). Temporal information processing in ADHD: Findings to date and new methods. Journal of Neuroscience Methods, 151(1), $15-29$.

Tysk, L. (1984). Time perception and affective disorders. Perceptual and Motor Skills, 58(2), 455-464.

Wade, T.R., de Wit, H., \& Richards, J.B. (2000). Effects of dopaminergic drugs on delayed reward as a measure of impulsive behavior in rats. Psychopharmacology. 150, 90-101.

Winstanley, C. A., Eagle, D. M., \& Robbins, T. W. (2006). Behavioral models of impulsivity in relation to ADHD: translation between clinical and preclinical studies. Clinical Psychology Review, 26(4), 379-395. 
Table 1. Duration values (in seconds) that comprise each series.

\begin{tabular}{lllll} 
Duration Type & $\begin{array}{l}\text { Duration } \\
\text { Series 1 }\end{array}$ & $\begin{array}{l}\text { Duration } \\
\text { Series 2 }\end{array}$ & $\begin{array}{l}\text { Duration } \\
\text { Series 3 }\end{array}$ & $\begin{array}{l}\text { Duration } \\
\text { Series 4 }\end{array}$ \\
\hline Short & 2.0 & 4.0 & 10.0 & 15.0 \\
Intermediate 1 & 2.5 & 5.0 & 12.6 & 18.9 \\
Intermediate 2 & 3.2 & 6.3 & 15.9 & 23.8 \\
Intermediate 3 & 4.0 & 8.0 & 20.0 & 30.0 \\
Intermediate 4 & 5.0 & 10.0 & 25.2 & 37.8 \\
Intermediate 5 & 6.3 & 12.7 & 31.8 & 47.6 \\
Long & 8.0 & 16.0 & 40.0 & 60.0
\end{tabular}


Table 2. Baseline results summary. Arrows represent significant increases or decreases that occurred with increasing series.

\begin{tabular}{|c|c|c|c|c|c|}
\hline Category & $\begin{array}{c}\text { Dependent } \\
\text { Variable } \\
\end{array}$ & $\begin{array}{c}\text { Strain } \\
\text { Difference }\end{array}$ & $\begin{array}{c}\text { Series } \\
\text { Difference }\end{array}$ & $\begin{array}{c}\text { Strain x Series } \\
\text { Interaction } \\
\end{array}$ & $\begin{array}{c}\text { Pair-wise } \\
\text { Significance }\end{array}$ \\
\hline & $\begin{array}{l}\text { Average } \\
\text { Proportion Long } \\
\text { Response }\end{array}$ & LEW > F344 & -- & -- & -- \\
\hline \multirow{11}{*}{ 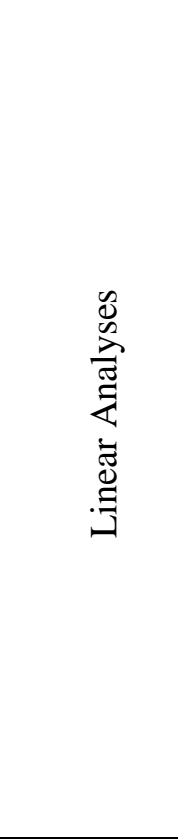 } & & & & & 2-8 and 4-16 \\
\hline & & & & & $2-8$ and $10-40$ \\
\hline & & & & & $2-8$ and $15-60$ \\
\hline & Bisection Point & -- & $\uparrow$ & -- & 4-16 and 10- \\
\hline & & & & & 40 \\
\hline & & & & & $\begin{array}{c}4-16 \text { and } 15- \\
60 \\
\end{array}$ \\
\hline & & & & & $2-8$ and $10-40$ \\
\hline & Difference & & $\uparrow$ & & $2-8$ and $15-60$ \\
\hline & Limen & -- & 1 & -- & $\begin{array}{c}\text { 4-16 and 15- } \\
60 \\
\end{array}$ \\
\hline & Weber Fraction & -- & -- & -- & -- \\
\hline & $R^{2}$ & -- & -- & -- & -- \\
\hline \multirow{3}{*}{ 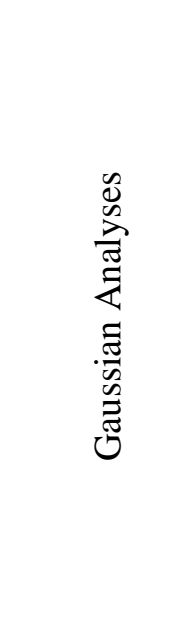 } & Bisection Point & LEW < F344 & $\uparrow$ & $\begin{array}{l}\text { Yes, } \\
\text { Larger increase in } \\
\text { bisection points } \\
\text { across series for } \\
\text { F344 rats than LEW }\end{array}$ & $\begin{array}{l}\text { Each series } \\
\text { combination, } \\
\text { No strain } \\
\text { differences } \\
\text { with simple } \\
\text { effects }\end{array}$ \\
\hline & $\begin{array}{l}\text { Standard } \\
\text { Deviation }\end{array}$ & -- & $\uparrow$ & -- & $\begin{array}{l}\text { Each series } \\
\text { combination }\end{array}$ \\
\hline & $R^{2}$ & -- & -- & -- & -- \\
\hline
\end{tabular}


Table 3. Drug administration results summary. Arrows represent significant increases or decreases that occurred with increasing doses.

\begin{tabular}{|c|c|c|c|c|c|c|}
\hline \multicolumn{2}{|c|}{ Category } & \multirow{2}{*}{\begin{tabular}{l}
\multicolumn{1}{c}{$\begin{array}{c}\text { Dependent } \\
\text { Variable }\end{array}$} \\
Average \\
Proportion Long \\
Response \\
\end{tabular}} & \multirow{2}{*}{$\begin{array}{c}\begin{array}{c}\text { Strain } \\
\text { Difference }\end{array} \\
\text { LEW > F344 }\end{array}$} & \multirow{2}{*}{$\begin{array}{c}\text { Dose } \\
\text { Difference } \\
--\end{array}$} & \multirow{2}{*}{$\begin{array}{c}\text { Dose x Strain } \\
\text { Interaction } \\
--\end{array}$} & \multirow{2}{*}{$\begin{array}{c}\text { Pair-wise } \\
\text { Significance } \\
--\end{array}$} \\
\hline \multirow{8}{*}{ 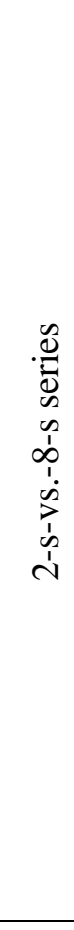 } & & & & & & \\
\hline & \multirow{4}{*}{ 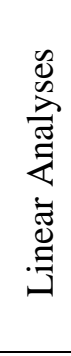 } & Bisection Point & -- & -- & -- & -- \\
\hline & & $\begin{array}{l}\text { Difference } \\
\text { Limen }\end{array}$ & No main effect & $\uparrow$ & -- & $\begin{array}{c}\text { LEW }<\text { F344 at } \\
0.3 \mathrm{mg} / \mathrm{kg}\end{array}$ \\
\hline & & Weber Fraction & -- & $\uparrow$ & -- & -- \\
\hline & & $R^{2}$ & -- & -- & -- & -- \\
\hline & \multirow{3}{*}{ 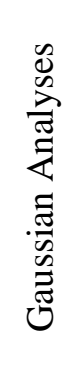 } & Bisection Point & LEW < F344 & -- & -- & -- \\
\hline & & $\begin{array}{l}\text { Standard } \\
\text { Deviation }\end{array}$ & -- & $\uparrow$ & Yes & $\begin{array}{c}\text { SAL \& } 1.0 \\
\text { LEW }<\text { F344 at } \\
1.0 \mathrm{mg} / \mathrm{kg}\end{array}$ \\
\hline & & $R^{2}$ & -- & -- & -- & -- \\
\hline \multirow{8}{*}{ 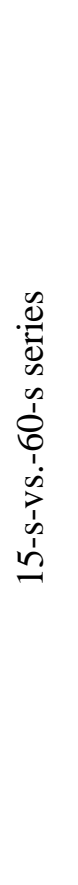 } & & $\begin{array}{l}\text { Average } \\
\text { Proportion Long } \\
\text { Response } \\
\end{array}$ & LEW > F344 & -- & -- & -- \\
\hline & \multirow{4}{*}{ 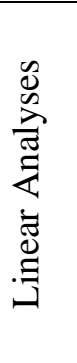 } & Bisection Point & -- & -- & -- & -- \\
\hline & & $\begin{array}{l}\text { Difference } \\
\text { Limen }\end{array}$ & -- & $\uparrow$ & -- & -- \\
\hline & & Weber Fraction & -- & $\uparrow$ & -- & SAL \& 1.0 \\
\hline & & $R^{2}$ & & & & \\
\hline & \multirow{3}{*}{ 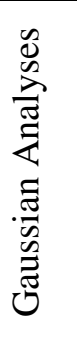 } & Bisection Point & -- & -- & -- & -- \\
\hline & & $\begin{array}{l}\text { Standard } \\
\text { Deviation }\end{array}$ & -- & $\uparrow$ & -- & $\begin{array}{l}\text { SAL \& } 1.0 \\
0.1 \& 1.0\end{array}$ \\
\hline & & $R^{2}$ & -- & $\downarrow$ & -- & $\begin{array}{c}\text { SAL \& } 1.0 \\
0.1 \& 1.0\end{array}$ \\
\hline
\end{tabular}


Table 4. Average omissions per session and standard error of the mean (in parentheses) for sessions meeting exclusion criteria, and number of sessions excluded for F344 and LEW rats. All excluded sessions occurred during the drug administration phase.

\begin{tabular}{|c|c|c|c|}
\hline Series & Variable & F344 & LEW \\
\hline \multirow{5}{*}{$\begin{array}{l}\infty \\
\infty \\
\infty \\
\dot{\infty} \\
\infty \\
\infty \\
\dot{N}\end{array}$} & Average omissions & $32.91(3.46)$ & $23.88(2.34)$ \\
\hline & $\begin{array}{l}\text { Total number of } \\
\text { sessions excluded }\end{array}$ & 11 & 8 \\
\hline & Number of excluded & SAL: 1 & SAL: 3 \\
\hline & sessions per drug dose & $1.0 \mathrm{mg} / \mathrm{kg}: 2$ & $1.0 \mathrm{mg} / \mathrm{kg}: 2$ \\
\hline & & $1.8 \mathrm{mg} / \mathrm{kg}: 8$ & $1.8 \mathrm{mg} / \mathrm{kg}: 3$ \\
\hline \multirow{3}{*}{$\begin{array}{l}\infty \\
\hat{0} \\
0 \\
\dot{0} \\
p \\
\infty \\
1 \\
1\end{array}$} & Average omissions & $22.43(4.22)$ & N/A \\
\hline & $\begin{array}{l}\text { Total number of } \\
\text { sessions excluded }\end{array}$ & 7 & 0 \\
\hline & $\begin{array}{l}\text { Number of excluded } \\
\text { sessions per drug dose }\end{array}$ & $\begin{array}{l}\text { SAL: } 1 \\
0.1 \mathrm{mg} / \mathrm{kg}: 1 \\
1.8 \mathrm{mg} / \mathrm{kg}: 5\end{array}$ & N/A \\
\hline
\end{tabular}


Table 5. Average omissions per session for each rat (included sessions only).

\begin{tabular}{|c|c|c|c|c|c|c|c|}
\hline Series & Strain & Rat/Dose & SAL & $\begin{array}{l}0.1 \\
\mathrm{mg} / \mathrm{kg}\end{array}$ & $\begin{array}{l}0.3 \\
\mathrm{mg} / \mathrm{kg}\end{array}$ & $1.0 \mathrm{mg} / \mathrm{kg}$ & $1.8 \mathrm{mg} / \mathrm{kg}$ \\
\hline \multirow{12}{*}{$\begin{array}{l}0 \\
\infty \\
\infty \\
\dot{D} \\
\infty \\
\dot{d}\end{array}$} & \multirow{6}{*}{$\underset{I I}{\stackrel{J}{J}}$} & F-1 & -- & -- & 3.33 & -- & 2.00 \\
\hline & & $\mathrm{F}-2$ & -- & -- & -- & -- & Excluded \\
\hline & & F-3 & -- & -- & -- & -- & Excluded \\
\hline & & F-4 & -- & -- & -- & -- & 5.50 \\
\hline & & F-5 & -- & -- & -- & -- & Excluded \\
\hline & & F-6 & -- & -- & -- & -- & 23.00 \\
\hline & \multirow{6}{*}{ 咅 } & L-1 & -- & -- & -- & Excluded & Excluded \\
\hline & & L-2 & -- & -- & -- & -- & -- \\
\hline & & L-3 & -- & -- & -- & -- & 8.00 \\
\hline & & L-4 & -- & -- & -- & -- & -- \\
\hline & & L-5 & -- & -- & 0.67 & -- & -- \\
\hline & & L-6 & -- & -- & 2.00 & 8.67 & -- \\
\hline \multirow{12}{*}{ 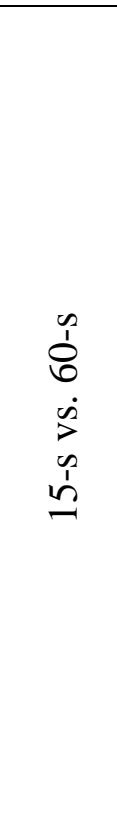 } & \multirow{6}{*}{ 念 } & F-1 & -- & -- & -- & 0.33 & 15.00 \\
\hline & & $\mathrm{F}-2$ & -- & -- & -- & -- & 27.00 \\
\hline & & F-3 & -- & 0.25 & -- & 1.00 & 1.50 \\
\hline & & F-4 & -- & -- & -- & -- & -- \\
\hline & & F-5 & -- & -- & 2.33 & 4.25 & 7.00 \\
\hline & & F-6 & -- & -- & -- & 1.33 & 3.00 \\
\hline & \multirow{6}{*}{ 疍 } & L-1 & -- & -- & -- & -- & 0.33 \\
\hline & & L-2 & -- & -- & -- & -- & 0.67 \\
\hline & & L-3 & -- & -- & -- & -- & -- \\
\hline & & L-4 & -- & -- & -- & -- & -- \\
\hline & & L-5 & -- & -- & -- & -- & -- \\
\hline & & L-6 & -- & -- & -- & -- & -- \\
\hline
\end{tabular}


Table 6. Bisection point (BP), difference limen $(D L)$, Weber fraction $(W F)$, and coefficient of determination $\left(R^{2}\right)$ for each series of the baseline phase.

\begin{tabular}{|c|c|c|c|c|c|c|c|c|c|}
\hline \multicolumn{5}{|c|}{ Fischer 344} & \multicolumn{5}{|c|}{ Lewis } \\
\hline \multicolumn{10}{|c|}{$2 \mathrm{~s}$ VS. $8 \mathrm{~s}$} \\
\hline Rat & $\mathrm{BP}$ & DL & WF & $\mathrm{R}^{2}$ & Rat & $\mathrm{BP}$ & $\mathrm{DL}$ & WF & $\mathrm{R}^{2}$ \\
\hline $\mathrm{F} 1$ & 5.12 & 1.57 & 0.31 & $0.32 *$ & L1 & 4.23 & 0.65 & 0.15 & $0.02 *$ \\
\hline $\mathrm{F} 2$ & 4.39 & 0.65 & 0.15 & 0.99 & L2 & 3.82 & 0.75 & 0.20 & 0.99 \\
\hline F3 & 5.48 & 1.41 & 0.26 & 0.93 & L3 & 4.83 & 0.70 & 0.15 & 0.77 \\
\hline $\mathrm{F} 4$ & 4.17 & 0.61 & 0.15 & 0.97 & L4 & 3.79 & 0.56 & 0.15 & 0.87 \\
\hline F5 & 4.47 & 0.81 & 0.18 & 0.94 & L5 & 4.16 & 0.55 & 0.13 & 0.96 \\
\hline F6 & 4.13 & 0.81 & 0.20 & 0.98 & L6 & 4.25 & 0.74 & 0.17 & 1.00 \\
\hline Mean & 4.63 & 0.98 & 0.21 & 0.86 & Mean & 4.18 & 0.66 & 0.16 & 0.85 \\
\hline SEM & 0.20 & 0.12 & 0.02 & 0.02 & SEM & 0.15 & $\mathbf{0 . 0 3}$ & 0.01 & 0.91 \\
\hline \multicolumn{10}{|c|}{$4 \mathrm{~s}$ VS. $16 \mathrm{~s}$} \\
\hline Rat & $\mathrm{BP}$ & $\mathrm{DL}$ & WF & $\mathrm{R}^{2}$ & Rat & $\mathrm{BP}$ & $\mathrm{DL}$ & WF & $\mathrm{R}^{2}$ \\
\hline F1 & 23.82 & 17.15 & 0.72 & $0.08 *$ & L1 & 10.64 & 2.54 & 0.24 & 0.71 \\
\hline $\mathrm{F} 2$ & 7.15 & 1.27 & 0.18 & 0.71 & L2 & 9.20 & 1.88 & 0.20 & 0.90 \\
\hline F3 & 9.61 & 1.64 & 0.17 & 1.00 & L3 & 8.71 & 1.47 & 0.17 & 0.97 \\
\hline $\mathrm{F} 4$ & 8.24 & 1.65 & 0.20 & 0.99 & L4 & 16.17 & 16.14 & 1.00 & $0.21 *$ \\
\hline F5 & 7.62 & 1.14 & 0.15 & 0.99 & L5 & 7.53 & 1.37 & 0.18 & 0.85 \\
\hline F6 & 9.08 & 1.47 & 0.16 & 0.97 & L6 & 7.48 & 1.24 & 0.17 & 1.00 \\
\hline Mean & 10.92 & 4.05 & 0.26 & 0.79 & Mean & 9.95 & 4.11 & 0.33 & 0.77 \\
\hline SEM & 0.57 & 0.44 & 0.02 & 0.05 & SEM & 1.33 & 2.39 & 0.13 & 0.12 \\
\hline \multicolumn{10}{|c|}{$10 \mathrm{~s}$ vs. $40 \mathrm{~s}$} \\
\hline Rat & $\mathrm{BP}$ & DL & WF & $\mathrm{R}^{2}$ & Rat & $\mathrm{BP}$ & DL & WF & $\mathrm{R}^{2}$ \\
\hline $\mathrm{F} 1$ & 29.71 & 9.34 & 0.31 & 1.00 & L1 & 22.70 & 4.67 & 0.21 & 1.00 \\
\hline $\mathrm{F} 2$ & 23.08 & 5.43 & 0.24 & 0.91 & L2 & 16.66 & 5.56 & 0.33 & 0.69 \\
\hline F3 & 15.92 & 6.67 & 0.42 & $0.45^{*}$ & L3 & 19.75 & 3.71 & 0.19 & 1.00 \\
\hline $\mathrm{F} 4$ & 22.82 & 3.68 & 0.16 & 0.98 & L4 & 16.04 & 7.42 & 0.46 & 1.00 \\
\hline F5 & 23.95 & 6.15 & 0.26 & 0.99 & L5 & 19.73 & 3.80 & 0.19 & 0.92 \\
\hline F6 & 22.50 & 6.40 & 0.28 & 0.82 & L6 & 26.36 & 11.99 & 0.45 & 0.81 \\
\hline Mean & 23.00 & 6.28 & 0.28 & 0.86 & Mean & 20.21 & 6.19 & 0.31 & 0.90 \\
\hline SEM & 1.21 & 0.45 & 0.03 & 0.08 & SEM & 1.50 & 1.25 & 0.05 & 0.05 \\
\hline \multicolumn{10}{|c|}{$15 \mathrm{~s}$ vs. $60 \mathrm{~s}$} \\
\hline Rat & $\mathrm{BP}$ & $\mathrm{DL}$ & WF & $\mathrm{R}^{2}$ & Rat & $\mathrm{BP}$ & $\mathrm{DL}$ & WF & $\mathrm{R}^{2}$ \\
\hline F1 & 23.50 & 28.12 & 1.20 & 1.00 & L1 & 34.05 & 14.06 & 0.41 & 1.00 \\
\hline $\mathrm{F} 2$ & 30.53 & 7.24 & 0.24 & 0.79 & L2 & 17.87 & 18.99 & 1.06 & 0.94 \\
\hline F3 & 32.18 & 9.88 & 0.31 & 0.56 & L3 & 29.34 & 14.33 & 0.49 & 0.88 \\
\hline $\mathrm{F} 4$ & 31.75 & 7.31 & 0.23 & 0.69 & L4 & 28.49 & 8.17 & 0.29 & 0.91 \\
\hline F5 & 32.48 & 11.69 & 0.36 & 0.69 & L5 & 26.91 & 7.24 & 0.27 & 0.79 \\
\hline F6 & 64.64 & 29.24 & 0.45 & 0.69 & L6 & 28.49 & 8.17 & 0.29 & 0.91 \\
\hline Mean & 35.85 & 15.58 & 0.46 & 0.74 & Mean & 27.53 & 11.83 & 0.47 & 0.90 \\
\hline SEM & 5.40 & 3.40 & 0.04 & $\mathbf{0 . 0 3}$ & SEM & 1.75 & 1.87 & 0.12 & 0.02 \\
\hline
\end{tabular}


Table 7. Minimum (Min), range, bisection point (Mu), standard deviation (Sigma), and coefficient of determination $\left(R^{2}\right)$ for baseline phase.

\begin{tabular}{|c|c|c|c|c|c|c|c|c|c|c|c|}
\hline \multicolumn{6}{|c|}{ Fischer 344} & \multicolumn{6}{|c|}{ Lewis } \\
\hline \multicolumn{12}{|c|}{$2 \mathrm{~s}$ VS. $8 \mathrm{~s}$} \\
\hline Rat & Min & Range & $\mathrm{Mu}$ & Sigma & $\mathrm{R}^{2}$ & Rat & Min & Range & $\mathrm{Mu}$ & Sigma & $\mathrm{R}^{2}$ \\
\hline $\mathrm{F} 1$ & 0.04 & 0.94 & 4.74 & 1.59 & 0.87 & L1 & 0.01 & 0.99 & 4.25 & 0.94 & 1.00 \\
\hline $\mathrm{F} 2$ & 0.01 & 0.99 & 4.46 & 1.05 & 0.98 & L2 & 0.01 & 0.99 & 3.67 & 0.66 & 0.90 \\
\hline F3 & 0.02 & 0.96 & 5.07 & 1.44 & 0.97 & L3 & 0.00 & 1.00 & 4.83 & 0.54 & 0.99 \\
\hline $\mathrm{F} 4$ & 0.00 & 1.00 & 4.12 & 0.80 & 0.99 & L4 & 0.00 & 1.00 & 3.72 & 0.57 & 1.00 \\
\hline F5 & 0.02 & 0.97 & 4.45 & 1.26 & 0.98 & L5 & 0.00 & 1.00 & 4.14 & 0.71 & 1.00 \\
\hline F6 & 0.04 & 0.96 & 4.13 & 1.19 & 1.00 & L6 & 0.04 & 0.96 & 4.34 & 1.31 & 0.92 \\
\hline Mean & 0.02 & 0.97 & 4.49 & 1.22 & 0.96 & Mean & 0.01 & 0.99 & 4.16 & 0.79 & 0.97 \\
\hline SEM & 0.01 & 0.01 & 0.15 & 0.11 & 0.02 & SEM & 0.01 & 0.01 & 0.18 & 0.12 & 0.02 \\
\hline \multicolumn{12}{|c|}{$4 \mathrm{~s}$ VS. $16 \mathrm{~s}$} \\
\hline Rat & Min & Range & $\mathrm{Mu}$ & Sigma & $\mathrm{R}^{2}$ & Rat & Min & Range & $\mathrm{Mu}$ & Sigma & $\mathrm{R}^{2}$ \\
\hline F1 & 0.06 & 0.84 & 10.52 & 4.23 & 0.90 & L1 & 0.04 & 0.85 & 11.16 & 3.99 & 0.94 \\
\hline $\mathrm{F} 2$ & 0.00 & 1.00 & 6.92 & 0.72 & 0.99 & L2 & 0.03 & 0.97 & 9.28 & 2.72 & 0.98 \\
\hline F3 & 0.01 & 0.98 & 9.89 & 2.53 & 0.99 & L3 & 0.01 & 0.99 & 8.87 & 2.13 & 0.99 \\
\hline $\mathrm{F} 4$ & 0.04 & 0.95 & 8.44 & 2.59 & 0.96 & L4 & 0.26 & 0.70 & 7.21 & 5.07 & 0.81 \\
\hline F5 & 0.00 & 1.00 & 7.54 & 1.31 & 0.99 & L5 & 0.00 & 1.00 & 7.29 & 1.15 & 0.99 \\
\hline F6 & 0.00 & 1.00 & 9.14 & 1.73 & 1.00 & L6 & 0.01 & 0.99 & 7.44 & 1.43 & 1.00 \\
\hline Mean & 0.02 & 0.96 & 8.74 & 2.18 & 0.97 & Mean & 0.06 & 0.92 & 8.54 & 2.75 & 0.95 \\
\hline SEM & 0.01 & $\mathbf{0 . 0 3}$ & 0.56 & $\mathbf{0 . 5 0}$ & 0.01 & SEM & 0.04 & 0.05 & 0.63 & 0.62 & $\mathbf{0 . 0 3}$ \\
\hline \multicolumn{12}{|c|}{$10 \mathrm{~s}$ vs. $40 \mathrm{~s}$} \\
\hline Rat & Min & Range & $\mathrm{Mu}$ & Sigma & $\mathrm{R}^{2}$ & Rat & Min & Range & $\mathrm{Mu}$ & Sigma & $\mathrm{R}^{2}$ \\
\hline $\mathrm{F} 1$ & 0.05 & 0.80 & 28.40 & 11.10 & 0.98 & L1 & 0.04 & 0.95 & 23.06 & 7.31 & 0.98 \\
\hline $\mathrm{F} 2$ & 0.08 & 0.88 & 23.90 & 9.71 & 0.98 & L2 & 0.22 & 0.78 & 16.72 & 8.60 & 0.87 \\
\hline F3 & 0.00 & 1.00 & 16.87 & 2.60 & 0.91 & L3 & 0.08 & 0.92 & 19.55 & 6.77 & 0.98 \\
\hline $\mathrm{F} 4$ & 0.02 & 0.98 & 23.64 & 6.46 & 0.97 & L4 & 0.20 & 0.79 & 17.68 & 9.20 & 0.92 \\
\hline F5 & 0.13 & 0.69 & 26.82 & 14.74 & 0.90 & L5 & 0.02 & 0.98 & 19.48 & 4.58 & 0.98 \\
\hline F6 & 0.17 & 0.70 & 23.94 & 14.57 & 0.94 & L6 & 0.24 & 0.71 & 18.86 & 12.68 & 0.72 \\
\hline Mean & 0.07 & 0.84 & 23.93 & 9.86 & 0.95 & Mean & 0.13 & 0.86 & 19.22 & 8.19 & 0.91 \\
\hline SEM & $\mathbf{0 . 0 3}$ & 0.05 & 1.62 & 1.93 & 0.01 & SEM & 0.04 & 0.04 & 0.89 & 1.11 & 0.04 \\
\hline \multicolumn{12}{|c|}{$15 \mathrm{~s}$ vs. $60 \mathrm{~s}$} \\
\hline Rat & Min & Range & $\mathrm{Mu}$ & Sigma & $\mathrm{R}^{2}$ & Rat & Min & Range & $\mathrm{Mu}$ & Sigma & $\mathrm{R}^{2}$ \\
\hline F1 & 0.19 & 0.76 & 31.06 & 18.13 & 0.89 & L1 & 0.09 & 0.88 & 33.48 & 14.04 & 0.98 \\
\hline $\mathrm{F} 2$ & 0.06 & 0.93 & 30.93 & 10.48 & 0.93 & L2 & 0.28 & 0.69 & 25.69 & 18.21 & 0.82 \\
\hline F3 & 0.09 & 0.87 & 34.14 & 14.33 & 0.89 & L3 & 0.15 & 0.83 & 30.60 & 15.03 & 0.97 \\
\hline $\mathrm{F} 4$ & 0.06 & 0.93 & 32.09 & 11.00 & 0.92 & L4 & 0.07 & 0.93 & 29.41 & 9.85 & 0.94 \\
\hline F5 & 0.12 & 0.84 & 33.44 & 15.52 & 0.94 & L5 & 0.05 & 0.95 & 26.95 & 7.16 & 0.97 \\
\hline F6 & 0.02 & 0.90 & 42.38 & 12.69 & 0.97 & L6 & 0.23 & 0.70 & 30.27 & 20.64 & 0.87 \\
\hline Mean & 0.09 & 0.87 & 34.01 & 13.69 & 0.92 & Mean & 0.15 & 0.83 & 29.40 & 14.15 & 0.92 \\
\hline SEM & 0.02 & 0.03 & 1.75 & 1.18 & 0.01 & SEM & 0.04 & 0.05 & 1.13 & 2.05 & 0.03 \\
\hline
\end{tabular}


Table 8. Bisection point (BP), difference limen (DL), Weber fraction $(W F)$, and coefficient of determination $\left(R^{2}\right)$ for the 2-s-vs.-8-s duration series of the drug administration phase.

\begin{tabular}{|c|c|c|c|c|c|c|c|c|c|}
\hline \multicolumn{5}{|c|}{ Fischer 344} & \multicolumn{5}{|c|}{ Lewis } \\
\hline \multicolumn{10}{|c|}{ Saline } \\
\hline Rat & $\mathrm{BP}$ & DL & WF & $\mathrm{R}^{2}$ & Rat & $\mathrm{BP}$ & DL & WF & $\mathrm{R}^{2}$ \\
\hline F1 & 2.93 & 1.95 & 0.67 & $0.37 *$ & L1 & 4.53 & 1.05 & 0.23 & 0.80 \\
\hline $\mathrm{F} 2$ & 2.97 & 2.64 & 0.89 & $0.30 *$ & $\mathrm{~L} 2$ & 4.24 & 0.77 & 0.18 & 1.00 \\
\hline F3 & 4.56 & 0.74 & 0.16 & 0.70 & L3 & 4.24 & 0.80 & 0.19 & 0.81 \\
\hline F4 & 4.94 & 0.87 & 0.18 & 0.80 & L4 & 3.59 & 1.08 & 0.30 & 1.00 \\
\hline F5 & 4.49 & 1.28 & 0.29 & 0.63 & L5 & 3.73 & 0.68 & 0.18 & 0.77 \\
\hline F6 & 4.66 & 1.08 & 0.23 & 1.00 & L6 & 3.63 & 1.04 & 0.29 & 0.98 \\
\hline $\begin{array}{l}\text { Mean } \\
\text { (SEM) }\end{array}$ & $\begin{array}{l}4.09 \\
(0.37)\end{array}$ & $\begin{array}{l}1.43 \\
(0.30)\end{array}$ & $\begin{array}{l}0.40 \\
(0.12)\end{array}$ & $\begin{array}{l}0.63 \\
(0.11)\end{array}$ & $\begin{array}{l}\text { Mean } \\
\text { (SEM) }\end{array}$ & $\begin{array}{l}3.99 \\
(0.16)\end{array}$ & $\begin{array}{l}0.90 \\
(0.07)\end{array}$ & $\begin{array}{l}0.23 \\
(0.02)\end{array}$ & $\begin{array}{l}0.89 \\
(0.05)\end{array}$ \\
\hline \multicolumn{10}{|c|}{$0.1 \mathrm{mg} / \mathrm{kg} d$-AMP } \\
\hline Rat & $\mathrm{BP}$ & DL & WF & $\mathrm{R}^{2}$ & Rat & BP & DL & WF & $\mathrm{R}^{2}$ \\
\hline F1 & 4.69 & 1.41 & 0.30 & 0.69 & L1 & 3.54 & 0.79 & 0.22 & 0.91 \\
\hline $\mathrm{F} 2$ & 5.69 & 4.88 & 0.86 & $0.31 *$ & L2 & 5.55 & 4.44 & 0.80 & $0.07 *$ \\
\hline F3 & 4.88 & 0.70 & 0.14 & 0.80 & L3 & 4.07 & 0.60 & 0.15 & 1.00 \\
\hline F4 & 4.46 & 0.60 & 0.13 & 0.98 & L4 & 4.07 & 0.90 & 0.22 & 1.00 \\
\hline F5 & 4.31 & 0.54 & 0.13 & 1.00 & L5 & 3.44 & 0.63 & 0.18 & 0.69 \\
\hline F6 & 4.40 & 0.75 & 0.17 & 0.90 & L6 & 3.66 & 1.83 & 0.50 & 0.94 \\
\hline $\begin{array}{l}\text { Mean } \\
\text { (SEM) }\end{array}$ & $\begin{array}{l}4.74 \\
(0.21)\end{array}$ & $\begin{array}{l}1.48 \\
(0.69)\end{array}$ & $\begin{array}{l}\mathbf{0 . 2 9} \\
(0.12)\end{array}$ & $\begin{array}{l}0.78 \\
(0.11)\end{array}$ & $\begin{array}{l}\text { Mean } \\
\text { (SEM) }\end{array}$ & $\begin{array}{l}4.05 \\
(0.32)\end{array}$ & $\begin{array}{l}1.53 \\
(0.61)\end{array}$ & $\begin{array}{l}0.35 \\
(0.10)\end{array}$ & $\begin{array}{l}0.77 \\
(0.15)\end{array}$ \\
\hline \multicolumn{10}{|c|}{$0.3 \mathrm{mg} / \mathrm{kg} d$-AMP } \\
\hline Rat & BP & DL & WF & $\mathrm{R}^{2}$ & Rat & BP & DL & WF & $\mathrm{R}^{2}$ \\
\hline F1 & N/A & N/A & N/A & N/A & L1 & 3.33 & 0.89 & 0.27 & 0.95 \\
\hline $\mathrm{F} 2$ & 5.23 & 1.16 & 0.22 & 0.80 & L2 & 4.07 & 0.60 & 0.15 & 1.00 \\
\hline F3 & 4.46 & 1.19 & 0.27 & 0.98 & L3 & 3.33 & 0.74 & 0.22 & 0.85 \\
\hline F4 & 3.27 & 1.19 & 0.36 & 0.98 & L4 & 3.14 & 0.93 & 0.30 & 0.79 \\
\hline F5 & 6.57 & 3.75 & 0.57 & 0.69 & L5 & 3.98 & 0.75 & 0.19 & 0.87 \\
\hline F6 & 4.83 & 0.92 & 0.19 & 0.89 & L6 & 3.67 & 0.89 & 0.24 & 0.65 \\
\hline $\begin{array}{l}\text { Mean } \\
\text { (SEM) }\end{array}$ & $\begin{array}{l}4.87 \\
(0.54)\end{array}$ & $\begin{array}{l}1.64 \\
(0.53)\end{array}$ & $\begin{array}{l}\mathbf{0 . 3 2} \\
(\mathbf{0 . 0 7})\end{array}$ & $\begin{array}{l}0.87 \\
(0.06)\end{array}$ & $\begin{array}{l}\text { Mean } \\
\text { (SEM) }\end{array}$ & $\begin{array}{l}3.59 \\
(0.16)\end{array}$ & $\begin{array}{l}\mathbf{0 . 8 0} \\
(\mathbf{0 . 0 5})\end{array}$ & $\begin{array}{l}0.23 \\
(0.02)\end{array}$ & $\begin{array}{l}0.85 \\
(0.05)\end{array}$ \\
\hline \multicolumn{10}{|c|}{$1.0 \mathrm{mg} / \mathrm{kg} d$-AMP } \\
\hline Rat & BP & DL & WF & $\mathrm{R}^{2}$ & Rat & BP & DL & WF & $\mathrm{R}^{2}$ \\
\hline F1 & 4.52 & 0.90 & 0.20 & 1.00 & L1 & N/A & N/A & N/A & N/A \\
\hline $\mathrm{F} 2$ & 6.10 & 2.44 & 0.40 & 0.94 & L2 & 1.88 & 1.88 & 1.00 & 0.69 \\
\hline F3 & 5.23 & 1.74 & 0.33 & 0.80 & L3 & -3.05 & 4.58 & 1.50 & $0.15^{*}$ \\
\hline F4 & 2.44 & 1.33 & 0.55 & 0.95 & L4 & 4.79 & 1.31 & 0.27 & 0.80 \\
\hline F5 & 3.49 & 1.74 & 0.50 & 0.80 & L5 & 2.93 & 0.93 & 0.32 & 0.83 \\
\hline F6 & 2.44 & 1.63 & 0.67 & $0.31 *$ & L6 & 3.33 & 1.11 & 0.33 & 0.85 \\
\hline $\begin{array}{l}\text { Mean } \\
\text { (SEM) }\end{array}$ & $\begin{array}{l}4.04 \\
(0.61)\end{array}$ & $\begin{array}{l}1.63 \\
(0.21)\end{array}$ & $\begin{array}{l}0.44 \\
(0.07)\end{array}$ & $\begin{array}{l}0.80 \\
(0.10)\end{array}$ & $\begin{array}{l}\text { Mean } \\
\text { (SEM) }\end{array}$ & $\begin{array}{l}1.98 \\
(1.10)\end{array}$ & $\begin{array}{l}1.96 \\
(0.67)\end{array}$ & $\begin{array}{l}\mathbf{0 . 6 8} \\
(0.24)\end{array}$ & $\begin{array}{l}0.66 \\
(0.13)\end{array}$ \\
\hline \multicolumn{10}{|c|}{$1.8 \mathrm{mg} / \mathrm{kg} d$-AMP } \\
\hline Rat & $\mathrm{BP}$ & $\mathrm{DL}$ & WF & $\mathrm{R}^{2}$ & Rat & BP & DL & WF & $\mathrm{R}^{2}$ \\
\hline & & & & & L2 & 10.32 & 3.75 & 0.36 & 0.69 \\
\hline & & & & & L3 & 6.34 & 1.76 & 0.28 & 0.88 \\
\hline F4 & 5.39 & 0.95 & 0.18 & 0.80 & L4 & 10.32 & 3.75 & 0.36 & 0.69 \\
\hline & & & & & L5 & 4.36 & 1.31 & 0.30 & 0.80 \\
\hline Mean & & & & & Mean & 7.84 & 2.64 & 0.33 & 0.77 \\
\hline (SEM) & N/A & N/A & N/A & N/A & (SEM) & (1.49) & (1.65) & $(0.02)$ & $(0.05)$ \\
\hline
\end{tabular}

$* \mathrm{R}^{2}$ value less than 0.5 . 
Table 9. Minimum (Min), range, bisection point (Mu), standard deviation (Sigma), and coefficient of determination $\left(R^{2}\right)$ for the $2-s-v s .-8-s$ duration series of the drug administration phase.

\begin{tabular}{|c|c|c|c|c|c|c|c|c|c|c|c|}
\hline \multicolumn{6}{|c|}{ Fischer 344} & \multicolumn{6}{|c|}{ Lewis } \\
\hline \multicolumn{12}{|c|}{ Saline } \\
\hline Rat & Min & Range & $\mathrm{Mu}$ & Sigma & $\mathrm{R}^{2}$ & Rat & Min & Range & $\mathrm{Mu}$ & Sigma & $\mathrm{R}^{2}$ \\
\hline F1 & 0.12 & 0.88 & 3.51 & 1.26 & 0.91 & L1 & 0.03 & 0.96 & 4.63 & 1.40 & 0.97 \\
\hline $\mathrm{F} 2$ & 0.13 & 0.87 & 3.87 & 1.63 & 0.84 & L2 & 0.04 & 0.95 & 4.33 & 1.36 & 0.98 \\
\hline F3 & 0.00 & 1.00 & 4.66 & 0.51 & 0.93 & L3 & 0.03 & 0.97 & 4.24 & 1.18 & 0.95 \\
\hline F4 & 0.00 & 0.99 & 5.00 & 1.15 & 0.94 & $\mathrm{~L} 4$ & 0.23 & 0.75 & 3.57 & 2.11 & 0.96 \\
\hline F5 & 0.05 & 0.93 & 4.58 & 1.98 & 0.95 & L5 & 0.00 & 1.00 & 3.59 & 0.50 & 0.97 \\
\hline F6 & 0.04 & 0.96 & 4.60 & 1.44 & 1.00 & L6 & 0.05 & 0.95 & 3.73 & 1.07 & 0.98 \\
\hline Mean & 0.06 & 0.94 & 4.37 & 1.33 & 0.93 & Mean & 0.06 & 0.93 & 4.01 & 1.27 & 0.97 \\
\hline SEM & 0.02 & 0.02 & 0.23 & 0.20 & 0.02 & SEM & 0.03 & 0.04 & 0.18 & 0.21 & 0.00 \\
\hline \multicolumn{12}{|c|}{$0.1 \mathrm{mg} / \mathrm{kg} d$-AMP } \\
\hline Rat & Min & Range & $\mathrm{Mu}$ & Sigma & $\mathrm{R}^{2}$ & Rat & Min & Range & $\mathrm{Mu}$ & Sigma & $\mathrm{R}^{2}$ \\
\hline F1 & 0.07 & 0.92 & 4.41 & 1.61 & 0.94 & L1 & 0.24 & 0.71 & 3.78 & 2.53 & 0.61 \\
\hline $\mathrm{F} 2$ & 0.08 & 0.89 & 4.60 & 1.84 & 0.90 & L2 & 0.15 & 0.77 & 4.60 & 2.49 & 0.78 \\
\hline F3 & 0.00 & 1.00 & 4.93 & 0.22 & 0.98 & L3 & 0.01 & 0.99 & 4.01 & 0.92 & 0.98 \\
\hline F4 & 0.05 & 0.93 & 4.70 & 1.16 & 0.87 & L4 & 0.10 & 0.88 & 4.32 & 1.82 & 0.89 \\
\hline F5 & 0.05 & 0.93 & 4.72 & 1.64 & 0.83 & L5 & 0.00 & 1.00 & 3.36 & 0.24 & 0.99 \\
\hline F6 & 0.01 & 0.99 & 4.53 & 1.14 & 0.96 & L6 & 0.11 & 0.89 & 3.86 & 1.50 & 0.96 \\
\hline Mean & 0.04 & 0.94 & 4.65 & 1.27 & 0.91 & Mean & 0.10 & 0.87 & 3.99 & 1.58 & 0.87 \\
\hline SEM & 0.01 & 0.02 & 0.07 & 0.24 & 0.02 & SEM & 0.04 & 0.05 & 0.18 & 0.37 & 0.06 \\
\hline \multicolumn{12}{|c|}{$0.3 \mathrm{mg} / \mathrm{kg} d-\mathrm{AMP}$} \\
\hline Rat & Min & Range & $\mathrm{Mu}$ & Sigma & $\mathrm{R}^{2}$ & Rat & Min & Range & $\mathrm{Mu}$ & Sigma & $\mathrm{R}^{2}$ \\
\hline F1 & 0.16 & 0.70 & 4.95 & 2.91 & 0.78 & L1 & 0.10 & 0.90 & 3.40 & 1.11 & 0.97 \\
\hline $\mathrm{F} 2$ & 0.00 & 0.99 & 5.05 & 1.16 & 0.97 & L2 & 0.00 & 1.00 & 4.04 & 0.78 & 0.99 \\
\hline F3 & 0.05 & 0.94 & 4.52 & 1.55 & 0.98 & L3 & 0.03 & 0.97 & 3.33 & 0.71 & 0.98 \\
\hline F4 & 0.09 & 0.91 & 3.55 & 1.17 & 0.93 & L4 & 0.29 & 0.71 & 2.90 & 1.65 & 0.85 \\
\hline F5 & 0.07 & 0.82 & 5.20 & 2.22 & 0.94 & L5 & 0.08 & 0.92 & 3.97 & 1.37 & 0.92 \\
\hline F6 & 0.01 & 0.98 & 4.85 & 1.29 & 0.97 & L6 & 0.09 & 0.91 & 3.64 & 1.21 & 0.87 \\
\hline Mean & 0.07 & 0.89 & 4.69 & 1.72 & 0.93 & Mean & 0.10 & 0.90 & 3.55 & 1.14 & 0.93 \\
\hline SEM & 0.02 & 0.05 & 0.25 & 0.29 & 0.03 & SEM & 0.04 & 0.04 & 0.17 & 0.15 & 0.02 \\
\hline \multicolumn{12}{|c|}{$1.0 \mathrm{mg} / \mathrm{kg} d-\mathrm{AMP}$} \\
\hline Rat & Min & Range & $\mathrm{Mu}$ & Sigma & $\mathrm{R}^{2}$ & Rat & Min & Range & $\mathrm{Mu}$ & Sigma & $\mathrm{R}^{2}$ \\
\hline F1 & 0.15 & 0.69 & 5.08 & 2.94 & 0.87 & & & & & & \\
\hline $\mathrm{F} 2$ & 0.10 & 0.70 & 5.61 & 2.81 & 0.98 & L2 & 0.23 & 0.77 & 2.92 & 1.22 & $0.34 *$ \\
\hline $\mathrm{F} 3$ & 0.17 & 0.70 & 4.75 & 2.91 & 0.83 & L3 & 0.57 & 0.43 & 1.69 & 1.86 & 0.81 \\
\hline $\mathrm{F} 4$ & 0.29 & 0.71 & 2.81 & 1.47 & 0.90 & L4 & 0.08 & 0.83 & 5.11 & 2.18 & 0.96 \\
\hline F5 & 0.27 & 0.70 & 3.57 & 2.51 & 0.95 & L5 & 0.03 & 0.97 & 3.18 & 0.63 & 1.00 \\
\hline F6 & 0.34 & 0.66 & 2.81 & 1.96 & 0.50 & L6 & 0.06 & 0.94 & 3.49 & 0.97 & 0.96 \\
\hline Mean & 0.22 & 0.69 & 4.11 & 2.43 & 0.84 & Mean & 0.19 & 0.79 & 3.28 & 1.37 & 0.81 \\
\hline SEM & 0.04 & 0.01 & 0.49 & 0.24 & 0.07 & SEM & 0.10 & 0.10 & 0.55 & 0.29 & 0.12 \\
\hline \multicolumn{12}{|c|}{$1.8 \mathrm{mg} / \mathrm{kg} d$-AMP } \\
\hline Rat & Min & Range & $\mathrm{Mu}$ & Sigma & $\mathrm{R}^{2}$ & Rat & Min & Range & $\mathrm{Mu}$ & Sigma & $\mathrm{R}^{2}$ \\
\hline $\mathrm{F} 1$ & 0.06 & 0.08 & 21.47 & 12.28 & $0.06^{*}$ & $\mathrm{~L} 2$ & 0.02 & 0.52 & 7.74 & 2.77 & 0.95 \\
\hline F4 & 0.19 & 0.22 & 10.25 & 9.21 & $0.14^{*}$ & L3 & 0.07 & 0.26 & 10.66 & 5.72 & 0.57 \\
\hline & & & & & & L5 & 0.06 & 0.93 & 4.47 & 1.57 & 0.96 \\
\hline & & & & & & L6 & 0.00 & 1.00 & 3.06 & 0.12 & 0.99 \\
\hline Mean & 0.12 & 0.15 & 15.86 & 10.75 & 0.10 & Mean & 0.04 & 0.68 & 6.48 & 2.55 & 0.87 \\
\hline SEM & 0.06 & 0.07 & 5.61 & 1.53 & 0.04 & SEM & 0.02 & 0.18 & 1.70 & 1.19 & 0.10 \\
\hline
\end{tabular}


Table 10. Bisection point (BP), difference limen $(D L)$, Weber fraction $(W F)$, and coefficient of determination $\left(R^{2}\right)$ for the 15-s-vs.-60-s duration series of the drug administration phase.

\begin{tabular}{|c|c|c|c|c|c|c|c|c|c|}
\hline \multicolumn{5}{|c|}{ Fischer 344} & \multicolumn{5}{|c|}{ Lewis } \\
\hline \multicolumn{10}{|c|}{ Saline } \\
\hline Rat & BP & DL & WF & $\mathrm{R}^{2}$ & Rat & $\mathrm{BP}$ & DL & WF & $\mathrm{R}^{2}$ \\
\hline F1 & 31.30 & 6.94 & 0.22 & 0.98 & L1 & 35.05 & 6.77 & 0.19 & 0.80 \\
\hline F2 & 31.15 & 11.07 & 0.36 & 0.59 & L2 & 32.92 & 10.75 & 0.33 & 0.88 \\
\hline F3 & 35.25 & 8.08 & 0.23 & 0.98 & L3 & 28.95 & 6.33 & 0.22 & 0.94 \\
\hline F4 & 44.08 & 13.54 & 0.31 & 0.80 & L4 & 33.41 & 8.63 & 0.26 & 0.85 \\
\hline F5 & 33.41 & 11.51 & 0.34 & 0.85 & L5 & 33.62 & 23.14 & 0.69 & 0.98 \\
\hline F6 & 35.05 & 13.54 & 0.39 & 0.80 & L6 & 81.72 & 47.24 & 0.58 & 0.15 \\
\hline Mean & 35.04 & 10.78 & 0.31 & 0.84 & Mean & 40.94 & 17.15 & 0.38 & 0.77 \\
\hline SEM & 1.94 & 1.12 & 0.03 & 0.06 & SEM & 8.20 & 6.53 & 0.08 & 0.13 \\
\hline \multicolumn{10}{|c|}{$0.1 \mathrm{mg} / \mathrm{kg} d$-AMP } \\
\hline Rat & BP & DL & WF & $\mathrm{R}^{2}$ & Rat & BP & DL & WF & $\mathrm{R}^{2}$ \\
\hline F1 & 28.10 & 10.96 & 0.39 & 0.69 & $\mathrm{~L} 1$ & 27.37 & 4.75 & 0.17 & 0.94 \\
\hline $\mathrm{F} 2$ & 28.78 & 5.27 & 0.18 & 1.00 & L2 & 26.81 & 11.18 & 0.42 & 0.51 \\
\hline F3 & 40.28 & 19.49 & 0.48 & 0.69 & L3 & 31.33 & 7.21 & 0.23 & 0.82 \\
\hline F4 & 36.84 & 18.93 & 0.51 & 0.31 & L4 & 29.34 & 10.75 & 0.37 & 0.88 \\
\hline F5 & 26.02 & 40.63 & 1.56 & 0.80 & L5 & 24.78 & 10.35 & 0.42 & 0.95 \\
\hline F6 & 32.29 & 7.03 & 0.22 & 1.00 & L6 & 31.60 & 4.79 & 0.15 & 0.86 \\
\hline Mean & 32.05 & 17.05 & 0.56 & 0.75 & Mean & 28.54 & 8.17 & 0.29 & 0.83 \\
\hline SEM & 2.26 & 5.30 & 0.21 & 0.10 & SEM & 1.10 & 1.22 & 0.05 & 0.07 \\
\hline \multicolumn{10}{|c|}{$0.3 \mathrm{mg} / \mathrm{kg} d$-AMP } \\
\hline Rat & BP & DL & WF & $\mathrm{R}^{2}$ & Rat & BP & DL & WF & $\mathrm{R}^{2}$ \\
\hline F1 & 36.18 & 10.16 & 0.28 & 0.80 & L1 & 6.17 & 43.85 & 7.11 & 0.69 \\
\hline $\mathrm{F} 2$ & 37.93 & 22.20 & 0.59 & 0.09 & L2 & 13.13 & 14.24 & 1.08 & 0.94 \\
\hline F3 & 53.11 & 20.32 & 0.38 & 0.80 & & & & & \\
\hline F4 & 44.59 & 10.55 & 0.24 & 1.00 & L4 & 34.89 & 19.60 & 0.56 & 0.49 \\
\hline F5 & 81.72 & 106.30 & 1.30 & 0.15 & L5 & 19.54 & 11.00 & 0.56 & 0.93 \\
\hline F6 & 34.49 & 8.91 & 0.26 & 0.54 & L6 & 35.41 & 73.09 & 2.06 & 0.69 \\
\hline Mean & 48.00 & 29.74 & 0.51 & 0.56 & Mean & 21.83 & 32.36 & 2.05 & 0.75 \\
\hline SEM & 7.30 & 15.48 & 0.17 & 0.15 & SEM & 5.84 & 11.70 & 1.33 & 0.08 \\
\hline \multicolumn{10}{|c|}{$1.0 \mathrm{mg} / \mathrm{kg} d$-AMP } \\
\hline Rat & BP & DL & WF & $\mathrm{R}^{2}$ & Rat & BP & DL & WF & $\mathrm{R}^{2}$ \\
\hline F1 & & & & & L1 & 14.66 & 63.50 & 4.33 & 0.20 \\
\hline $\mathrm{F} 2$ & 25.46 & 38.05 & 1.49 & 0.36 & L2 & 35.41 & 19.49 & 0.55 & 0.69 \\
\hline F3 & -8.45 & 21.93 & 2.60 & 0.69 & L3 & -14.62 & 54.18 & 3.71 & 0.80 \\
\hline F4 & 53.11 & 20.32 & 0.38 & 0.80 & L4 & -1.14 & 21.93 & 19.26 & 0.69 \\
\hline F5 & 66.02 & 27.77 & 0.42 & 0.98 & L5 & 41.00 & 52.35 & 1.28 & 0.06 \\
\hline F6 & 46.41 & 23.81 & 0.51 & 0.20 & L6 & 19.73 & 13.88 & 0.70 & 0.98 \\
\hline Mean & 36.51 & 26.38 & 1.08 & 0.61 & Mean & 15.84 & 37.56 & 4.97 & 0.57 \\
\hline SEM & 13.01 & 3.17 & 0.43 & 0.14 & SEM & 8.66 & 8.75 & 2.93 & 0.15 \\
\hline \multicolumn{10}{|c|}{$1.8 \mathrm{mg} / \mathrm{kg} d$-AMP } \\
\hline Rat & $\mathrm{BP}$ & $\mathrm{DL}$ & WF & $\mathrm{R}^{2}$ & Rat & BP & DL & WF & $\mathrm{R}^{2}$ \\
\hline F1 & 107.29 & 40.63 & 0.38 & 0.80 & L1 & -48.84 & 47.63 & 0.98 & 0.20 \\
\hline $\mathrm{F} 2$ & 19.73 & 9.26 & 0.47 & 0.98 & L2 & 42.88 & 13.88 & 0.32 & 0.98 \\
\hline & & & & & L3 & 94.45 & 95.87 & 1.02 & 0.03 \\
\hline F4 & 7.37 & 52.11 & 7.07 & 0.07 & L4 & -14.62 & 40.63 & 2.78 & 0.80 \\
\hline F5 & 38.99 & 7.36 & 0.19 & 0.99 & L5 & 36.92 & 76.70 & 2.08 & 0.03 \\
\hline Mean & 43.35 & 27.34 & 2.03 & 0.71 & Mean & 22.16 & 54.94 & 1.43 & 0.41 \\
\hline SEM & 22.28 & 11.24 & 1.68 & 0.22 & SEM & 24.77 & 14.30 & 0.44 & 0.20 \\
\hline
\end{tabular}


Table 11. Minimum (Min), range, bisection point (Mu), standard deviation (Sigma), and coefficient of determination $\left(R^{2}\right)$ for the 15-s-vs. $-60-s$ duration series of the drug administration phase.

\begin{tabular}{|c|c|c|c|c|c|c|c|c|c|c|c|}
\hline \multicolumn{6}{|c|}{ Fischer 344} & \multicolumn{6}{|c|}{ Lewis } \\
\hline \multicolumn{12}{|c|}{ Saline } \\
\hline Rat & Min & Range & $\mathrm{Mu}$ & Sigma & $\mathrm{R}^{2}$ & Rat & Min & Range & $\mathrm{Mu}$ & Sigma & $\mathrm{R}^{2}$ \\
\hline F1 & 0.06 & 0.94 & 31.55 & 10.66 & 0.99 & L1 & 0.01 & 0.99 & 35.34 & 8.05 & 0.97 \\
\hline $\mathrm{F} 2$ & 0.09 & 0.90 & 32.01 & 12.70 & 0.92 & L2 & 0.23 & 0.61 & 34.23 & 25.97 & 0.94 \\
\hline F3 & 0.05 & 0.90 & 37.11 & 13.66 & 0.97 & L3 & 0.06 & 0.94 & 28.77 & 8.94 & 0.96 \\
\hline F4 & 0.01 & 0.96 & 39.08 & 10.97 & 0.98 & L4 & 0.05 & 0.95 & 32.68 & 10.58 & 0.97 \\
\hline F5 & 0.13 & 0.78 & 35.43 & 18.11 & 0.93 & L5 & 0.20 & 0.69 & 33.73 & 22.00 & 0.94 \\
\hline F6 & 0.08 & 0.87 & 35.63 & 14.64 & 0.95 & L6 & 0.02 & 0.93 & 40.41 & 11.97 & 0.94 \\
\hline Mean & 0.07 & 0.89 & 35.14 & 13.46 & 0.96 & Mean & 0.09 & 0.85 & 34.19 & 14.58 & 0.95 \\
\hline SEM & 0.02 & 0.02 & 1.19 & 1.12 & 0.01 & SEM & 0.04 & 0.07 & 1.55 & 3.07 & 0.01 \\
\hline \multicolumn{12}{|c|}{$0.1 \mathrm{mg} / \mathrm{kg} d$-AMP } \\
\hline Rat & Min & Range & $\mathrm{Mu}$ & Sigma & $\mathrm{R}^{2}$ & Rat & Min & Range & $\mathrm{Mu}$ & Sigma & $\mathrm{R}^{2}$ \\
\hline F1 & 0.20 & 0.77 & 29.11 & 16.74 & 0.89 & L1 & 0.01 & 0.99 & 26.79 & 4.99 & 1.00 \\
\hline $\mathrm{F} 2$ & 0.01 & 0.99 & 28.64 & 6.26 & 0.99 & L2 & 0.20 & 0.78 & 27.89 & 15.21 & 0.91 \\
\hline F3 & 0.08 & 0.84 & 37.70 & 15.92 & 0.94 & L3 & 0.08 & 0.92 & 30.49 & 10.82 & 0.95 \\
\hline F4 & 0.05 & 0.94 & 33.74 & 11.53 & 0.91 & $\mathrm{~L} 4$ & 0.32 & 0.51 & 30.09 & 31.76 & 0.90 \\
\hline F5 & 0.12 & 0.84 & 33.19 & 15.30 & 0.83 & L5 & 0.20 & 0.79 & 26.55 & 13.93 & 0.96 \\
\hline F6 & 0.11 & 0.86 & 33.10 & 14.56 & 0.95 & L6 & 0.06 & 0.94 & 32.33 & 10.89 & 0.86 \\
\hline Mean & 0.09 & 0.87 & 32.58 & 13.38 & 0.92 & Mean & 0.14 & 0.82 & 29.02 & 14.60 & 0.93 \\
\hline SEM & 0.03 & 0.03 & 1.36 & 1.60 & 0.02 & SEM & 0.05 & 0.07 & 0.94 & 3.72 & 0.02 \\
\hline \multicolumn{12}{|c|}{$0.3 \mathrm{mg} / \mathrm{kg} d-\mathrm{AMP}$} \\
\hline Rat & Min & Range & $\mathrm{Mu}$ & Sigma & $\mathrm{R}^{2}$ & Rat & Min & Range & $\mathrm{Mu}$ & Sigma & $\mathrm{R}^{2}$ \\
\hline F1 & 0.11 & 0.69 & 41.70 & 21.83 & 0.88 & L1 & 0.31 & 0.67 & 23.70 & 17.89 & 0.90 \\
\hline $\mathrm{F} 2$ & 0.18 & 0.67 & 36.20 & 22.95 & 0.72 & L2 & 0.56 & 0.43 & 21.40 & 11.93 & 0.93 \\
\hline F3 & 0.03 & 0.83 & 43.53 & 15.35 & 0.98 & L3 & 0.24 & 0.74 & 26.70 & 16.71 & 0.86 \\
\hline F4 & 0.02 & 0.83 & 44.79 & 14.51 & 0.99 & $\mathrm{~L} 4$ & 0.53 & 0.07 & -6.53 & 255.21 & $0.08 *$ \\
\hline F5 & 0.21 & 0.62 & 36.09 & 25.79 & 0.91 & L5 & 0.28 & 0.72 & 23.13 & 13.67 & 0.84 \\
\hline F6 & 0.13 & 0.80 & 33.89 & 17.05 & 0.84 & L6 & 0.18 & 0.75 & 31.99 & 18.84 & 0.88 \\
\hline Mean & 0.11 & 0.74 & 39.37 & 19.58 & 0.89 & Mean & 0.35 & 0.56 & 20.07 & 55.71 & 0.75 \\
\hline SEM & 0.03 & 0.04 & 1.85 & 1.87 & 0.04 & SEM & 0.06 & 0.11 & 5.53 & 39.91 & 0.13 \\
\hline \multicolumn{12}{|c|}{$1.0 \mathrm{mg} / \mathrm{kg} d-\mathrm{AMP}$} \\
\hline Rat & Min & Range & $\mathrm{Mu}$ & Sigma & $\mathrm{R}^{2}$ & Rat & Min & Range & $\mathrm{Mu}$ & Sigma & $\mathrm{R}^{2}$ \\
\hline $\mathrm{F} 1$ & 0.01 & 0.17 & 89.47 & 33.20 & 0.70 & & & & & & \\
\hline $\mathrm{F} 2$ & 0.47 & 0.25 & 68.48 & 20.94 & 0.82 & L2 & 0.44 & 0.06 & 309.62 & 62.47 & $0.09 *$ \\
\hline & & & & & & L3 & 0.67 & 0.13 & -32.38 & 107.76 & 0.58 \\
\hline F4 & 0.10 & 0.58 & 48.05 & 25.85 & 0.95 & L4 & 0.74 & 0.18 & -24.73 & 62.01 & $0.40 *$ \\
\hline F5 & 0.17 & 0.15 & 101.42 & 91.72 & $0.32 *$ & L5 & 0.49 & 0.19 & 90.14 & 16.16 & $0.36 *$ \\
\hline F6 & 0.60 & 0.18 & -7.50 & 85.23 & $0.25 *$ & L6 & 0.58 & 0.22 & -0.08 & 71.21 & 0.58 \\
\hline Mean & 0.27 & 0.27 & 59.99 & 51.39 & 0.61 & Mean & 0.59 & 0.16 & 68.52 & 63.92 & 0.40 \\
\hline SEM & 0.11 & 0.08 & 19.18 & 15.30 & 0.14 & SEM & 0.05 & 0.03 & 64.10 & 14.60 & 0.09 \\
\hline \multicolumn{12}{|c|}{$1.8 \mathrm{mg} / \mathrm{kg} d-\mathrm{AMP}$} \\
\hline Rat & Min & Range & $\mathrm{Mu}$ & Sigma & $\mathrm{R}^{2}$ & Rat & Min & Range & $\mathrm{Mu}$ & Sigma & $\mathrm{R}^{2}$ \\
\hline & & & & & & $\mathrm{L} 2$ & 0.18 & 0.26 & 67.93 & 58.44 & 0.62 \\
\hline & & & & & & L3 & 0.30 & 0.07 & 133.30 & 220.94 & $0.14 *$ \\
\hline F5 & 0.12 & 0.09 & 157.12 & 120.95 & $0.05 *$ & $\mathrm{~L} 4$ & 0.68 & 0.21 & -12.96 & 58.80 & 0.51 \\
\hline F6 & 0.54 & 0.46 & 14.43 & 5.62 & $0.34 *$ & L6 & 0.48 & 0.18 & 18.66 & 96.22 & 0.62 \\
\hline Mean & 0.33 & 0.28 & 85.77 & 63.28 & 0.20 & Mean & 0.41 & 0.18 & 51.73 & 108.60 & 0.47 \\
\hline SEM & 0.21 & 0.18 & 71.34 & 57.67 & 0.14 & SEM & 0.11 & 0.04 & 31.88 & 38.48 & 0.12 \\
\hline
\end{tabular}




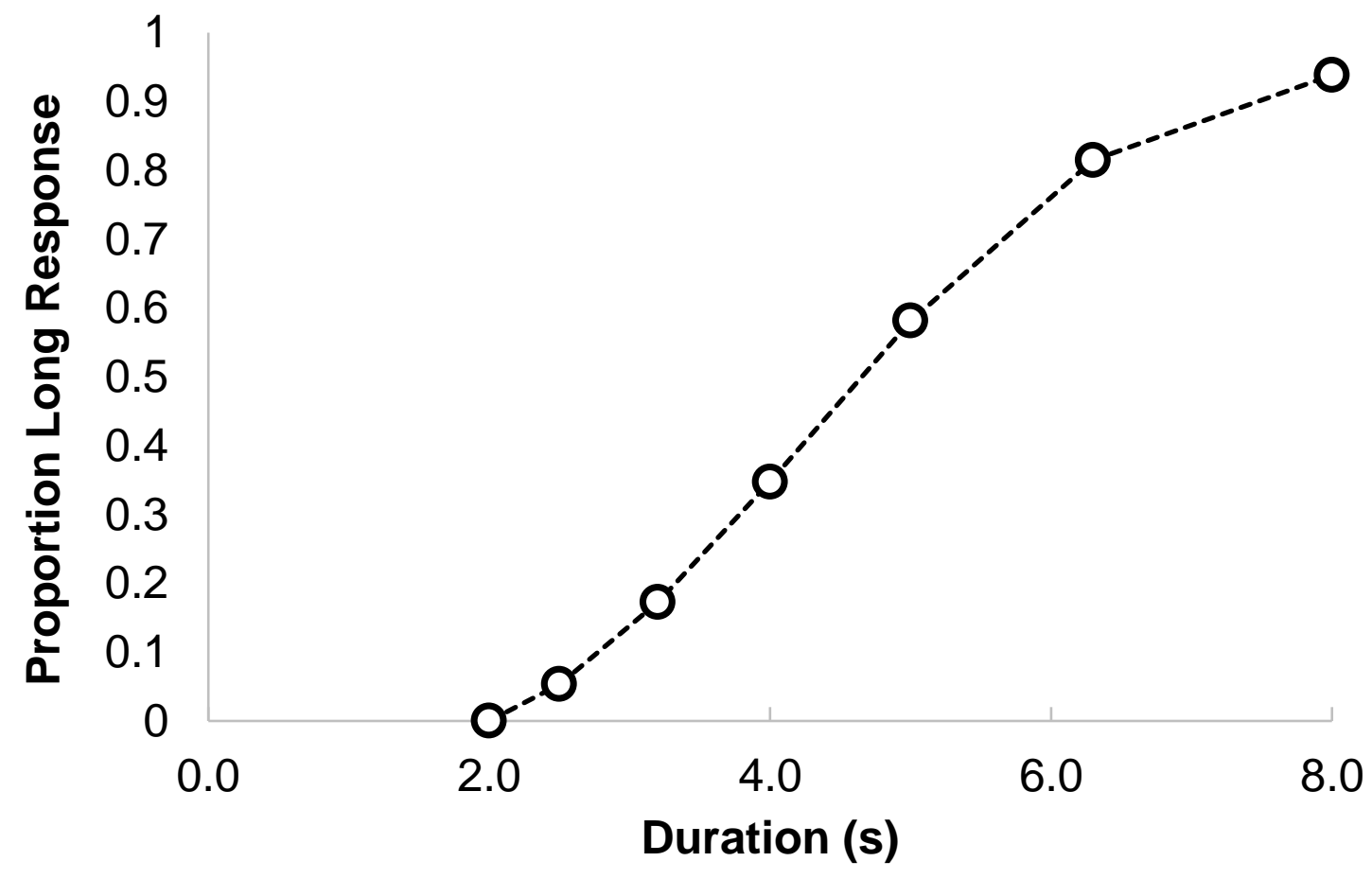

Figure 1. Hypothetical psychophysical function, where the bisection point is the mean of the function and the standard deviation is its slope. 

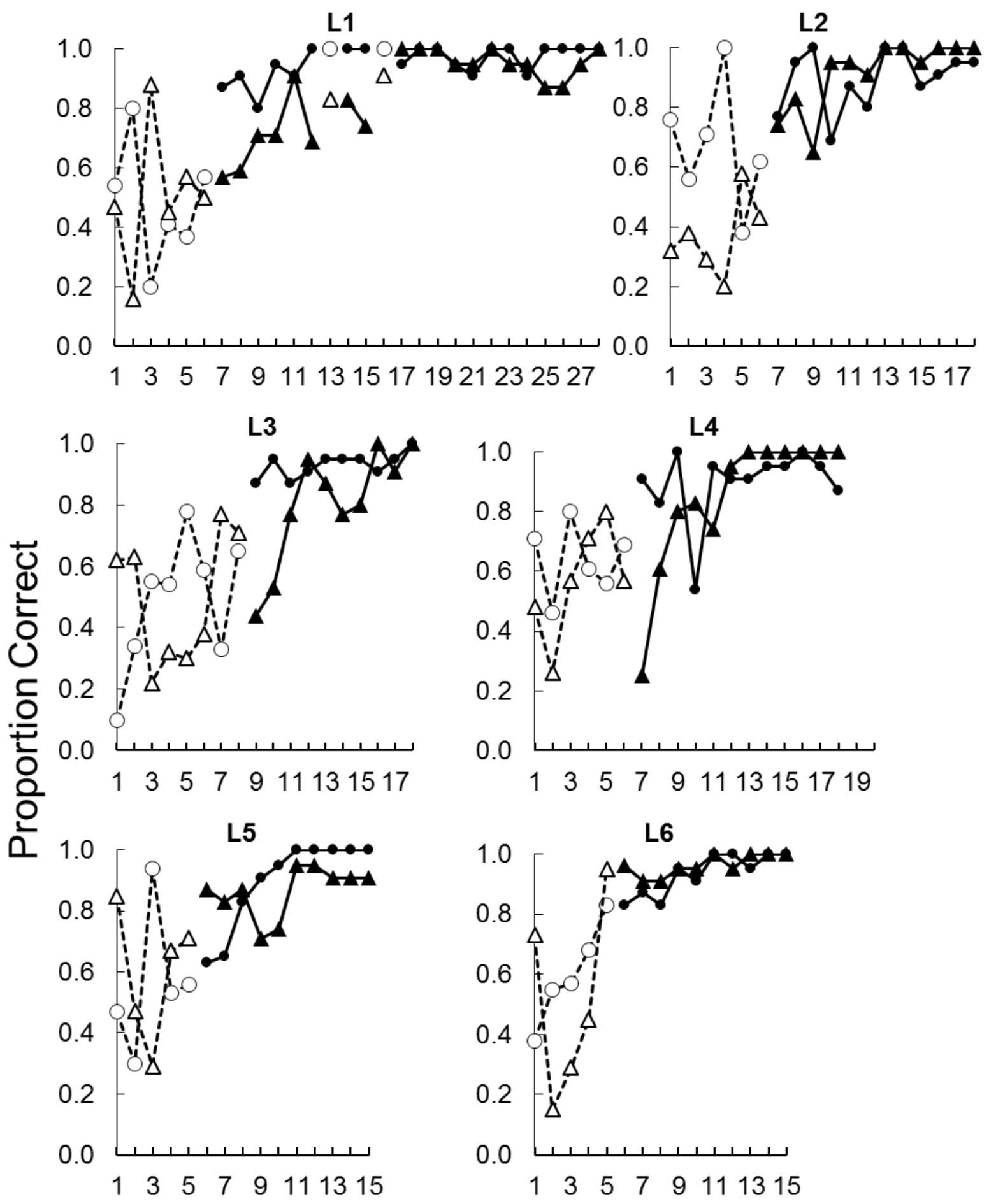

Session

Figure 2. Proportion correct across correction and regular training sessions for the initial temporal discrimination (2-s-vs.8-s duration pair) for individual LEW rats. Open symbols and dashed lines represent correction sessions whereas filled symbols and solid lines represent regular sessions. 

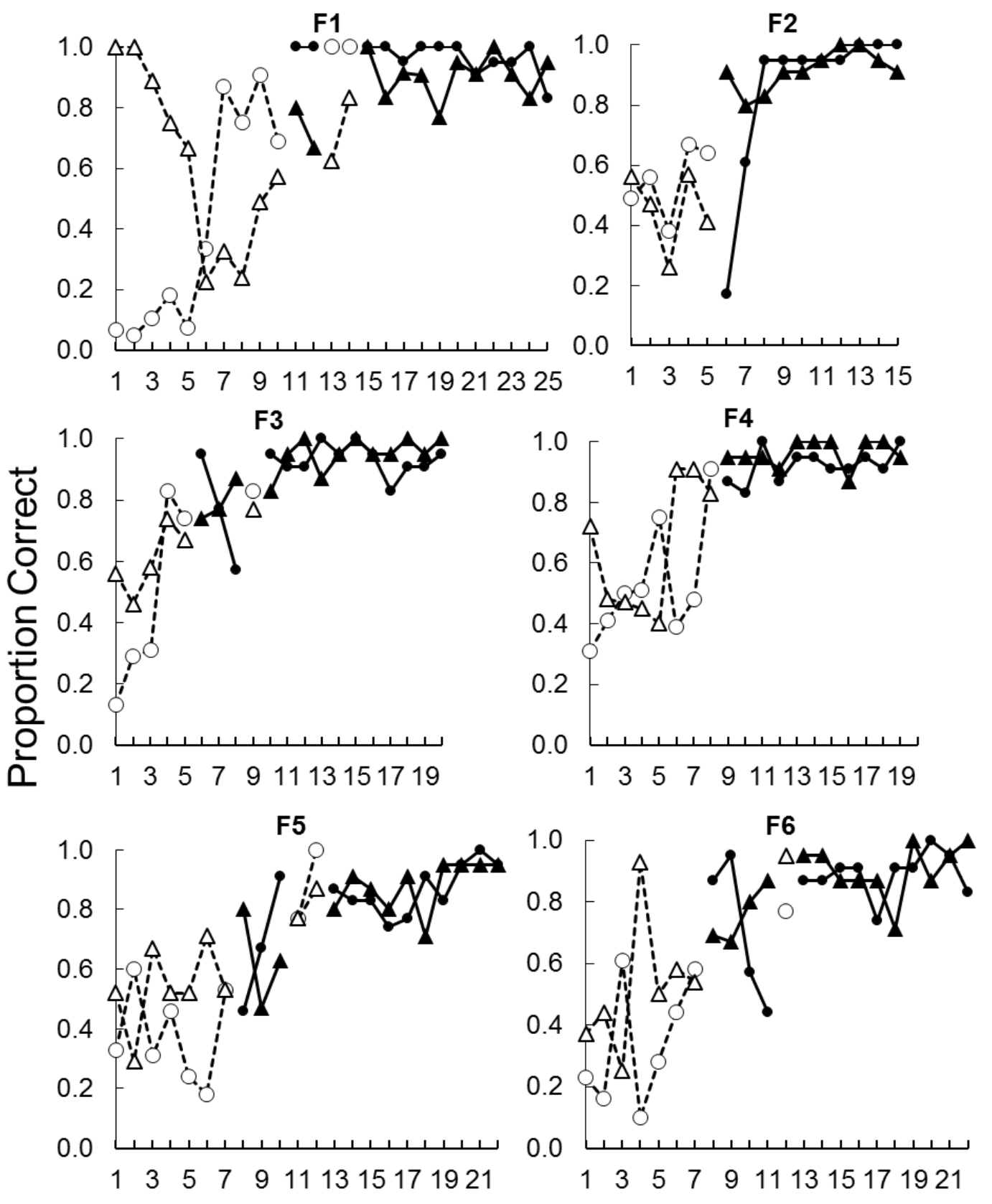

\section{Session}

Figure 3. Proportion correct across correction and regular training sessions for the initial temporal discrimination (2-s-vs.8-s duration pair) for individual F344 rats. Open symbols and dashed lines represent correction sessions whereas filled symbols and solid lines represent regular sessions. 

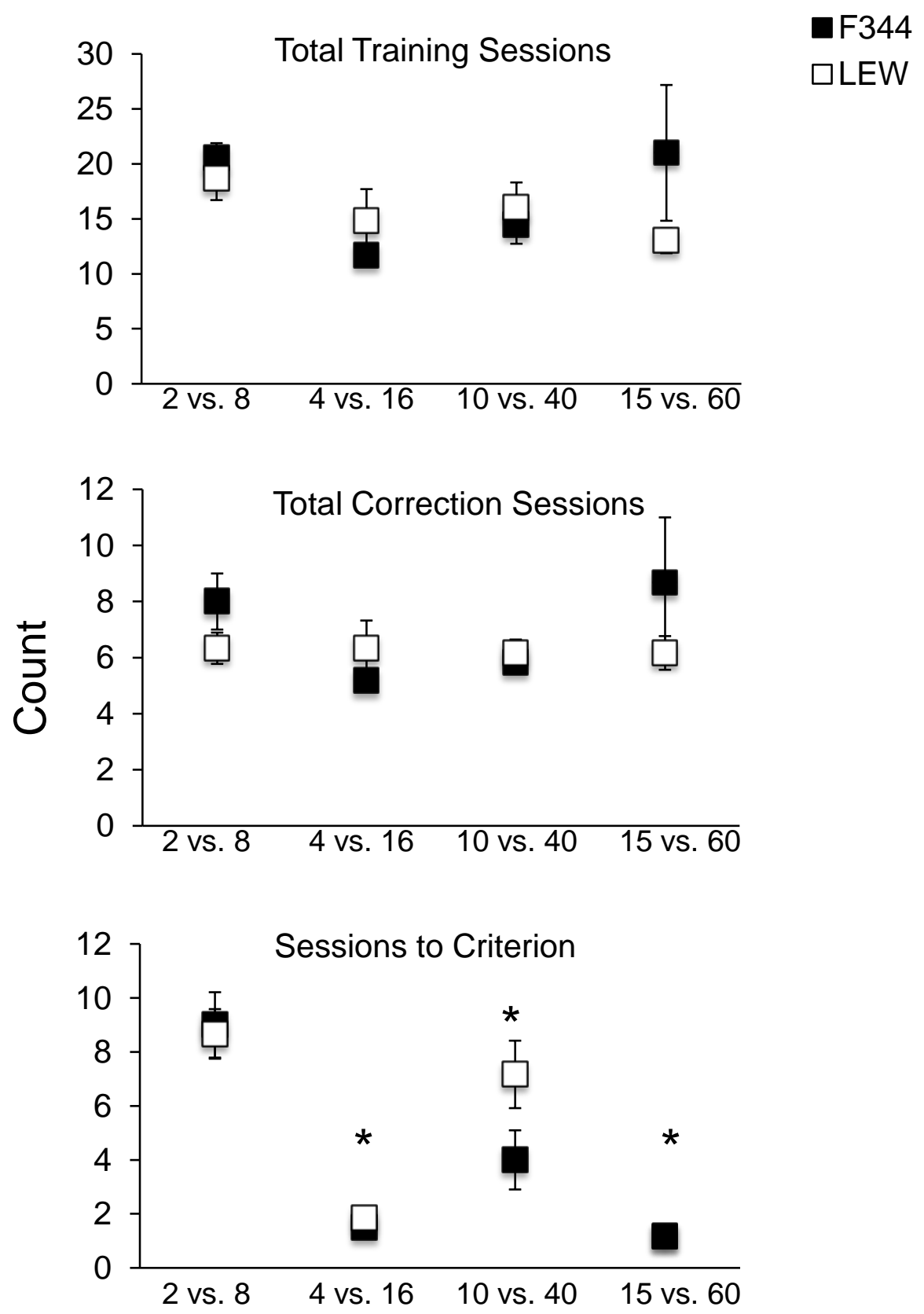

Figure 4. Results from two-duration training for each series (x-axes) during the baseline phase. Panels represent: Total training sessions (top), total correction sessions, number of sessions required to meet the criterion of $75 \%$ correct responses to both short and long durations (bottom). Error bars represent standard error of the mean. Asterisks indicate a significant difference $(\mathrm{p}<$ $.05)$ with the previous series. 


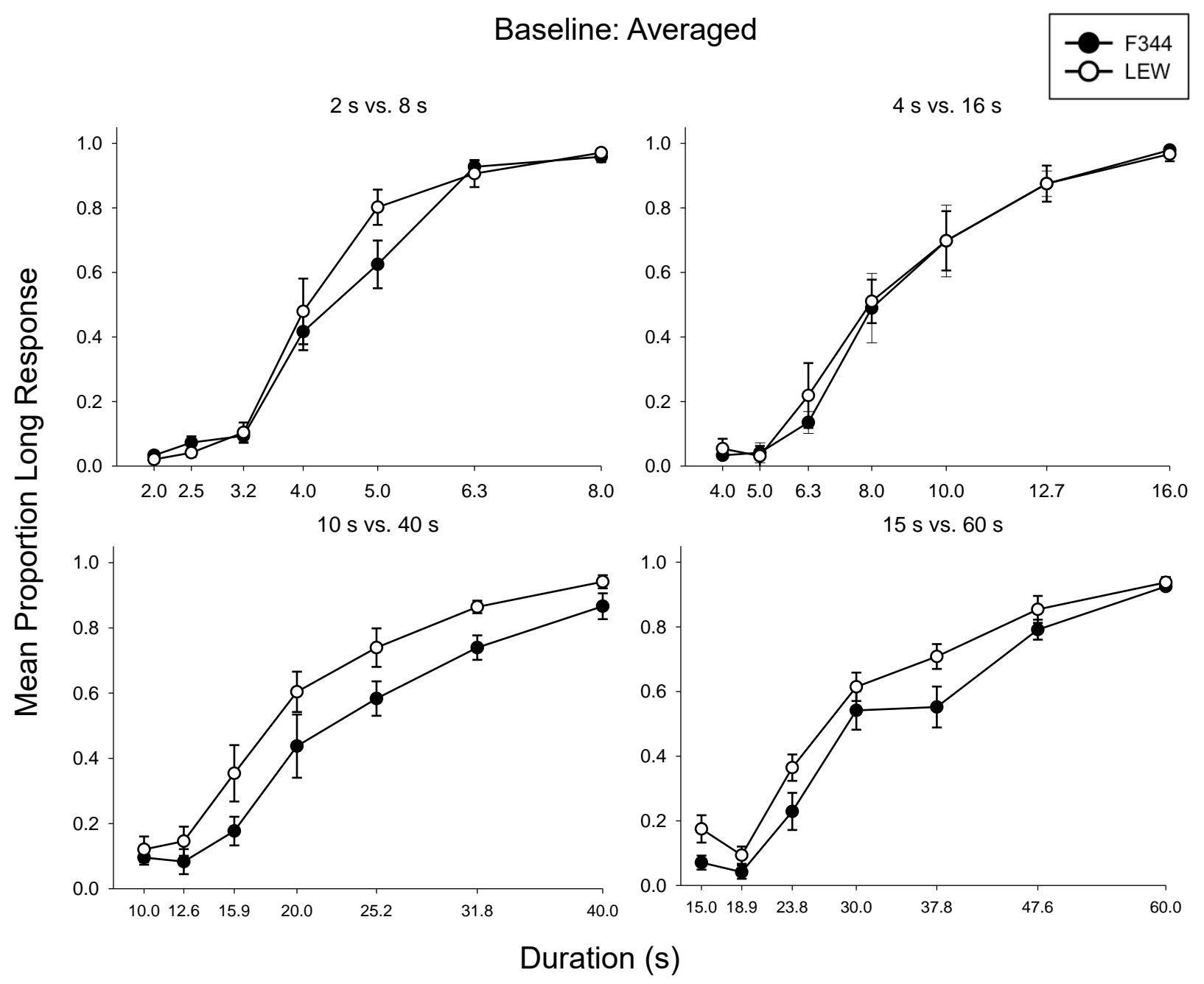

Figure 5. Baseline proportion long response across durations presented in baseline test sessions, averaged by each rat (4 sessions each) and strain (6 rats per strain). Panels represent the four different duration series. Error bars represent standard error of the mean. 


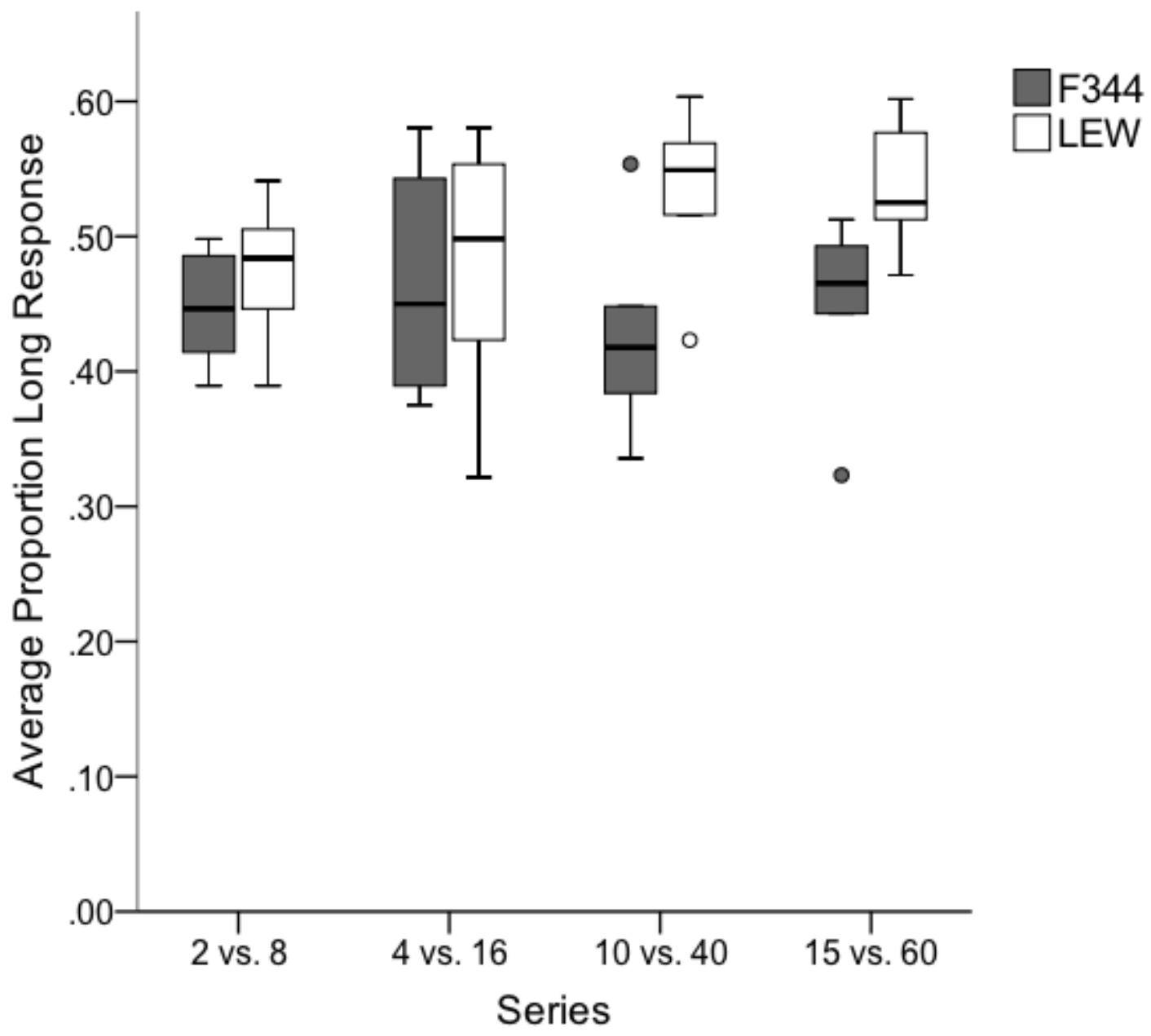

Figure 6. Boxplot of average proportion long response for each series of the baseline phase, under which there was a significant main effect of strain for this variable. Filled boxes represent data from F344 rats and open boxes represent data from LEW rats. Horizontal lines indicate the median, box edges indicate first and third quartiles, and error bars indicate minimum and maximum. Circular data points represent outliers. 

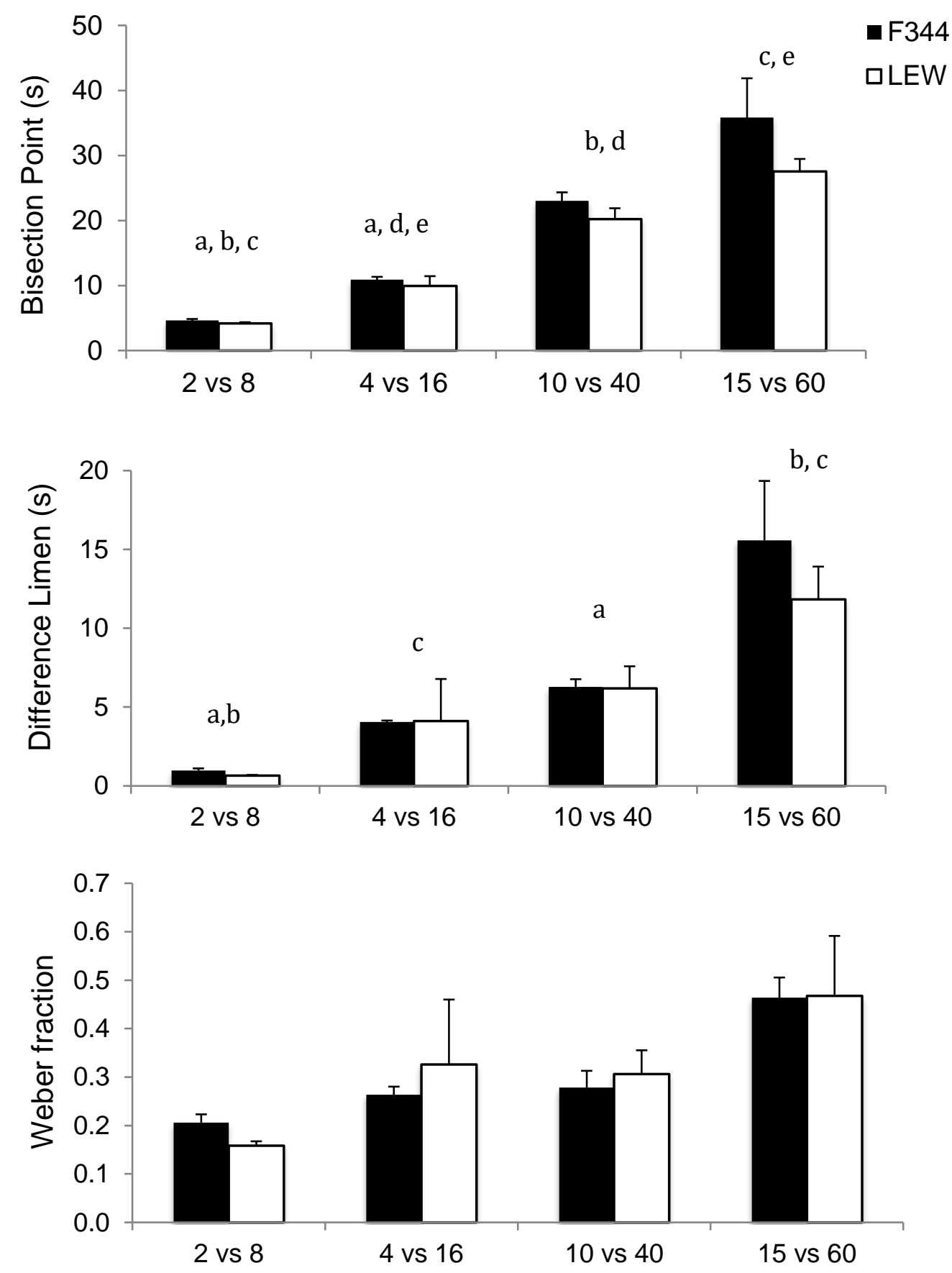

Figure 7. Mean bisection points, difference limen values, and Weber fractions by strain and series for the baseline phase (linear results). Error bars represent standard error of the mean. Pairwise significance for series is indicated by corresponding letters. 

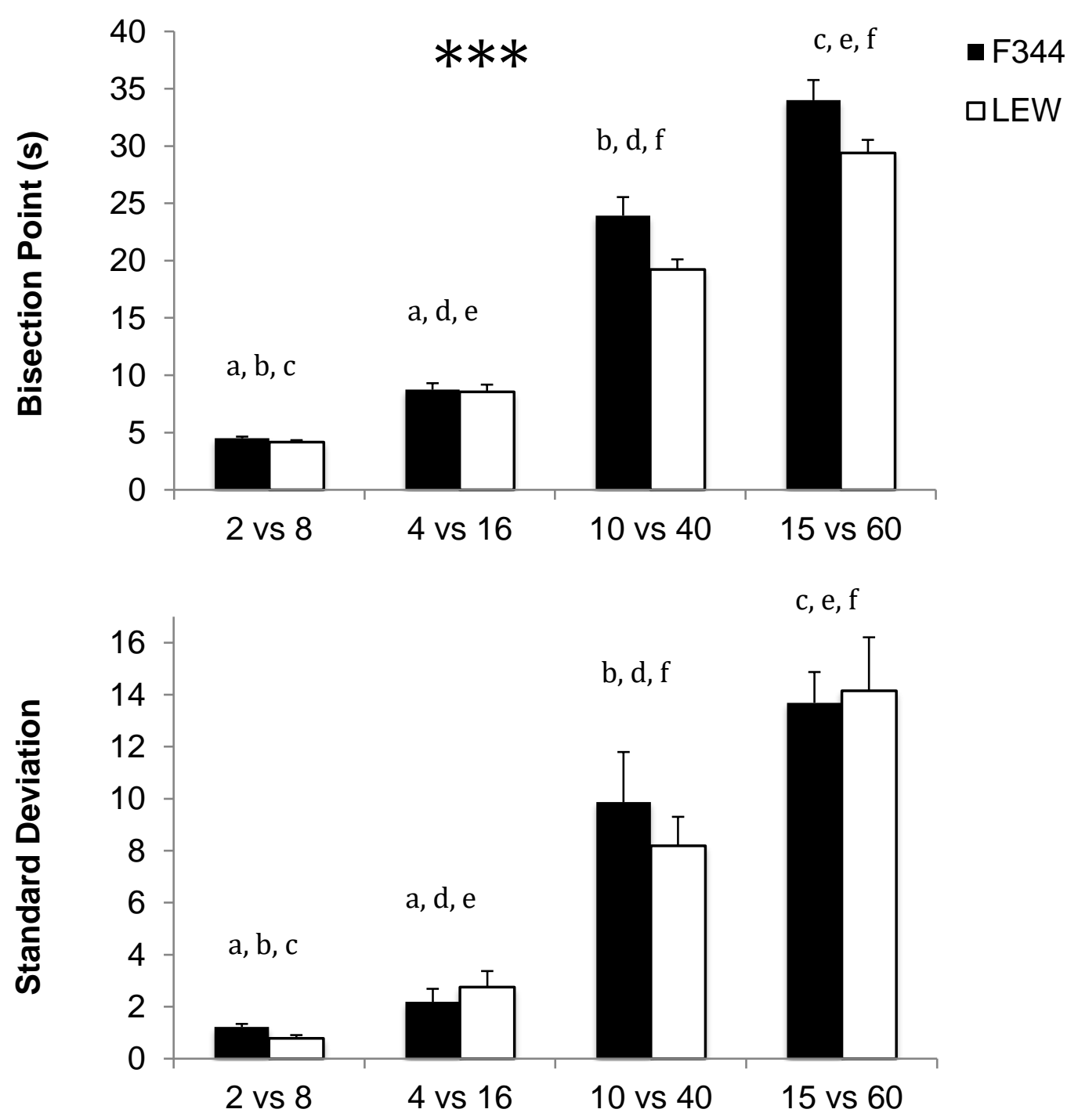

Figure 8. Mean, minimum, range, standard deviation (sigma), and bisection points of Gaussian functions across strains and series for the baseline phase. Error bars represent standard error of the mean. Pairwise significance for series is indicated by corresponding letters. ***Indicates a main effect of strain and strain $\mathrm{x}$ series interaction without significant pairwise comparisons. 
$2 \mathrm{~s}$ vs. 8 s: $d$-AMP Administration: Averaged

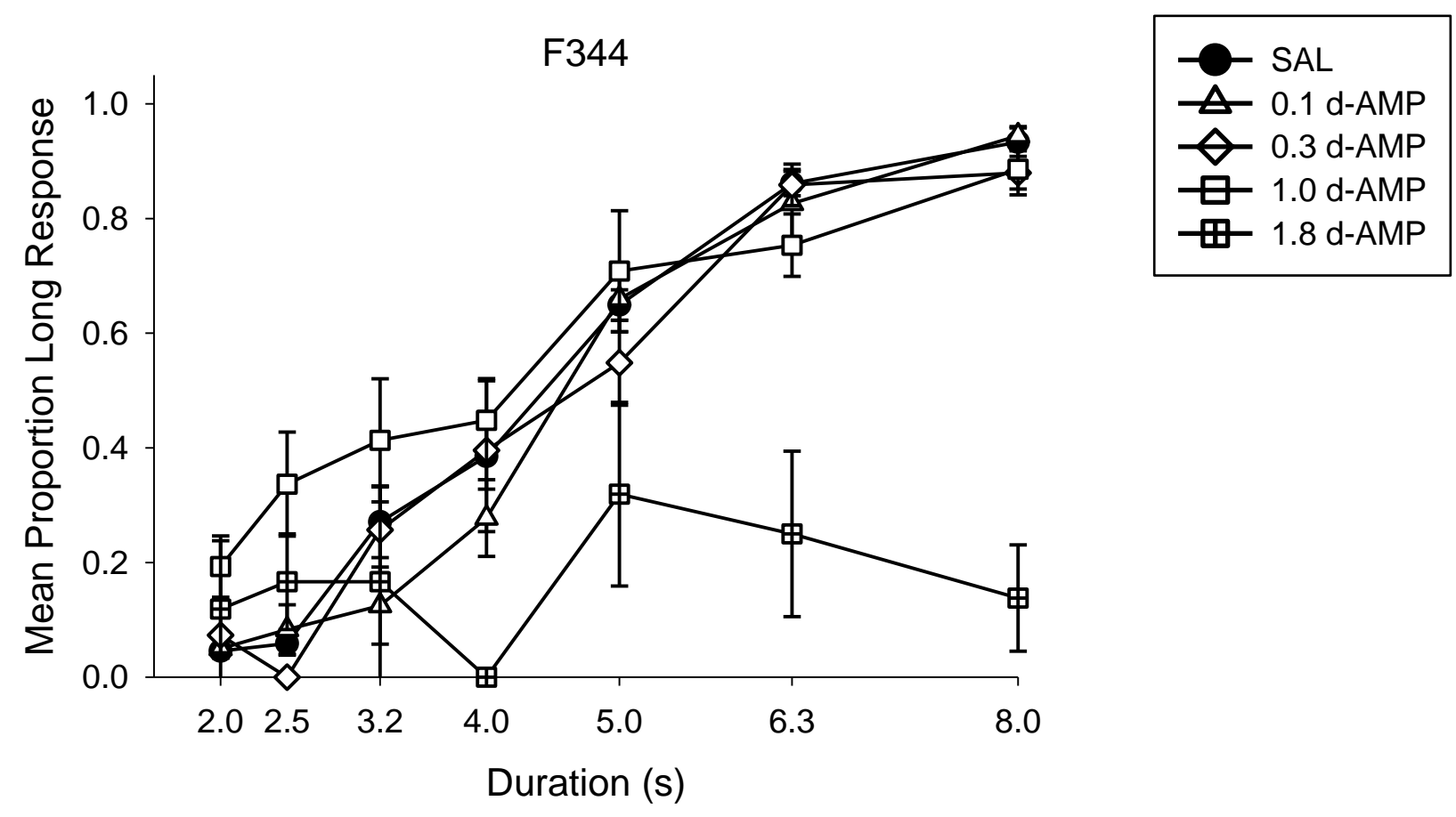

LEW

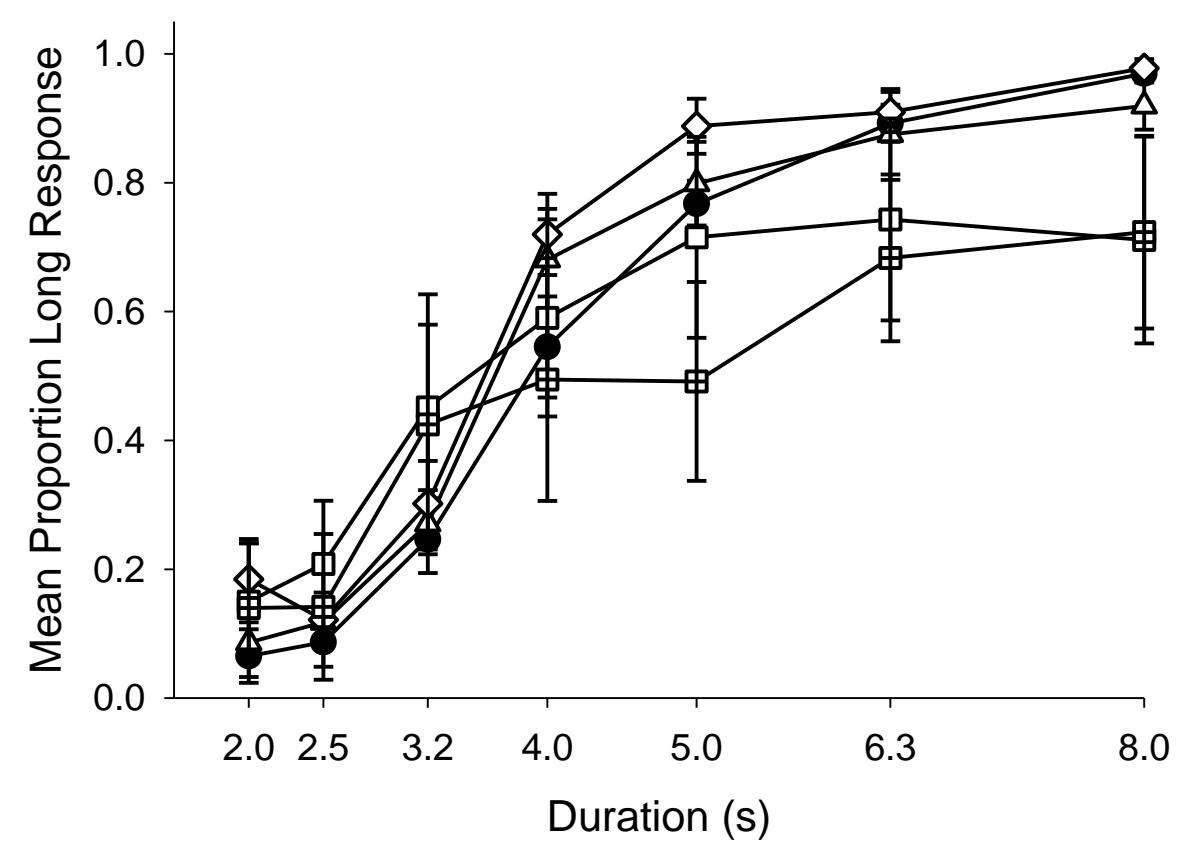

Figure 9. Proportion long response across durations from test sessions averaged by drug dose and strain for the 2-s-vs.8-s duration series. 


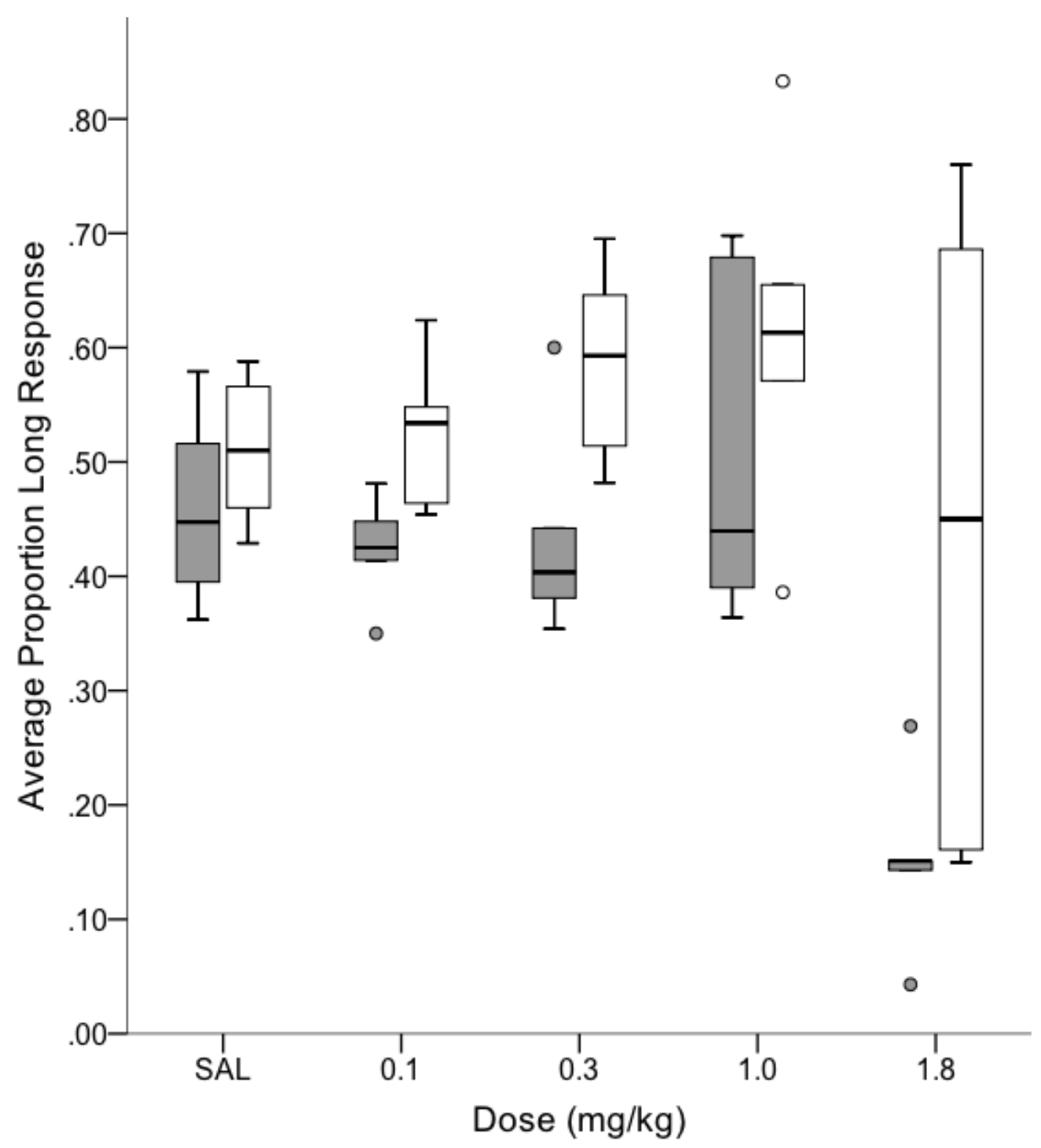

Figure 10. Boxplot of average proportion long response for each dose of the 2-s-vs.-8-s series of the drug administration phase, under which there was a significant main effect of strain for this variable. Data from $1.8 \mathrm{mg} / \mathrm{kg}$ dose shown, but not included in statistical analyses. Filled boxes represent data from F344 rats and open boxes represent data from LEW rats. Horizontal lines indicate the median, box edges indicate first and third quartiles, and error bars indicate minimum and maximum. Circular data points represent outliers. 

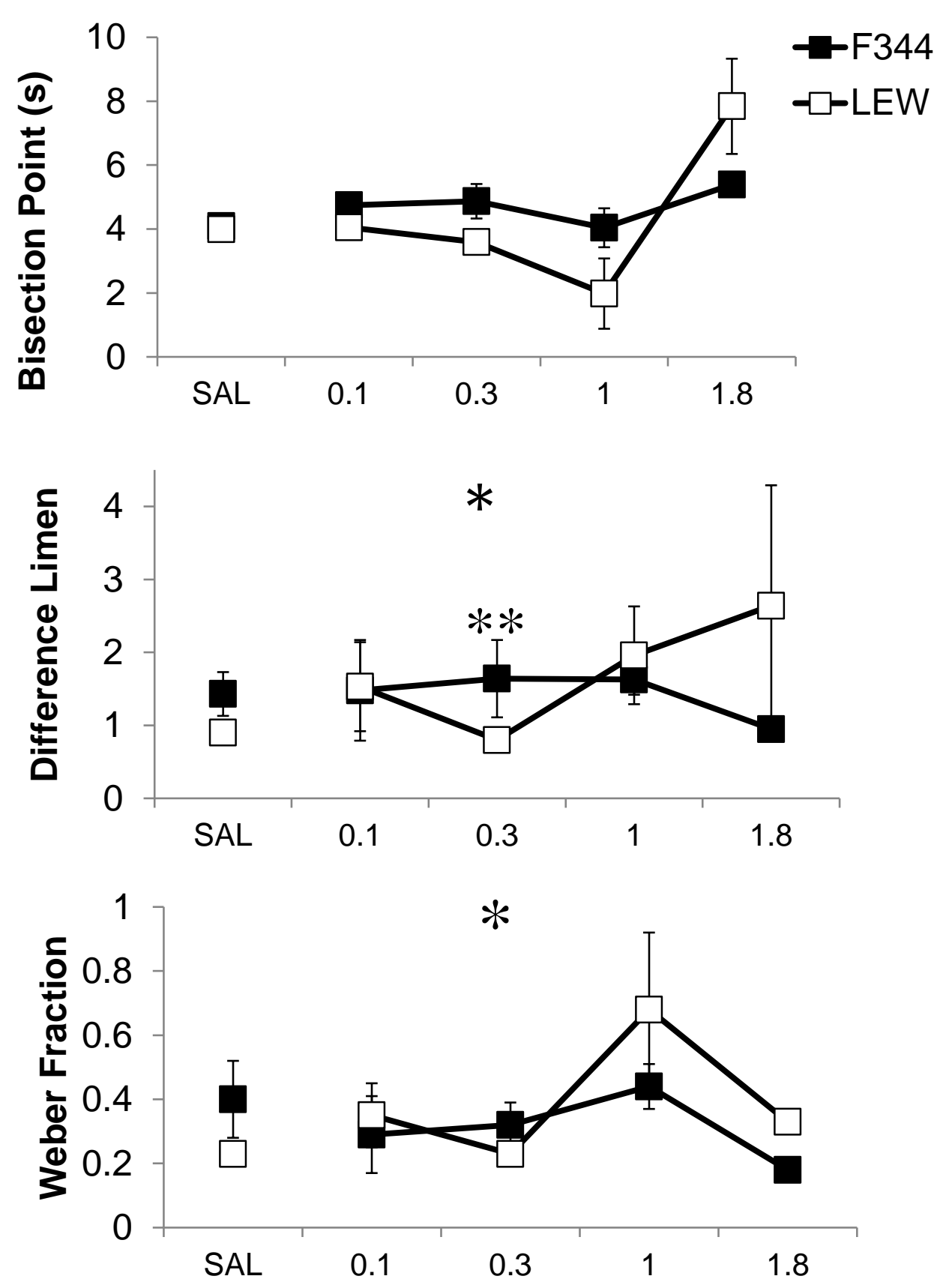

Figure 11. Mean bisection points, difference limen values, and Weber fractions from the linear analyses of the 2-s-vs.-8-s series across drug doses for LEW and F344 rats. The abscissa of each panel represents dose in $\mathrm{mg} / \mathrm{kg}$, with "SAL" indicating saline administration. *Indicates a main effect of dose with no significant pairwise comparisons. **Indicates a main effect of strain at dose indicated. 

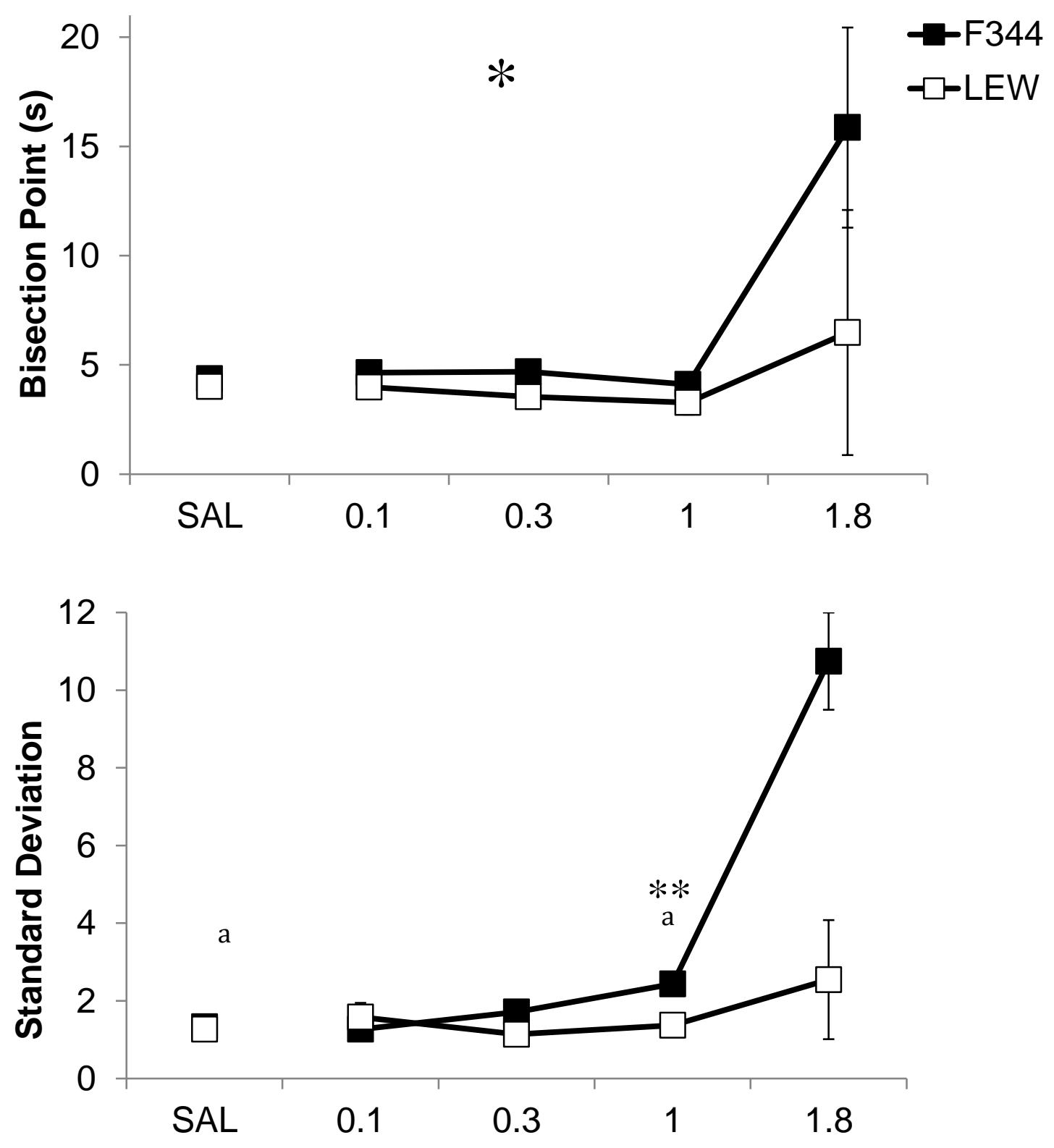

Figure 12. Mean Gaussian parameters across drug doses for LEW and F344 rats from the 2-s-vs.8 -s series. Error bars represent standard error of the mean. Pairwise comparisons indicated with where letters correspond. *Indicates a main effect of strain with no significant pairwise comparisons. **Indicates a dose $\mathrm{x}$ strain interaction with significant pairwise comparison at indicated dose. 
$15 \mathrm{~s}$ vs. 60 s: $d$-AMP Administration: Averaged
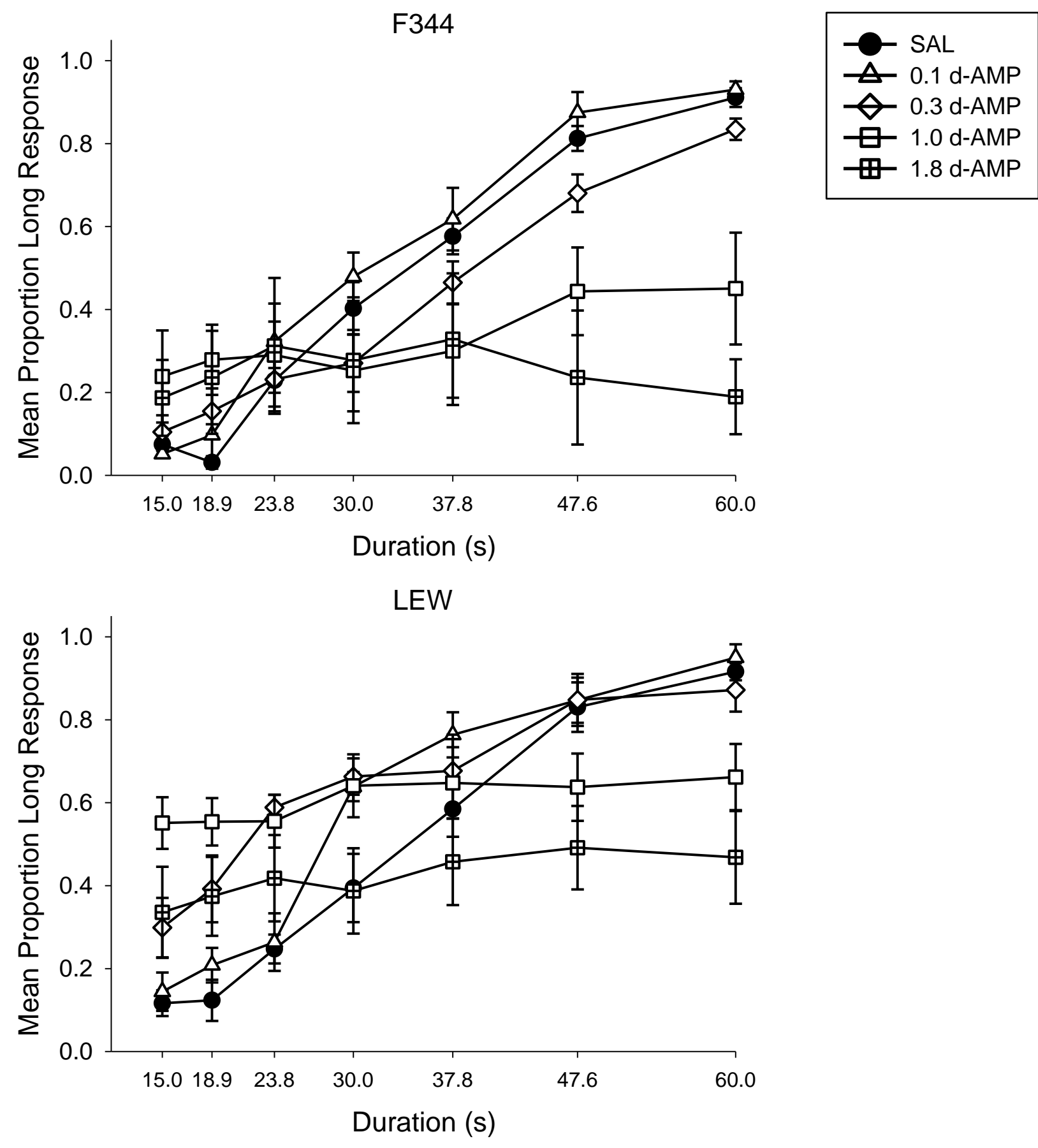

Figure 13. Proportion long response across durations from test sessions averaged by drug dose and strain for the 15 -s-vs.-60-s duration series. 


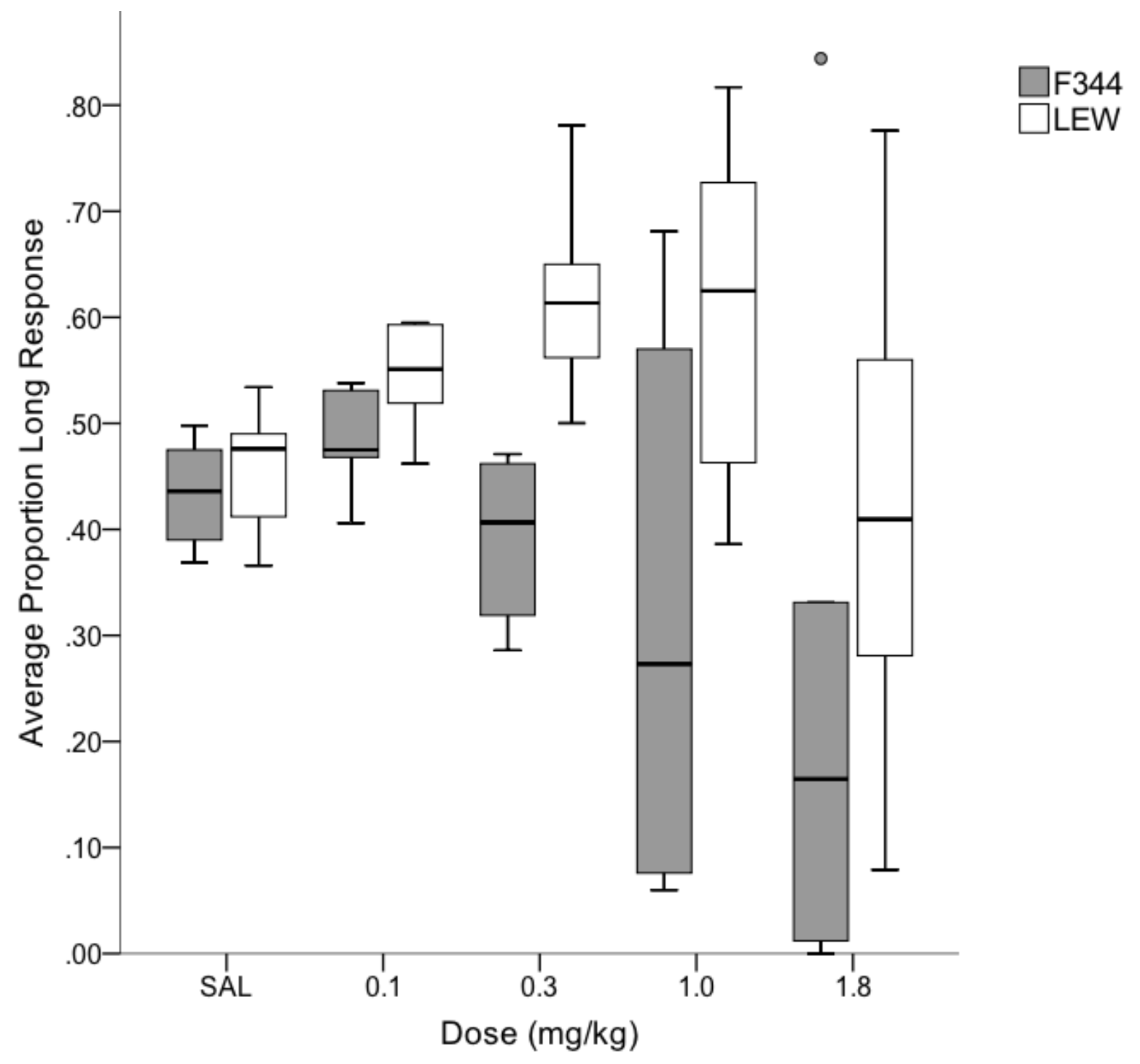

Figure 14. Boxplot of average proportion long response for each dose of the 15-s-vs.-60-s series of the drug administration phase, under which there was a significant main effect of strain for this variable. Data from $1.8 \mathrm{mg} / \mathrm{kg}$ dose shown, but not included in statistical analyses. Filled boxes represent data from F344 rats and open boxes represent data from LEW rats. Horizontal lines indicate the median, box edges indicate first and third quartiles, and error bars indicate minimum and maximum. Circular data points represent outliers. 

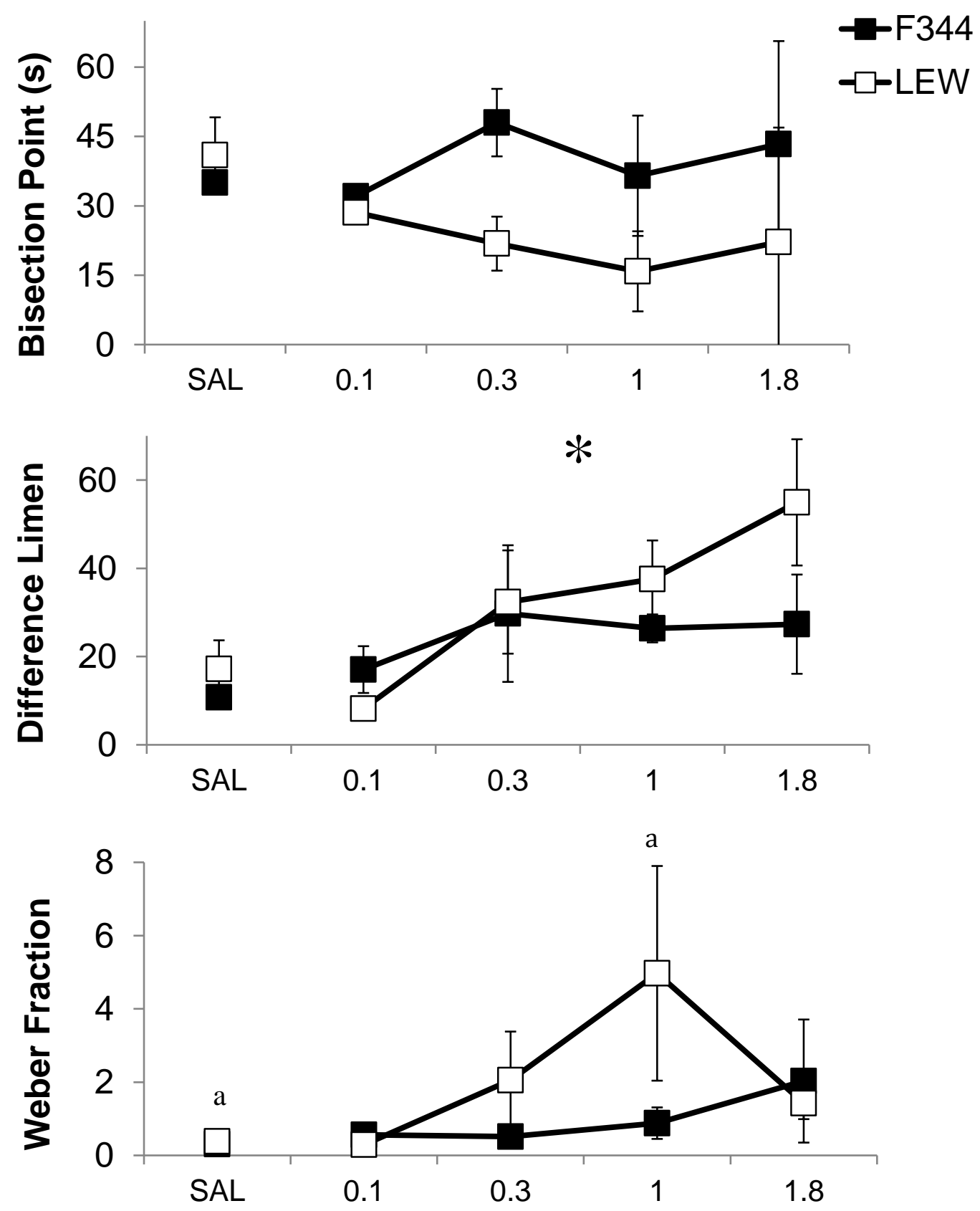

Figure 15. Mean bisection points, difference limen values, and Weber fractions from the linear analyses of the 15-s-vs.-60-s series across drug doses for LEW and F344 rats. The abscissa of each panel represents dose in $\mathrm{mg} / \mathrm{kg}$, with "SAL" indicating saline administration. *Indicates a significant effect of dose with no significant pairwise comparisons. Significant pairwise comparisons are indicated by corresponding letters. 

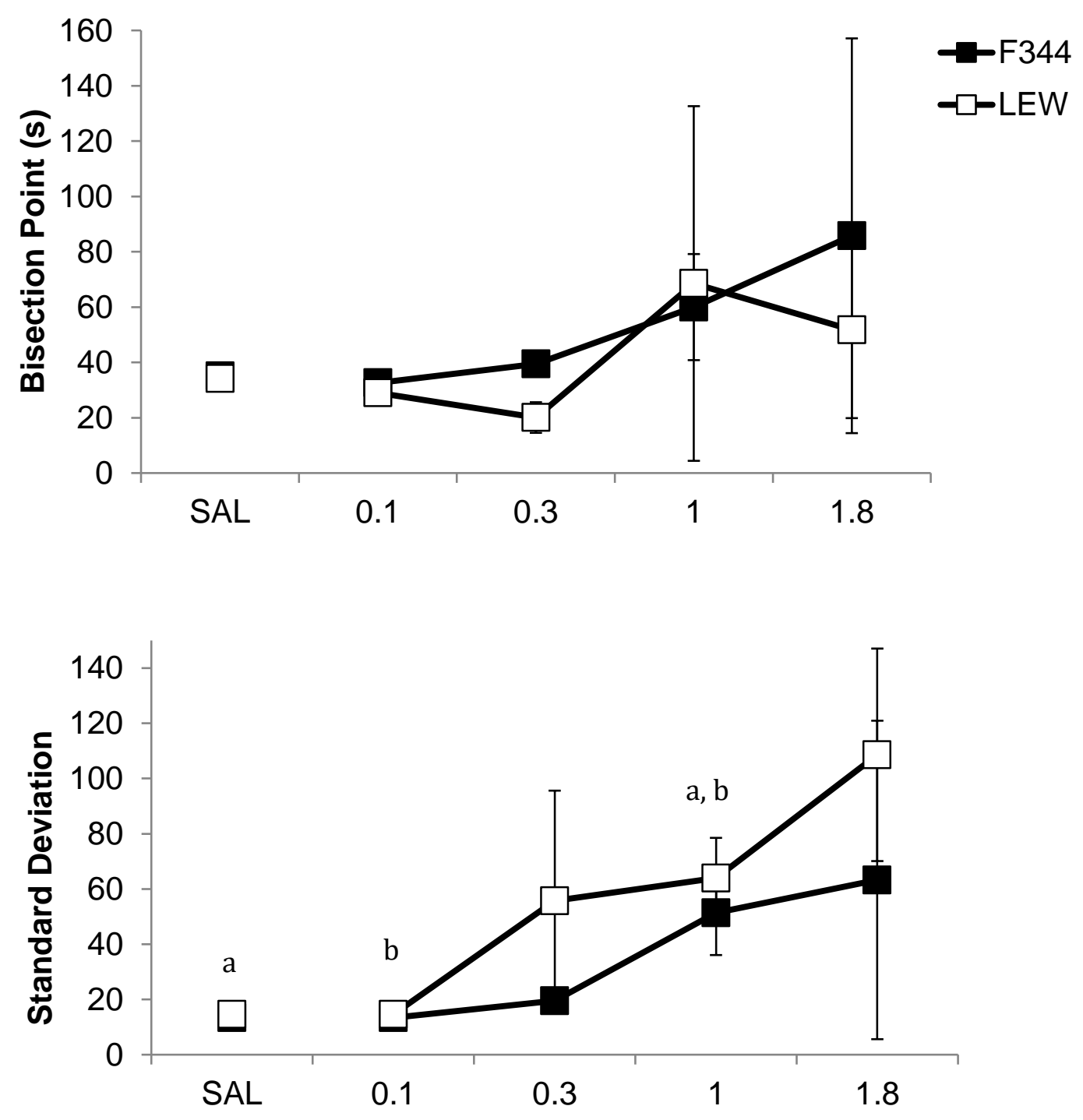

Figure 16. Mean Gaussian parameters across drug doses for LEW and F344 rats from the 15-svs.-60-s series. Error bars represent standard error of the mean. Pairwise comparisons are indicated by corresponding letters. 
Appendix A: Key Terms.

\begin{tabular}{|c|c|c|c|}
\hline Category & Term & Definition & Synonyms or Relevance \\
\hline \multirow{7}{*}{ 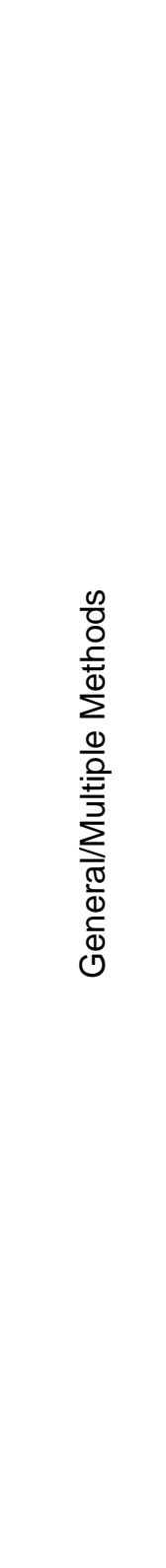 } & temporal control & $\begin{array}{l}\text { Behavior differentiated by durations of } \\
\text { time }\end{array}$ & $\begin{array}{l}\text { Timing, temporal } \\
\text { discrimination }\end{array}$ \\
\hline & $\begin{array}{l}\text { temporal } \\
\text { bisection }\end{array}$ & $\begin{array}{l}\text { Procedure in which temporal control is } \\
\text { established between two intervals, } \\
\text { each associated with their own } \\
\text { operandum. Subsequently, } \\
\text { intermediate values are presented to } \\
\text { determine the duration at which } \\
\text { responding is equivalently distributed } \\
\text { between the two operanda. }\end{array}$ & \\
\hline & $\begin{array}{l}\text { psychophysical } \\
\text { function }\end{array}$ & $\begin{array}{l}\text { The sigmoidal function generated when } \\
\text { proportion of responses on the lever } \\
\text { associated with the long duration are } \\
\text { plotted against the duration of the given } \\
\text { trial }\end{array}$ & Sigmoidal function \\
\hline & $\begin{array}{l}\text { intertrial interval } \\
\text { (ITI) }\end{array}$ & $\begin{array}{l}\text { Time between the offset of one trial } \\
\text { (e.g., reinforcer presentation) and the } \\
\text { onset of the next trial (and the stimulus } \\
\text { duration) }\end{array}$ & $\begin{array}{l}\text { ITls varied in the present } \\
\text { study to ensure all trial } \\
\text { lengths were } 100 \mathrm{~s}\end{array}$ \\
\hline & geometric mean & $\begin{array}{l}\text { The } n \text {th root of the product of } n \\
\text { numbers }\end{array}$ & $\begin{array}{l}\text { Organisms typically show } \\
\text { bisection points at the } \\
\text { geometric mean, inidcating } \\
\text { that temporal control relies } \\
\text { on relative, rather than } \\
\text { absolute, differences } \\
\text { between stimuli. }\end{array}$ \\
\hline & bisection point & $\begin{array}{l}\text { The duration at which responding in a } \\
\text { temporal bisection procedure is } \\
\text { equivalently distributed between both } \\
\text { operanda that were associated with the } \\
\text { two trained intervals. }\end{array}$ & $\begin{array}{l}\text { Mu, mean, point of } \\
\text { subjective equality } \\
\text { As average proportion long } \\
\text { response increases, } \\
\text { bisection points tend to } \\
\text { decrease. }\end{array}$ \\
\hline & & & $\begin{array}{l}\text { Can be determined using the } \\
\text { linear or Gaussian method. }\end{array}$ \\
\hline \multirow{3}{*}{ 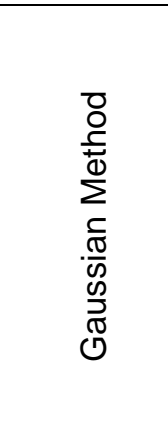 } & $\begin{array}{l}\text { standard } \\
\text { deviation }\end{array}$ & $\begin{array}{l}\text { Indicator of the steepness of the } \\
\text { psychophysical function, or the } \\
\text { precision of temporal control }\end{array}$ & Sigma \\
\hline & range & $\begin{array}{l}\text { The difference between the value of } y \\
\text { at the longest duration, and the value of } \\
x \text { at the shortest duration of the given } \\
\text { series (the minimum). }\end{array}$ & $\begin{array}{l}\text { A measure of accuracy at } \\
\text { the trained durations }\end{array}$ \\
\hline & minimum & $\begin{array}{l}\text { The value of } y \text { at the shortest duration } \\
\text { in the given series }\end{array}$ & $\begin{array}{l}\text { A measure of accuracy at } \\
\text { the shortest duration }\end{array}$ \\
\hline
\end{tabular}




\begin{tabular}{|c|c|c|c|}
\hline $\begin{array}{l}\text { D } \\
\stackrel{0}{+} \\
\sum_{1}^{\infty}\end{array}$ & Weber fraction & $\begin{array}{l}\text { Ratio of the difference limen to the } \\
\text { bisection point. Indicates the ratio of the } \\
\text { "just-noticeable difference" in duration } \\
\text { to the intensity (average length) of the } \\
\text { duration }\end{array}$ & $\begin{array}{l}\text { Standardized measure of } \\
\text { stimulus control, can be } \\
\text { used to quantify sensitivity to } \\
\text { changing stimuli across a } \\
\text { wide array of dimensions. } \\
\text { Within the same dimension, } \\
\text { the Weber fraction stays } \\
\text { constant across stimulus } \\
\text { values. }\end{array}$ \\
\hline$\stackrel{\oplus}{.}$ & difference limen & $\begin{array}{l}\text { Using the linear method, the difference } \\
\text { between the points at which } 25 \text { and } 75 \\
\% \text { of responses to the lever associated } \\
\text { with the long duration occur, divided by } \\
2\end{array}$ & $\begin{array}{l}\text { A measure of precision, } \\
\text { higher values indicate less } \\
\text { precision or differentiation } \\
\text { between responses. } \\
\text { Indicates the "just-noticeable } \\
\text { difference" between two } \\
\text { stimuli. }\end{array}$ \\
\hline 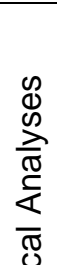 & $\begin{array}{l}\text { Levene's test of } \\
\text { the equality of } \\
\text { error variances }\end{array}$ & $\begin{array}{l}\text { Checks the assumption of homogeneity } \\
\text { of variance between groups }\end{array}$ & $\begin{array}{l}\text { Used when determining if } \\
\text { ANOVA is appropriate. Log- } \\
\text { transformations can make } \\
\text { variance more similar } \\
\text { between groups to overcome } \\
\text { a significant Levene's test. }\end{array}$ \\
\hline 莺 & $\begin{array}{l}\text { Mauchly's test of } \\
\text { sphericity }\end{array}$ & $\begin{array}{l}\text { Tests the variance differences between } \\
\text { all possible pairs of within-subject } \\
\text { conditions (here, drug doses across rat } \\
\text { strains). }\end{array}$ & $\begin{array}{l}\text { Violations of sphericity in } \\
\text { ANOVA can be corrected for } \\
\text { by using adjusted degrees of } \\
\text { freedom. }\end{array}$ \\
\hline
\end{tabular}


Appendix B: Method and Data from Original Analyses.

Table B1. Data from original Gaussian analyses at baseline. Minimum (Min), range, bisection point $(\mathrm{Mu})$, standard deviation (Sigma).

\begin{tabular}{|c|c|c|c|c|c|c|c|c|c|}
\hline \multicolumn{5}{|c|}{ Fischer 344} & \multicolumn{5}{|c|}{ Lewis } \\
\hline \multicolumn{10}{|c|}{$2 \mathrm{~s}$ vs. $8 \mathrm{~s}$} \\
\hline Rat & Min & Range & $\mathrm{Mu}$ & Sigma & Rat & Min & Range & $\mathrm{Mu}$ & Sigma \\
\hline F1 & -0.11 & 1.07 & 4.32 & 1.80 & L1 & 0.04 & 0.94 & 4.27 & 0.80 \\
\hline $\mathrm{F} 2$ & 0.05 & 0.86 & 4.38 & 0.70 & L2 & 0.03 & 0.82 & 3.54 & 0.40 \\
\hline F3 & 0.10 & 0.84 & 5.17 & 0.85 & L3 & 0.03 & 0.95 & 4.93 & 0.20 \\
\hline F4 & -0.01 & 1.00 & 4.09 & 0.80 & L4 & -0.01 & 0.98 & 3.68 & 0.55 \\
\hline F5 & 0.03 & 0.95 & 4.47 & 1.14 & L5 & 0.02 & 0.98 & 4.15 & 0.68 \\
\hline F6 & -0.01 & 0.99 & 4.08 & 1.18 & L6 & 0.04 & 0.77 & 3.83 & 0.36 \\
\hline Mean & 0.01 & 0.95 & 4.42 & 1.08 & Mean & 0.02 & 0.91 & 4.07 & 0.50 \\
\hline SEM & $\mathbf{0 . 0 3}$ & 0.04 & 0.16 & 0.16 & SEM & 0.01 & 0.04 & 0.21 & 0.09 \\
\hline \multicolumn{10}{|c|}{$4 \mathrm{~s}$ vs. $16 \mathrm{~s}$} \\
\hline Rat & Min & Range & $\mathrm{Mu}$ & Sigma & Rat & Min & Range & $\mathrm{Mu}$ & Sigma \\
\hline F1 & -0.05 & 1.87 & 14.94 & 7.45 & L1 & -0.33 & 1.49 & 10.03 & 6.98 \\
\hline $\mathrm{F} 2$ & 0.04 & 0.91 & 6.83 & 0.53 & L2 & 0.03 & 0.78 & 7.97 & 0.46 \\
\hline $\mathrm{F} 3$ & -0.03 & 0.98 & 9.55 & 2.42 & L3 & 0.03 & 0.92 & 8.75 & 1.73 \\
\hline F4 & -0.02 & 0.92 & 7.81 & 2.07 & L4 & 0.00 & 0.92 & 6.55 & 4.13 \\
\hline F5 & 0.02 & 0.96 & 7.56 & 1.21 & L5 & 0.02 & 0.94 & 7.25 & 1.01 \\
\hline F6 & 0.03 & 0.97 & 9.20 & 1.61 & L6 & -0.03 & 1.04 & 7.39 & 1.54 \\
\hline Mean & 0.00 & 1.10 & 9.31 & 2.55 & Mean & -0.05 & 1.02 & 7.99 & 2.64 \\
\hline SEM & 0.02 & 0.15 & 1.20 & 1.02 & SEM & 0.06 & 0.10 & 0.51 & 1.01 \\
\hline \multicolumn{10}{|c|}{$10 \mathrm{~s}$ vs. $40 \mathrm{~s}$} \\
\hline Rat & Min & Range & $\mathrm{Mu}$ & Sigma & Rat & Min & Range & $\mathrm{Mu}$ & Sigma \\
\hline F1 & 0.04 & 0.90 & 28.02 & 9.45 & L1 & 0.00 & 0.89 & 21.63 & 5.86 \\
\hline $\mathrm{F} 2$ & 0.10 & 0.65 & 19.98 & 0.58 & L2 & 0.25 & 0.59 & 17.28 & 1.73 \\
\hline F3 & 0.02 & 0.84 & 15.96 & 0.31 & L3 & 0.13 & 0.80 & 20.16 & 3.96 \\
\hline F4 & 0.05 & 0.82 & 22.53 & 3.61 & L4 & 0.16 & 0.74 & 17.95 & 5.11 \\
\hline F5 & 0.02 & 0.96 & 18.94 & 2.96 & L5 & 0.00 & 0.94 & 18.84 & 3.79 \\
\hline F6 & -0.17 & 1.04 & 17.64 & 13.70 & L6 & 0.07 & 0.67 & 13.95 & 1.42 \\
\hline Mean & 0.01 & 0.87 & 20.51 & 5.10 & Mean & 0.10 & 0.77 & 18.30 & 3.64 \\
\hline SEM & 0.04 & 0.05 & 1.75 & 2.18 & SEM & 0.04 & 0.05 & 1.08 & 0.73 \\
\hline \multicolumn{10}{|c|}{15 s vs. $60 \mathrm{~s}$} \\
\hline Rat & Min & Range & $\mathrm{Mu}$ & Sigma & Rat & Min & Range & $\mathrm{Mu}$ & Sigma \\
\hline F1 & 0.24 & 0.52 & 29.84 & 0.58 & $\mathrm{~L} 1$ & 0.16 & 0.64 & 30.09 & 0.59 \\
\hline $\mathrm{F} 2$ & 0.10 & 0.73 & 29.68 & 0.58 & L2 & 0.24 & 0.56 & 23.60 & 0.93 \\
\hline $\mathrm{F} 3$ & 0.02 & 0.69 & 24.02 & 0.31 & L3 & -0.37 & 1.37 & 22.62 & 20.18 \\
\hline F4 & 0.04 & 0.76 & 27.67 & 3.27 & L4 & 0.01 & 0.86 & 26.94 & 6.45 \\
\hline F5 & -0.18 & 1.10 & 27.19 & 16.12 & L5 & 0.06 & 0.88 & 26.59 & 4.67 \\
\hline F6 & 0.13 & 0.69 & 41.73 & 0.58 & L6 & 0.22 & 0.55 & 27.59 & 3.80 \\
\hline Mean & 0.06 & 0.75 & 30.02 & 3.57 & Mean & 0.05 & 0.81 & 26.24 & 6.10 \\
\hline SEM & 0.06 & 0.08 & 2.49 & 2.55 & SEM & 0.09 & 0.13 & 1.12 & 2.96 \\
\hline
\end{tabular}


Table B2. Data from original Gaussian analyses at the 2-s-vs.-8-s series of drug administration. Minimum (Min), range, bisection point (Mu), standard deviation (Sigma) and coefficient of variation $\left(\mathrm{R}^{2}\right)$.

\begin{tabular}{|c|c|c|c|c|c|c|c|c|c|c|c|}
\hline \multicolumn{6}{|c|}{ Fischer 344} & \multicolumn{6}{|c|}{ Lewis } \\
\hline \multicolumn{12}{|c|}{ Saline } \\
\hline Rat & Min & Range & $\mathrm{Mu}$ & Sigma & $\mathrm{R}^{2}$ & Rat & Min & Range & $\mathrm{Mu}$ & Sigma & $\mathrm{R}^{2}$ \\
\hline F1 & 0.10 & 0.75 & 3.22 & 0.15 & 0.94 & L1 & -0.09 & 1.10 & 4.44 & 1.67 & 0.98 \\
\hline $\mathrm{F} 2$ & -0.01 & 0.80 & 3.13 & 0.49 & 0.94 & $\mathrm{~L} 2$ & 0.03 & 0.86 & 4.12 & 0.96 & 0.99 \\
\hline F3 & 0.07 & 0.80 & 4.66 & 0.32 & 0.98 & L3 & -0.04 & 1.01 & 4.07 & 1.18 & 0.95 \\
\hline F4 & 0.07 & 0.77 & 4.82 & 0.41 & 1.00 & L4 & 0.23 & 0.65 & 3.86 & 0.93 & 0.99 \\
\hline F5 & -0.02 & 1.00 & 4.46 & 1.61 & 0.95 & L5 & 0.07 & 0.86 & 3.61 & 0.37 & 0.99 \\
\hline F6 & 0.05 & 0.97 & 4.76 & 1.31 & 1.00 & L6 & -0.24 & 1.21 & 3.26 & 1.37 & 0.99 \\
\hline Mean & 0.04 & 0.85 & 4.17 & 0.71 & 0.97 & Mean & -0.01 & 0.95 & 3.90 & 1.08 & 0.98 \\
\hline SEM & 0.02 & 0.04 & 0.32 & 0.24 & 0.01 & SEM & 0.07 & 0.08 & 0.17 & 0.18 & 0.01 \\
\hline \multicolumn{12}{|c|}{$0.1 \mathrm{mg} / \mathrm{kg} d-\mathrm{AMP}$} \\
\hline Rat & Min & Range & $\mathrm{Mu}$ & Sigma & $\mathrm{R}^{2}$ & Rat & Min & Range & $\mathrm{Mu}$ & Sigma & $\mathrm{R}^{2}$ \\
\hline F1 & 0.13 & 0.69 & 3.99 & 0.15 & 0.81 & L1 & & & & & \\
\hline $\mathrm{F} 2$ & -0.10 & 1.08 & 4.21 & 2.04 & 0.91 & $\mathrm{~L} 2$ & 0.00 & 0.84 & 3.94 & 1.82 & 0.80 \\
\hline F3 & 0.00 & 0.91 & 4.88 & 0.26 & 1.00 & L3 & 0.09 & 0.90 & 4.14 & 0.68 & 1.00 \\
\hline $\mathrm{F} 4$ & 0.12 & 0.73 & 4.46 & 0.47 & 0.94 & L4 & 0.07 & 0.72 & 3.82 & 0.72 & 0.97 \\
\hline F5 & 0.05 & 0.76 & 4.05 & 0.15 & 0.90 & L5 & 0.06 & 0.94 & 3.36 & 0.19 & 1.00 \\
\hline F6 & 0.02 & 0.85 & 4.33 & 0.75 & 0.98 & L6 & 0.00 & 1.01 & 3.88 & 1.52 & 0.96 \\
\hline Mean & 0.04 & 0.84 & 4.32 & 0.64 & 0.92 & Mean & 0.05 & 0.88 & 3.83 & 0.98 & 0.94 \\
\hline SEM & 0.04 & 0.06 & 0.13 & 0.30 & $\mathbf{0 . 0 3}$ & SEM & 0.02 & 0.05 & 0.13 & 0.30 & 0.04 \\
\hline \multicolumn{12}{|c|}{$0.3 \mathrm{mg} / \mathrm{kg} d-\mathrm{AMP}$} \\
\hline Rat & Min & Range & $\mathrm{Mu}$ & Sigma & $\mathrm{R}^{2}$ & Rat & Min & Range & $\mathrm{Mu}$ & Sigma & $\mathrm{R}^{2}$ \\
\hline F1 & -1.36 & 2.14 & 0.64 & 3.40 & 0.84 & L1 & 0.08 & 0.93 & 3.58 & 0.99 & 0.97 \\
\hline $\mathrm{F} 2$ & 0.03 & 0.84 & 4.88 & 0.75 & 0.99 & L2 & -0.01 & 0.95 & 3.94 & 0.69 & 0.99 \\
\hline F3 & 0.00 & 0.91 & 4.28 & 1.33 & 0.99 & L3 & 0.13 & 0.87 & 3.48 & 0.48 & 1.00 \\
\hline $\mathrm{F} 4$ & 0.04 & 0.96 & 3.60 & 1.08 & 0.94 & L4 & 0.37 & 0.57 & 3.59 & 0.33 & 0.97 \\
\hline F5 & 0.11 & 0.55 & 4.00 & 0.16 & 0.74 & L5 & 0.12 & 0.72 & 3.79 & 0.38 & 0.98 \\
\hline F6 & -0.06 & 1.02 & 4.64 & 1.35 & 0.98 & L6 & 0.14 & 0.71 & 3.52 & 0.31 & 0.98 \\
\hline Mean & -0.21 & 1.07 & 3.67 & 1.35 & 0.91 & Mean & 0.14 & 0.79 & 3.65 & 0.53 & 0.98 \\
\hline SEM & 0.23 & 0.22 & 0.63 & 0.45 & 0.04 & SEM & 0.05 & 0.06 & 0.07 & 0.11 & 0.00 \\
\hline \multicolumn{12}{|c|}{$1.0 \mathrm{mg} / \mathrm{kg} d-\mathrm{AMP}$} \\
\hline Rat & Min & Range & $\mathrm{Mu}$ & Sigma & $\mathrm{R}^{2}$ & Rat & Min & Range & $\mathrm{Mu}$ & Sigma & $\mathrm{R}^{2}$ \\
\hline F1 & 0.22 & 0.49 & 4.86 & 0.15 & 0.87 & L1 & & & & & \\
\hline $\mathrm{F} 2$ & 0.00 & 1.75 & 8.18 & 4.16 & 0.99 & L2 & 0.00 & 0.78 & 2.56 & 0.80 & 0.69 \\
\hline $\mathrm{F} 3$ & 0.00 & 1.00 & 4.75 & 2.91 & 0.83 & L3 & 0.00 & 0.98 & 1.71 & 1.66 & 0.81 \\
\hline F4 & 0.25 & 0.68 & 3.16 & 0.84 & 0.93 & L4 & -0.39 & 1.37 & 3.73 & 3.14 & 0.97 \\
\hline F5 & 0.00 & 0.93 & 3.30 & 2.12 & 0.96 & L5 & -0.04 & 1.04 & 3.14 & 0.68 & 1.00 \\
\hline F6 & & & & & & L6 & 0.02 & 0.87 & 3.33 & 0.68 & 0.99 \\
\hline Mean & 0.09 & 0.97 & 4.85 & 2.03 & 0.92 & Mean & -0.08 & 1.01 & 2.89 & 1.39 & 0.89 \\
\hline SEM & 0.05 & 0.20 & 0.83 & 0.65 & $\mathbf{0 . 0 3}$ & SEM & 0.08 & 0.10 & 0.35 & 0.47 & 0.06 \\
\hline \multicolumn{12}{|c|}{$1.8 \mathrm{mg} / \mathrm{kg} d-\mathrm{AMP}$} \\
\hline Rat & Min & Range & $\mathrm{Mu}$ & Sigma & $\mathrm{R}^{2}$ & Rat & Min & Range & $\mathrm{Mu}$ & Sigma & $\mathrm{R}^{2}$ \\
\hline \multirow{5}{*}{$\mathrm{F} 4$} & \multirow{5}{*}{0.06} & \multirow{5}{*}{0.74} & \multirow{5}{*}{8.61} & \multirow{5}{*}{6.91} & \multirow{5}{*}{0.15} & $\mathrm{~L} 2$ & 0.00 & 0.53 & 5.68 & 1.44 & 0.97 \\
\hline & & & & & & L3 & & & & & \\
\hline & & & & & & $\begin{array}{l}\text { L5 } \\
\text { I6 }\end{array}$ & -0.26 & 1.31 & 3.92 & 2.29 & 0.97 \\
\hline & & & & & & Mean & -0.13 & 0.92 & 4.80 & 1.87 & 0.97 \\
\hline & & & & & & SEM & 0.09 & 0.27 & 0.62 & 0.30 & 0.00 \\
\hline
\end{tabular}


Table B3. Minimum (Min), range, bisection point (Mu), standard deviation (Sigma) and coefficient of variation $\left(\mathrm{R}^{2}\right)$ from original Gaussian analyses at the 15-s-vs.-60-s series of drug administration.

\begin{tabular}{|c|c|c|c|c|c|c|c|c|c|c|c|}
\hline \multicolumn{6}{|c|}{ Fischer 344} & \multicolumn{6}{|c|}{ Lewis } \\
\hline \multicolumn{12}{|c|}{ Saline } \\
\hline Rat & Min & Range & $\mathrm{Mu}$ & Sigma & $\mathrm{R}^{2}$ & Rat & Min & Range & $\mathrm{Mu}$ & Sigma & $\mathrm{R}^{2}$ \\
\hline F1 & 0.06 & 0.90 & 31.83 & 8.68 & 1.00 & $\mathrm{~L} 1$ & 0.07 & 0.84 & 35.28 & 4.66 & 0.99 \\
\hline $\mathrm{F} 2$ & -0.34 & 1.25 & 23.78 & 14.70 & 0.95 & L2 & -0.46 & 1.50 & 19.97 & 37.50 & 0.94 \\
\hline F3 & -0.07 & 0.94 & 32.22 & 11.91 & 0.99 & L3 & 0.10 & 0.80 & 28.20 & 4.93 & 0.99 \\
\hline $\mathrm{F} 4$ & 0.06 & 0.88 & 39.39 & 7.98 & 0.99 & L4 & -0.04 & 1.02 & 31.60 & 11.00 & 0.97 \\
\hline F5 & -0.08 & 0.90 & 28.13 & 13.56 & 0.97 & L5 & -0.16 & 2.00 & 53.95 & 43.74 & 0.96 \\
\hline F6 & -0.70 & 1.92 & 25.15 & 31.79 & 0.96 & L6 & 0.12 & 0.83 & 42.00 & 5.80 & 0.97 \\
\hline Mean & -0.18 & 1.13 & 30.08 & 14.77 & 0.97 & Mean & -0.06 & 1.16 & 35.17 & 17.94 & 0.97 \\
\hline SEM & 0.12 & 0.17 & 2.32 & 3.57 & 0.01 & SEM & 0.09 & 0.20 & 4.80 & 7.28 & 0.01 \\
\hline \multicolumn{12}{|c|}{$0.1 \mathrm{mg} / \mathrm{kg} d$-AMP } \\
\hline Rat & Min & Range & $\mathrm{Mu}$ & Sigma & $\mathrm{R}^{2}$ & Rat & Min & Range & $\mathrm{Mu}$ & Sigma & $\mathrm{R}^{2}$ \\
\hline F1 & -1.13 & 2.00 & 9.19 & 19.27 & 0.95 & L1 & 0.06 & 0.94 & 27.39 & 4.22 & 1.00 \\
\hline $\mathrm{F} 2$ & -0.01 & 0.98 & 28.16 & 6.04 & 0.99 & L2 & -0.98 & 2.00 & 10.71 & 24.91 & 0.93 \\
\hline F3 & -0.55 & 2.00 & 35.32 & 36.45 & 0.96 & L3 & -0.11 & 1.11 & 28.70 & 12.56 & 0.95 \\
\hline F4 & 0.06 & 0.97 & 35.35 & 10.43 & 0.91 & L4 & 0.33 & 0.38 & 29.24 & 1.82 & 0.95 \\
\hline F5 & -0.85 & 2.00 & 18.40 & 30.17 & 0.85 & L5 & -1.01 & 2.00 & 10.45 & 21.99 & 0.98 \\
\hline F6 & 0.00 & 0.87 & 30.01 & 10.99 & 0.97 & L6 & & & & & \\
\hline Mean & -0.41 & 1.47 & 26.07 & 18.89 & 0.94 & Mean & -0.34 & 1.29 & 21.30 & 13.10 & 0.96 \\
\hline SEM & 0.21 & 0.24 & 4.22 & 4.95 & 0.02 & SEM & 0.28 & 0.32 & 4.39 & 4.61 & 0.01 \\
\hline \multicolumn{12}{|c|}{$0.3 \mathrm{mg} / \mathrm{kg} d$-AMP } \\
\hline Rat & Min & Range & $\mathrm{Mu}$ & Sigma & $\mathrm{R}^{2}$ & Rat & Min & Range & $\mathrm{Mu}$ & Sigma & $\mathrm{R}^{2}$ \\
\hline F1 & 0.13 & 0.51 & 30.77 & 1.10 & 0.90 & L1 & -1.05 & 2.00 & 5.47 & 22.97 & 0.91 \\
\hline $\mathrm{F} 2$ & 0.25 & 0.53 & 37.09 & 1.24 & 0.81 & L2 & -0.79 & 1.74 & 0.01 & 20.70 & 0.96 \\
\hline F3 & 0.10 & 0.64 & 38.27 & 1.31 & 0.89 & L3 & -1.05 & 2.00 & 8.30 & 22.53 & 0.88 \\
\hline F4 & 0.06 & 0.65 & 38.07 & 1.31 & 0.92 & L4 & -0.10 & 0.68 & 13.73 & 1.29 & 0.22 \\
\hline F5 & 0.31 & 0.49 & 38.80 & 1.33 & 0.93 & L5 & 0.20 & 0.69 & 24.20 & 6.63 & 0.88 \\
\hline F6 & -0.05 & 1.01 & 31.36 & 17.07 & 0.84 & L6 & -1.08 & 2.00 & 8.49 & 26.36 & 0.91 \\
\hline Mean & 0.13 & 0.64 & 35.73 & 3.89 & 0.88 & Mean & -0.65 & 1.52 & 10.03 & 16.75 & 0.79 \\
\hline SEM & 0.05 & 0.08 & 1.49 & 2.64 & 0.02 & SEM & 0.23 & 0.27 & 3.37 & 4.17 & 0.11 \\
\hline \multicolumn{12}{|c|}{$1.0 \mathrm{mg} / \mathrm{kg} d$-AMP } \\
\hline Rat & Min & Range & $\mathrm{Mu}$ & Sigma & $\mathrm{R}^{2}$ & Rat & Min & Range & $\mathrm{Mu}$ & Sigma & $\mathrm{R}^{2}$ \\
\hline F1 & -0.03 & 0.30 & 48.45 & 23.60 & 0.74 & L1 & 0.40 & -0.06 & 42.45 & 1.01 & 0.20 \\
\hline $\mathrm{F} 2$ & -0.62 & 2.00 & 0.00 & 137.10 & 0.82 & L2 & 0.42 & 0.07 & 26.98 & 0.61 & 0.32 \\
\hline F3 & 0.31 & -0.43 & 0.00 & 383.67 & 0.01 & L3 & 0.69 & 0.07 & 26.98 & 0.61 & 0.33 \\
\hline $\mathrm{F} 4$ & 0.16 & 0.58 & 44.59 & 10.34 & 0.99 & $\mathrm{~L} 4$ & 0.72 & 0.17 & 24.31 & 0.61 & 0.81 \\
\hline F5 & & & & & & L5 & 0.50 & 0.14 & 26.68 & 0.60 & 0.39 \\
\hline F6 & 0.63 & 0.17 & 39.21 & 1.92 & 0.36 & L6 & 0.59 & 0.18 & 30.09 & 0.60 & 0.75 \\
\hline Mean & 0.09 & 0.52 & 26.45 & 111.33 & 0.58 & Mean & 0.55 & 0.09 & 29.58 & 0.67 & 0.47 \\
\hline SEM & 0.19 & 0.37 & 9.95 & 66.05 & 0.16 & SEM & 0.06 & 0.04 & 2.94 & 0.07 & 0.11 \\
\hline \multicolumn{12}{|c|}{$1.8 \mathrm{mg} / \mathrm{kg} d$-AMP } \\
\hline Rat & Min & Range & $\mathrm{Mu}$ & Sigma & $\mathrm{R}^{2}$ & Rat & Min & Range & $\mathrm{Mu}$ & Sigma & $\mathrm{R}^{2}$ \\
\hline F1 & 0.01 & -0.03 & 60.00 & 0.60 & 0.03 & L1 & 0.07 & 0.03 & 54.00 & 0.59 & 0.02 \\
\hline $\mathrm{F} 2$ & 0.18 & -0.06 & 60.00 & 0.60 & 0.01 & L2 & 0.27 & 0.10 & 54.00 & 0.59 & 0.09 \\
\hline & & & & & & L3 & 0.31 & 0.03 & 34.09 & 0.49 & 0.03 \\
\hline F4 & 0.35 & -0.11 & 54.00 & 0.59 & 0.19 & L4 & 0.69 & 0.18 & 32.27 & 6.22 & 0.64 \\
\hline F5 & 0.15 & 0.00 & 54.00 & 0.59 & 0.00 & L5 & 0.50 & -0.10 & 60.00 & 3.75 & 0.04 \\
\hline F6 & 0.88 & -0.28 & 54.00 & 0.59 & 0.28 & L6 & 0.53 & 0.43 & 60.00 & 8.20 & 0.90 \\
\hline Mean & 0.32 & -0.10 & 56.40 & 0.59 & 0.10 & Mean & 0.40 & 0.11 & 49.06 & 3.31 & 0.29 \\
\hline SEM & 0.20 & 0.07 & 1.90 & 0.00 & 0.07 & SEM & 0.11 & 0.09 & 6.30 & 1.66 & 0.19 \\
\hline
\end{tabular}




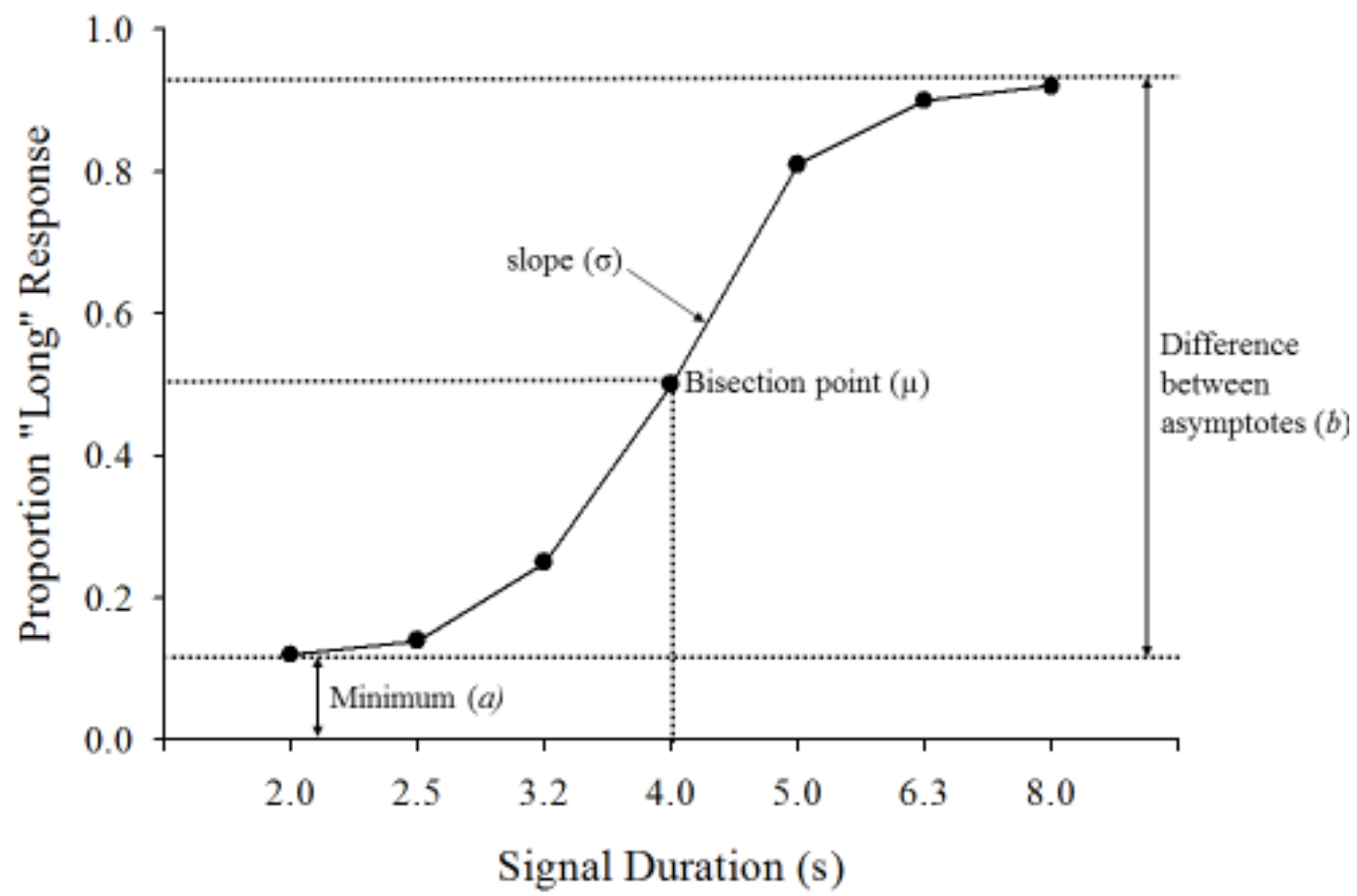

Figure B. Original hypothetical representation of a psychophysical function with free parameters (minimum, slope, bisection point, and difference between asymptotes) labeled (adapted from McClure et al., 2005). 


\section{Appendix C: Minimum and Range Analyses}

\section{Baseline}

Neither Mauchly's test of sphericity nor Levene's test of the equality of error variances were significant across the range or the minimum in any of the four duration series. There was a significant effect of series for the minimum and range of the function. This effect on both minimum and range indicates that accuracy at the training durations was reduced for series with longer durations, and the durations surrounding the training durations showed greater variability. In addition, this effect was not only seen for shorter or longer trials (variability in the tails of the function increased regardless of duration length within a series). Longer series resulted in greater minimum values $F(3,30)=7.29, \mathrm{p}=.001)$ and shorter ranges $F(3,30)=7.31, \mathrm{p}=.001)$. For the minimum, pairwise comparisons showed significant differences between the 2-8 and 10-40 series $(\mathrm{p}<.05)$, and the $2-8$ and the $15-60$ series $(\mathrm{p}<.01)$, with the $2-8$ series showing a smaller minimum in both cases. For the range, pairwise comparisons showed significant differences between the 2-8 series and the 10-40 series $(\mathrm{p}<.05)$, as well as the $2-8$ series and the $15-60$ series $(\mathrm{p}=.001)$.

\section{Drug Administration}

\section{2-s-vs.-8-s series.}

Mauchly's test of sphericity was significant for the minimum, $\chi^{2}(5)=14.89, \mathrm{p}<.05$.

Levene's test of the equality of error variances was only significant for range values at the $1.0 d$ AMP dose, $F(1,10)=6.12, \mathrm{p}<.05$, so data were not log-transformed. There was a significant effect of dose on the minimum $F(1.53,15.30)=5.02, \mathrm{p}<.05$ and the range, $F(3,30)=5.60, \mathrm{p}<.01 . d$-AMP dose dependently increased the minimum and decreased the range overall, across both strains of rats. These results indicate that at all durations, accuracy at both of the training durations 
decreased, and functions appeared flatter. There were no significant pairwise comparisons for the minimum. Pairwise comparisons for the range indicated significant differences between saline and $1.0 \mathrm{mg} / \mathrm{kg} d$-AMP, as well as $0.1 \mathrm{mg} / \mathrm{kg}$ and $1.0 \mathrm{mg} / \mathrm{kg} d$-AMP (both $\mathrm{p}<.05$ ).

\section{5-s-vs.-60-s Series.}

Levene's test of the equality of variances was significant for the minimum and the range at multiple doses. Levene's test remained significant after log-transforming the data. Therefore, due to the differences in variance between groups, nonparametric tests were used. There was a significant effect of dose on the minimum, $\chi^{2}(3)=19.40, \mathrm{p}<.001$, indicating that $d$-AMP reduced accuracy of responses on trials presenting the shorter training duration. Significant differences in the minimum were found between saline and $1.0 \mathrm{mg} / \mathrm{kg} d$-AMP $(Z=-2.90, \mathrm{p}<.004)$, between saline and $0.3 \mathrm{mg} / \mathrm{kg} d$-AMP $(Z=-2.90, \mathrm{p}=.004)$, and between 0.1 and $1.0 \mathrm{mg} / \mathrm{kg} d$-AMP $(Z=-$ 2.82, $\mathrm{p}=.005)$. There was also a significant effect of strain at the $0.3 \mathrm{mg} / \mathrm{kg} d$-AMP dose $(Z=-$ 2.72, $\mathrm{p}=.006$ ), indicating that this dose resulted in differences in responding to short durations between LEW and F344, with LEW showing larger minimum values.

There was also a significant effect of dose on the range, $\chi^{2}(3)=29.50, p<.001$. Significant differences were found between saline and $0.1 \mathrm{mg} / \mathrm{kg} d$-AMP $(Z=-3.06, \mathrm{p}=.002)$, saline and 0.3 $\mathrm{mg} / \mathrm{kg} d$-AMP $(Z=-2.98, \mathrm{p}=.003)$, saline and $1.0 \mathrm{mg} / \mathrm{kg} d$-AMP $(Z=-3.06, \mathrm{p}=.002), 0.1$ and 0.3 $\mathrm{mg} / \mathrm{kg} d$-AMP ( $Z=-3.06, \mathrm{p}=.002), 0.3$ and $1.0 \mathrm{mg} / \mathrm{kg} d$-AMP $(Z=-2.98, \mathrm{p}=.003)$, and, 0.1 and 1.0 $\mathrm{mg} / \mathrm{kg} d$-AMP $(Z=-3.06, \mathrm{p}=.002)$. There was no effect of strain on the range at any dose, indicating that effects of $d$-AMP on the range were similar across strains. 

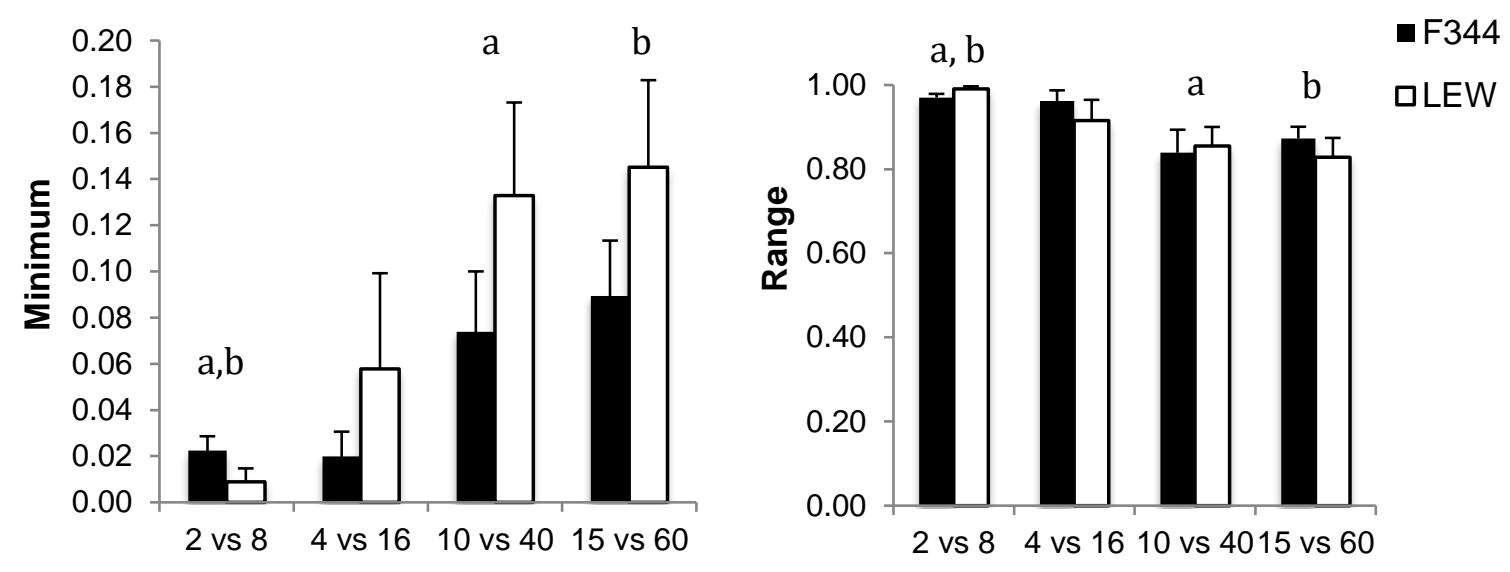

Figure C1. Minimum and range of Gaussian functions across strains and series for the baseline phase. Error bars represent standard error of the mean. Pairwise significance for series indicated by corresponding letters. 

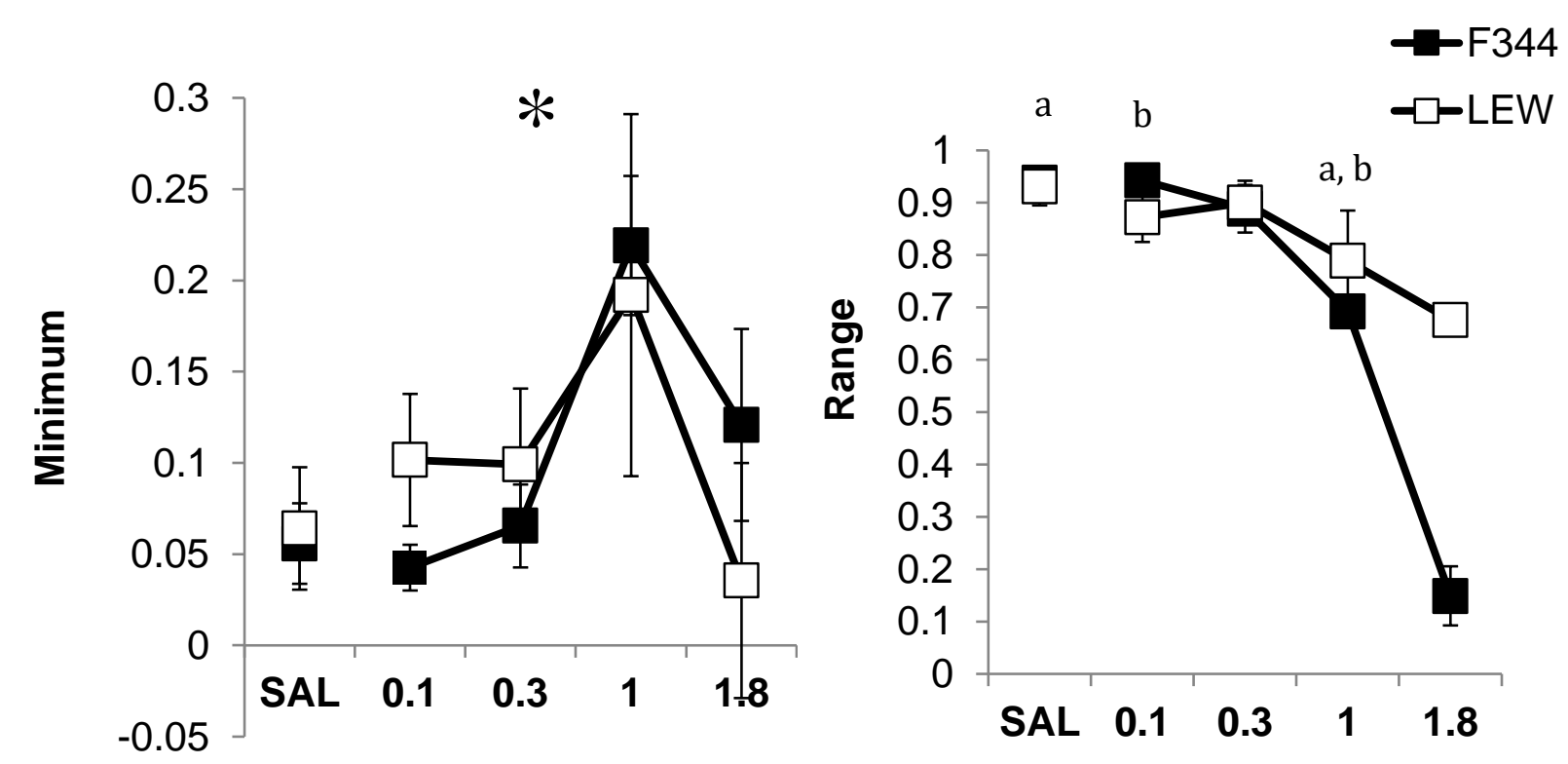

Figure C2. Mean minimum and range parameters across drug doses for LEW and F344 rats from the 2-s-vs.-8-s series. Error bars represent standard error of the mean. Pairwise comparisons indicated with where letters correspond. *Indicates a main effect of dose with no significant pairwise comparisons. 


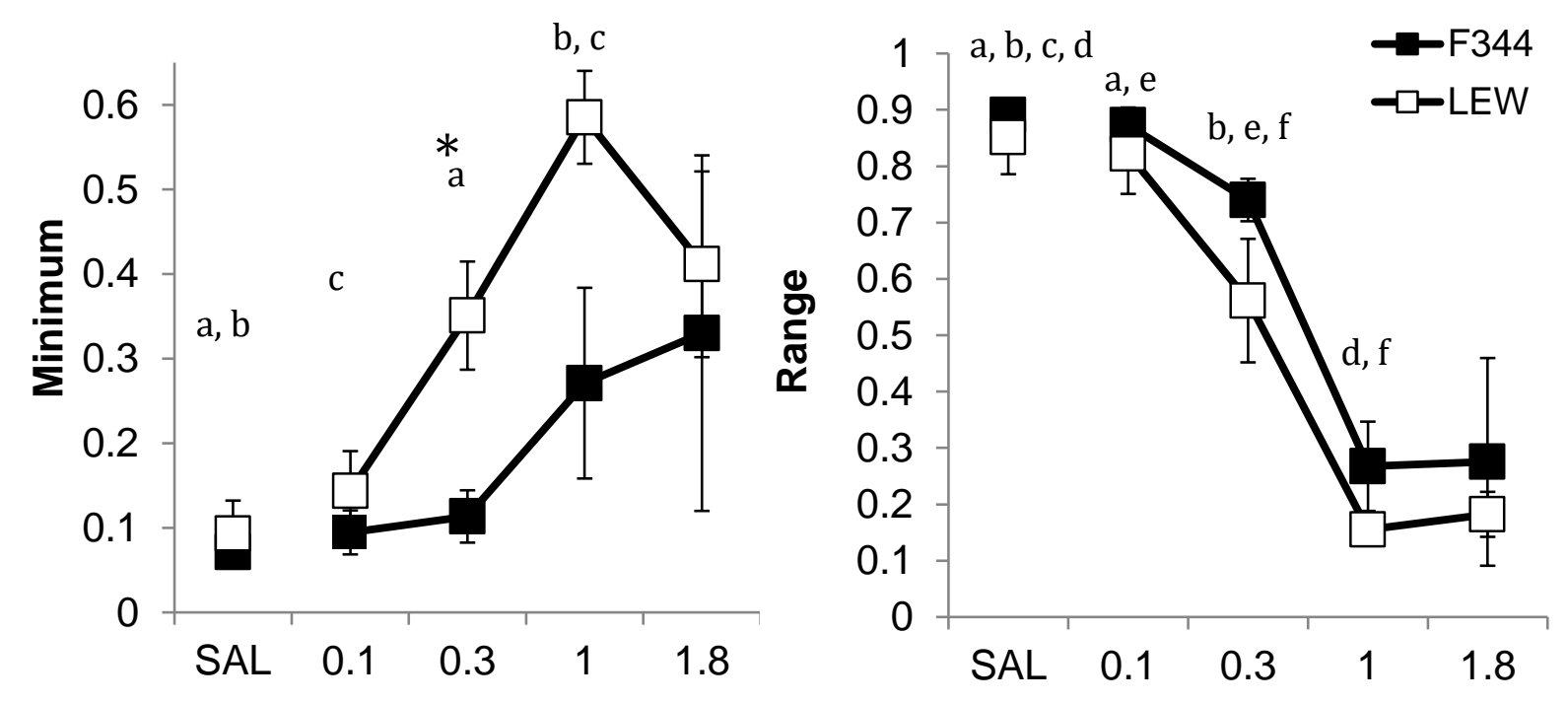

Figure C3. Mean minimum and range parameters across drug doses for LEW and F344 rats from the 15-s-vs.-60-s series. Error bars represent standard error of the mean. Pairwise comparisons are indicated by corresponding letters. *Indicates significant strain difference at designated dose. 
Appendix D: Individual Rat Data

F344: 2 s vs. $8 \mathrm{~s}$
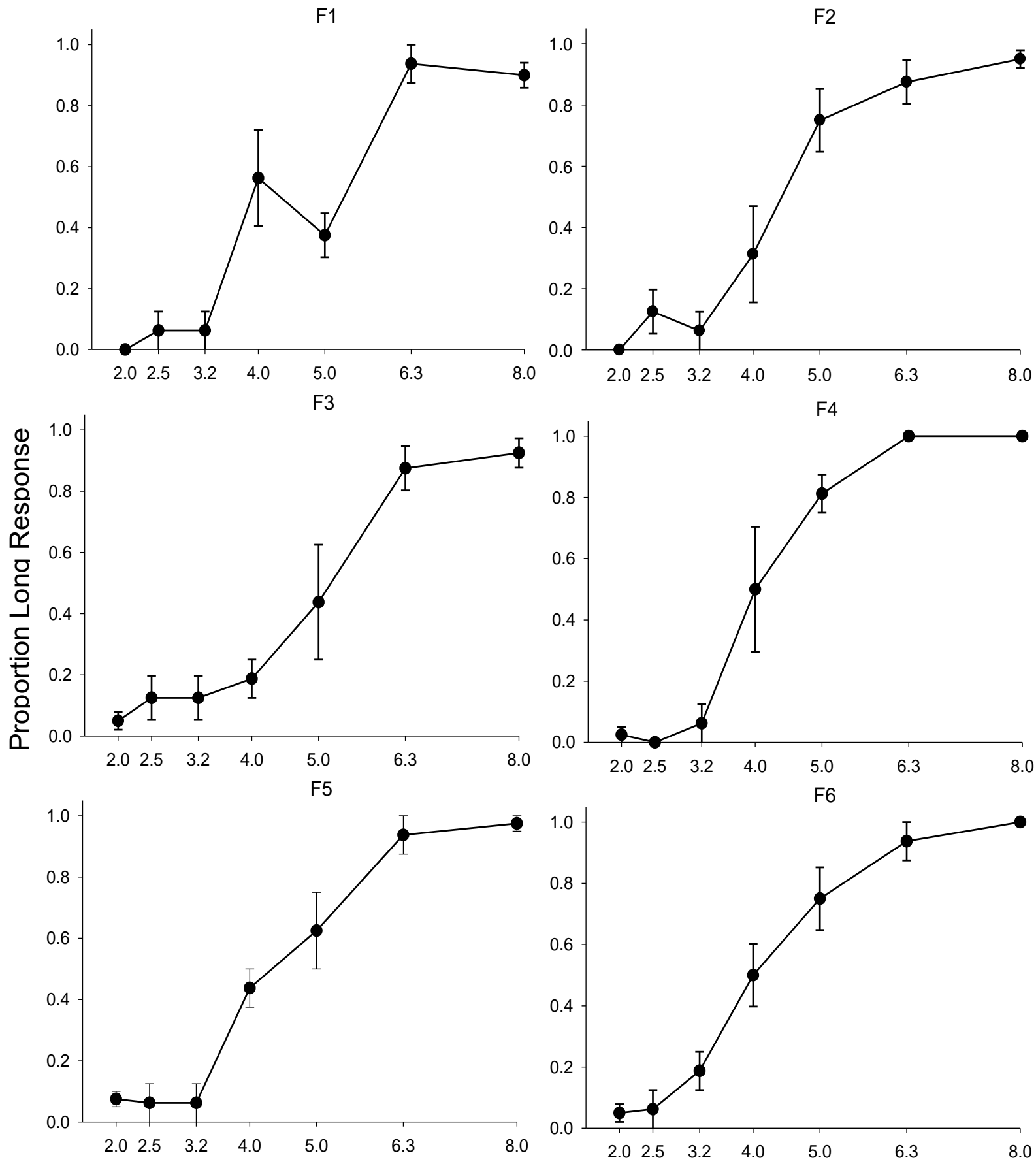

Duration (s)

Figure D1. Individual obtained functions averaged across sessions for F344 rats in the 2-s-vs.-8-s series of the baseline phase. Error bars represent standard error of the mean. 
LEW: $2 \mathrm{~s}$ vs. $8 \mathrm{~s}$
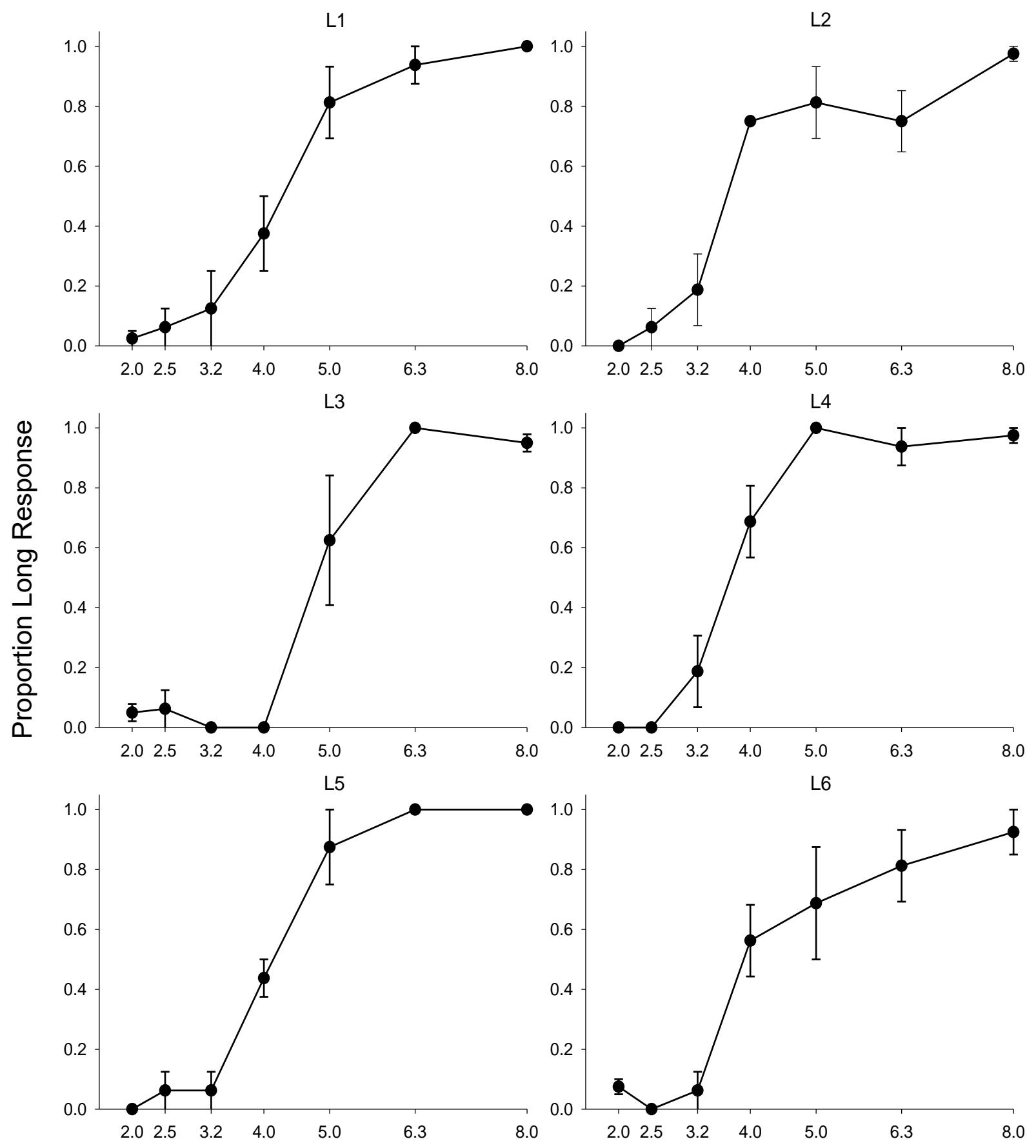

Duration (s)

Figure D2. Individual obtained functions averaged across sessions for LEW rats in the 2-s-vs.-8$\mathrm{s}$ series of the baseline phase. Error bars represent standard error of the mean. 
F344: $4 \mathrm{~s}$ vs. $16 \mathrm{~s}$
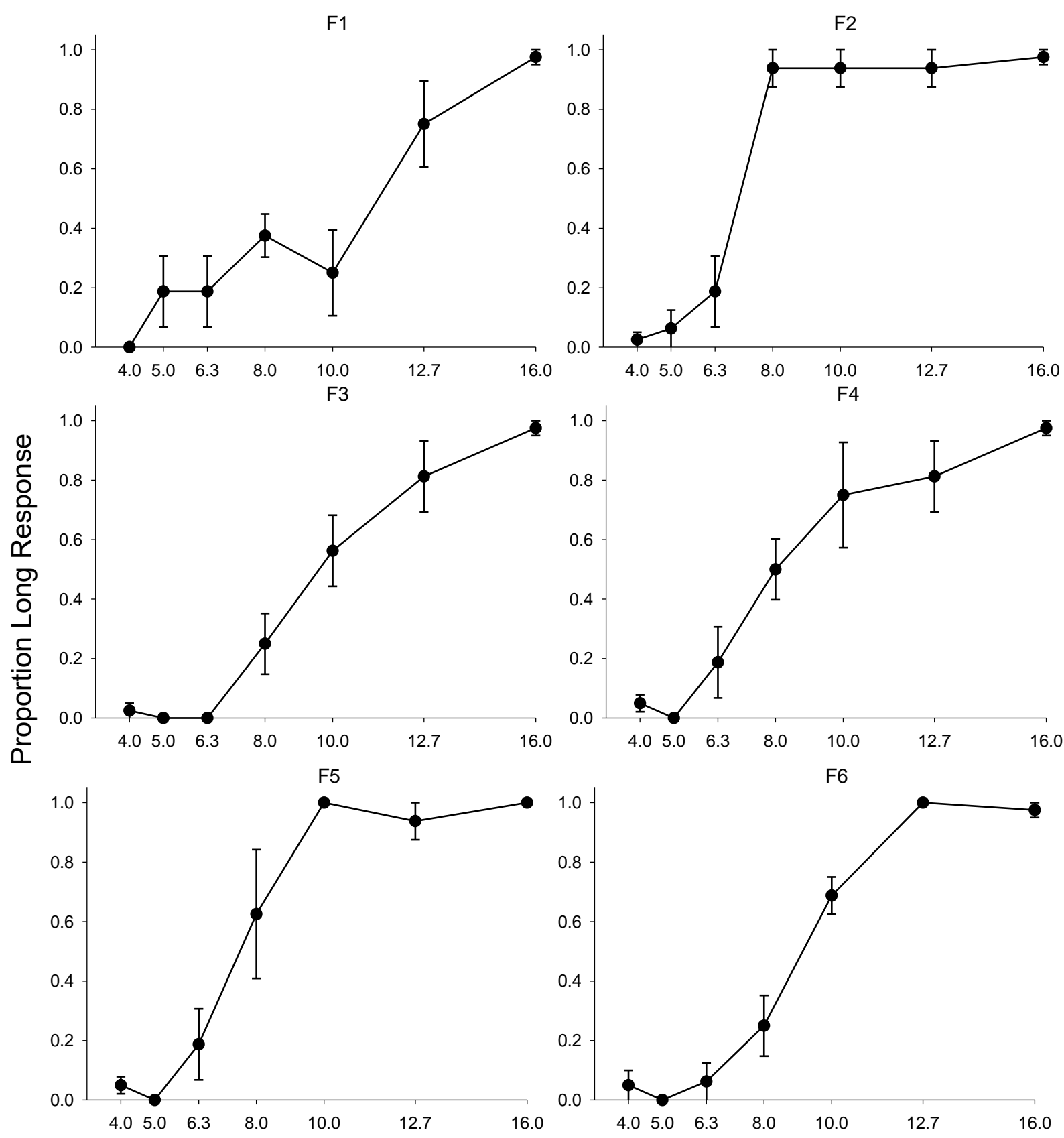

\section{Duration (s)}

Figure D3. Individual obtained functions averaged across sessions for F344 rats in the 4-s-vs.16-s series of the baseline phase. Error bars represent standard error of the mean. 
LEW: $4 \mathrm{~s}$ vs. $16 \mathrm{~s}$
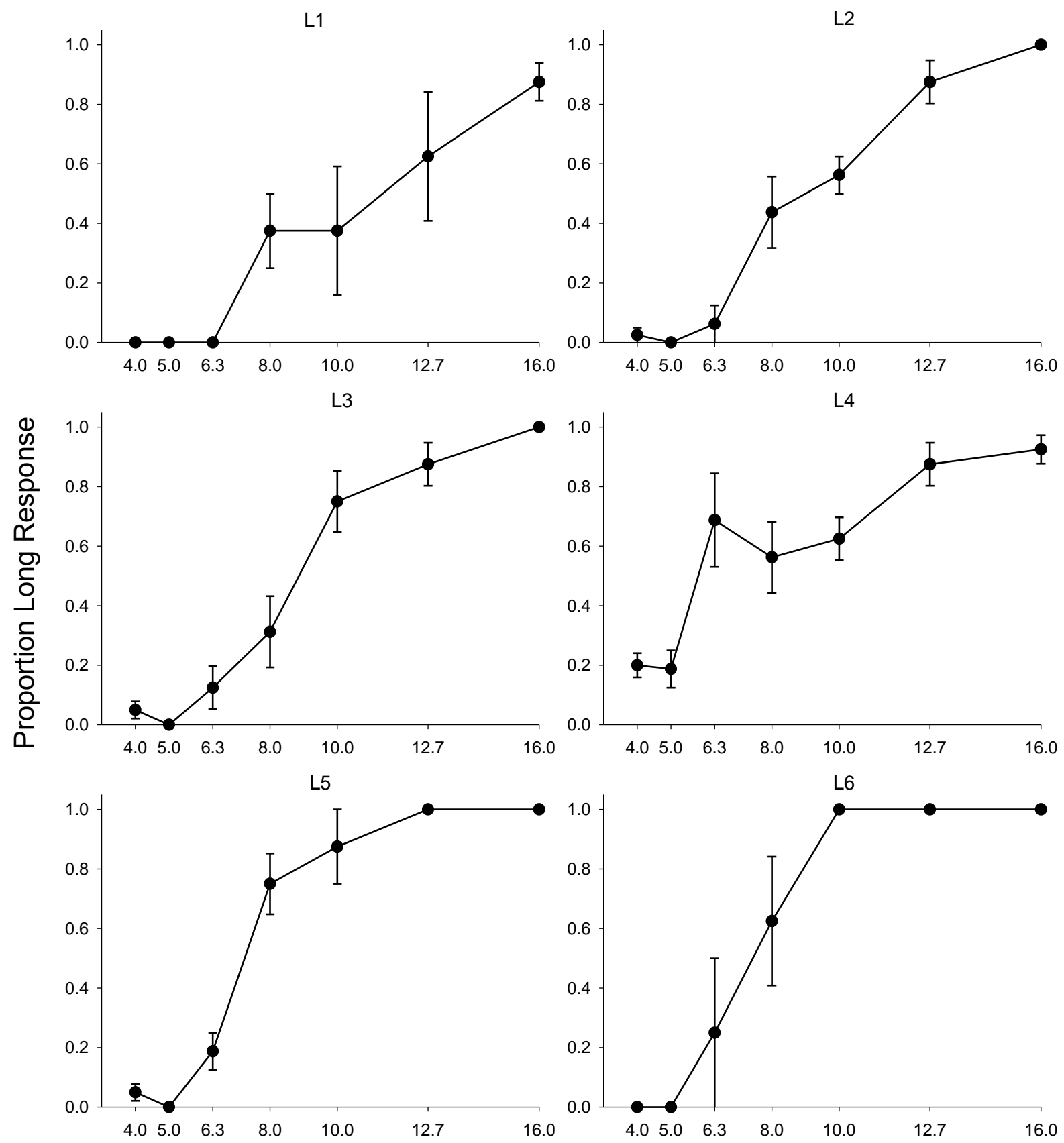

\section{Duration (s)}

Figure D4. Individual obtained functions averaged across sessions for LEW rats in the 4-s-vs.16-s series of the baseline phase. Error bars represent standard error of the mean. 
F344: $10 \mathrm{~s}$ vs. $40 \mathrm{~s}$
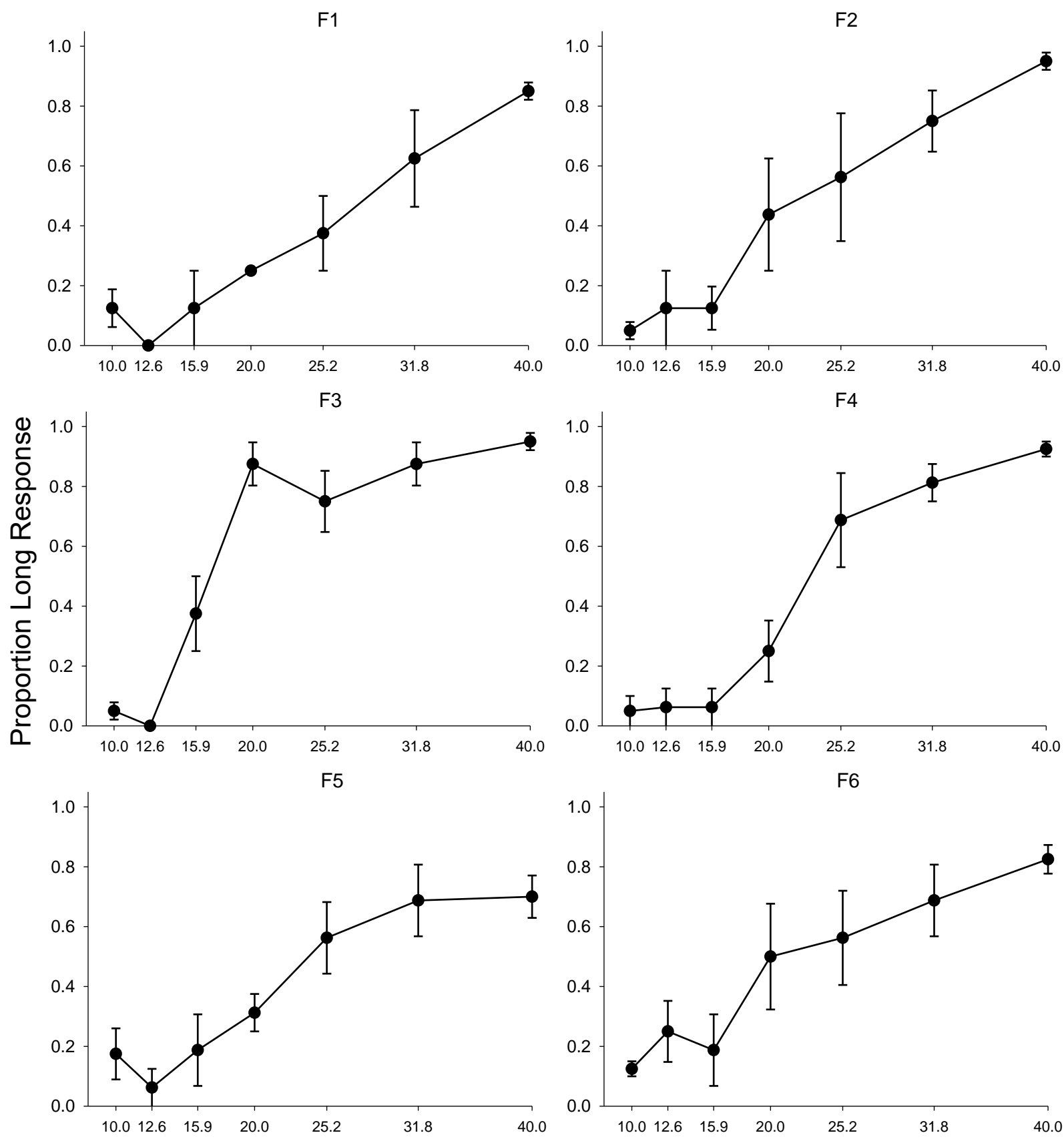

\section{Duration (s)}

Figure D5. Individual obtained functions averaged across sessions for F344 rats in the 10-s-vs.40-s series of the baseline phase. Error bars represent standard error of the mean. 
LEW: $10 \mathrm{~s}$ vs. $40 \mathrm{~s}$

L1
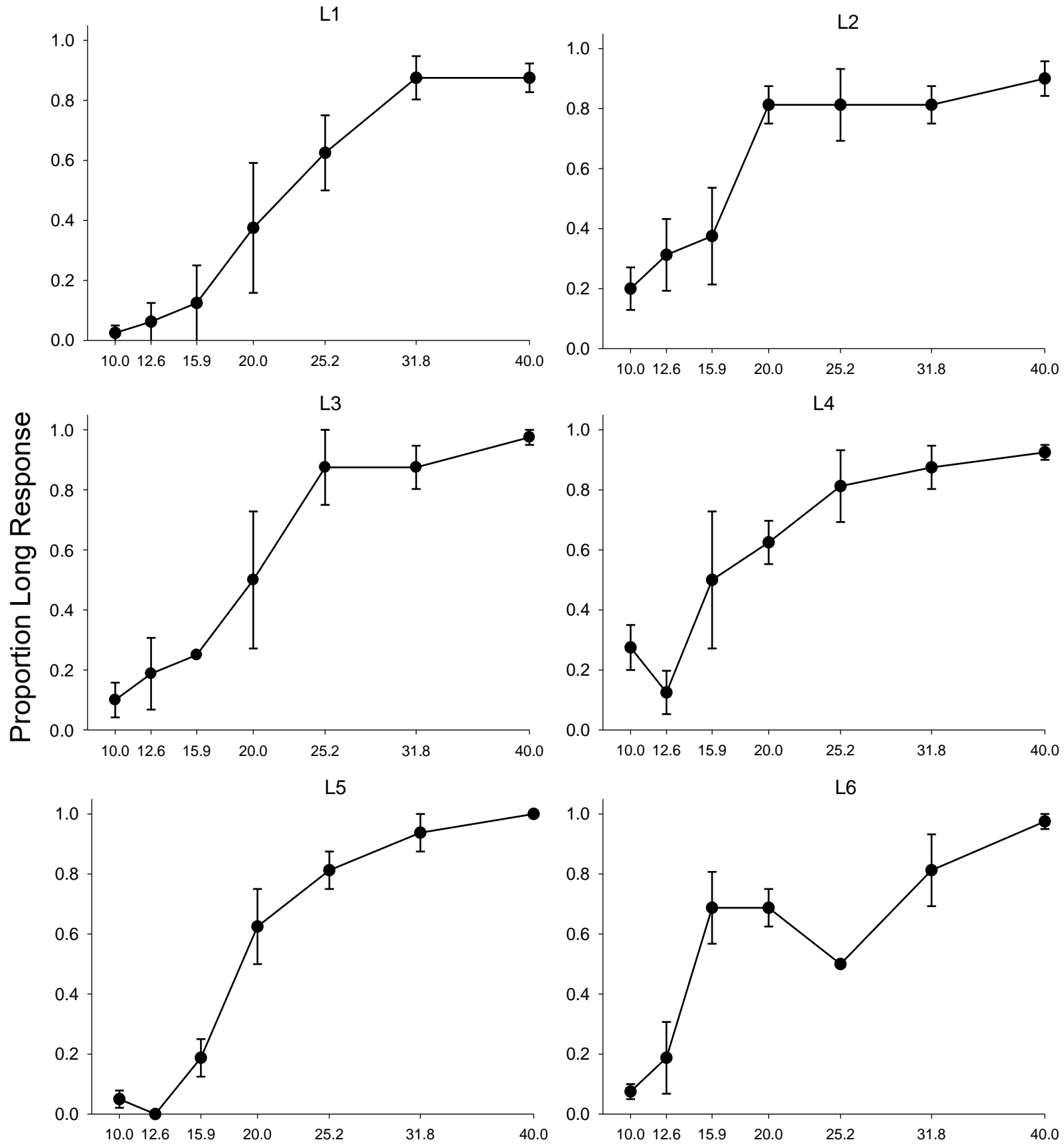

\section{Duration (s)}

Figure D6. Individual obtained functions averaged across sessions for LEW rats in the 10-s-vs.40-s series of the baseline phase. Error bars represent standard error of the mean. 
F344: $15 \mathrm{~s}$ vs. $60 \mathrm{~s}$
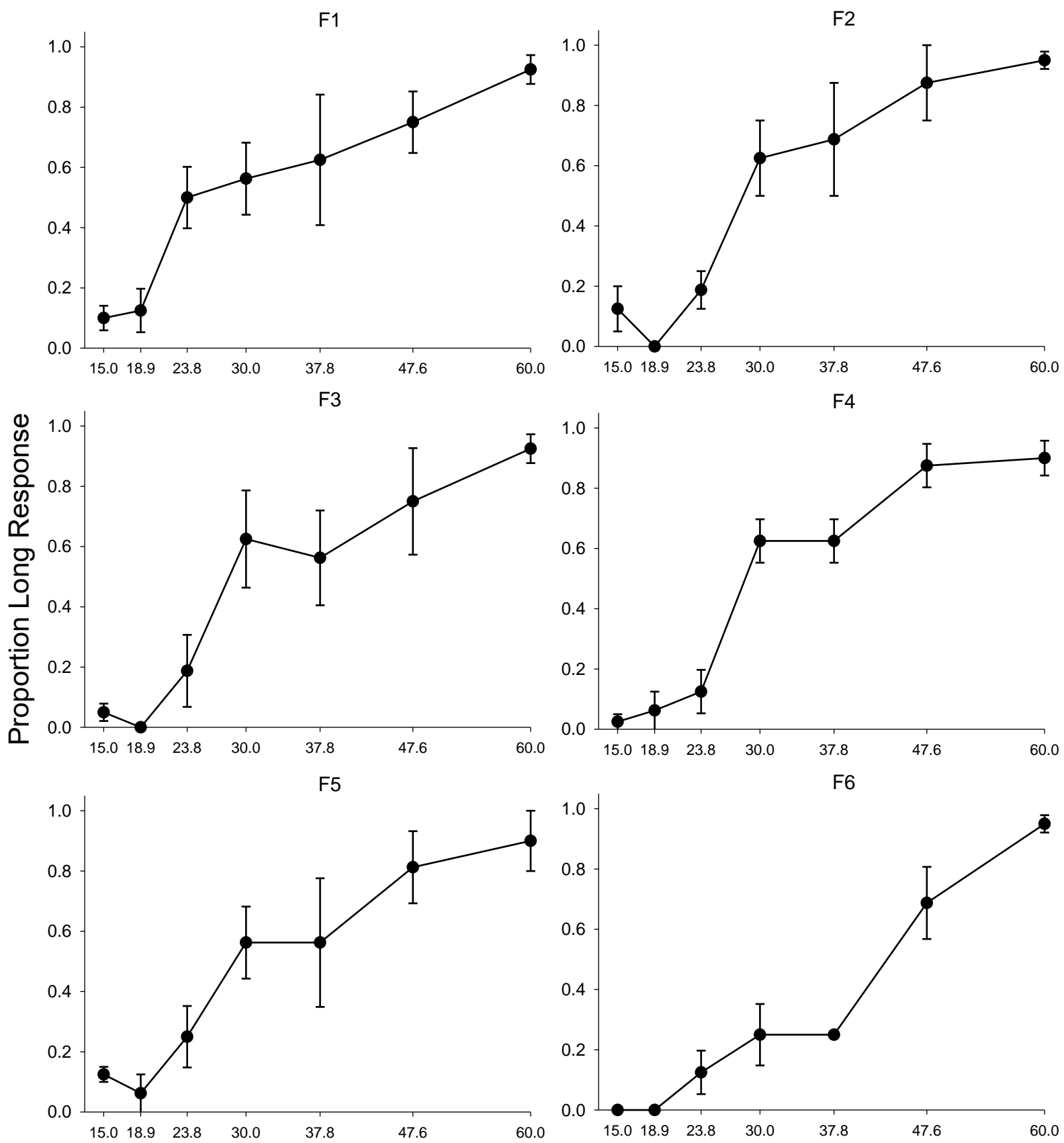

Duration (s)

Figure D7. Individual obtained functions averaged across sessions for F344 rats in the 15-s-vs.60-s series of the baseline phase. Error bars represent standard error of the mean. 
LEW: $15 \mathrm{~s}$ vs. $60 \mathrm{~s}$

L1
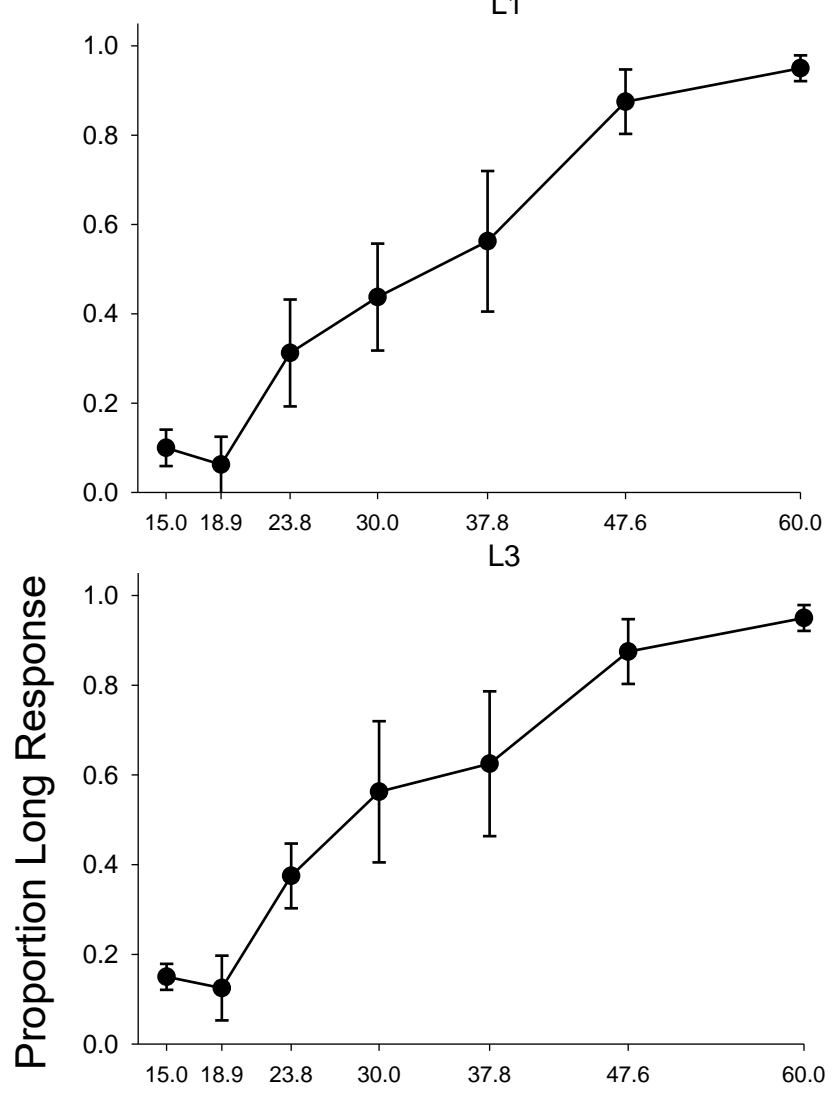

L5

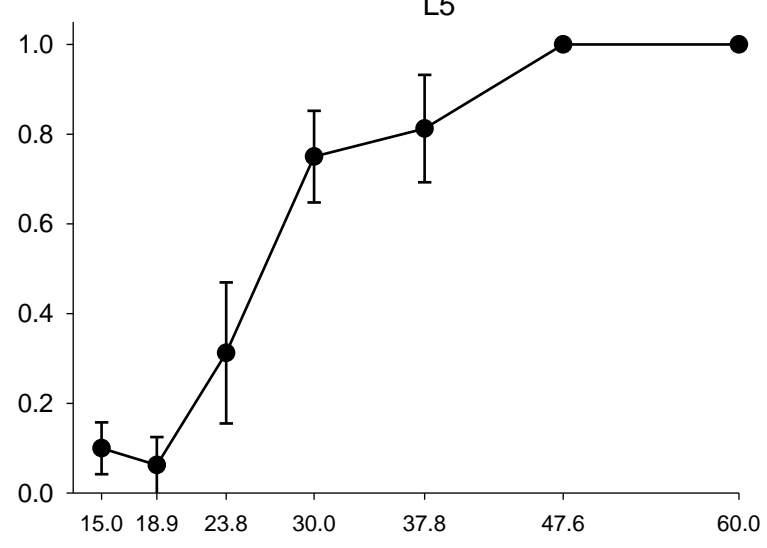

L2
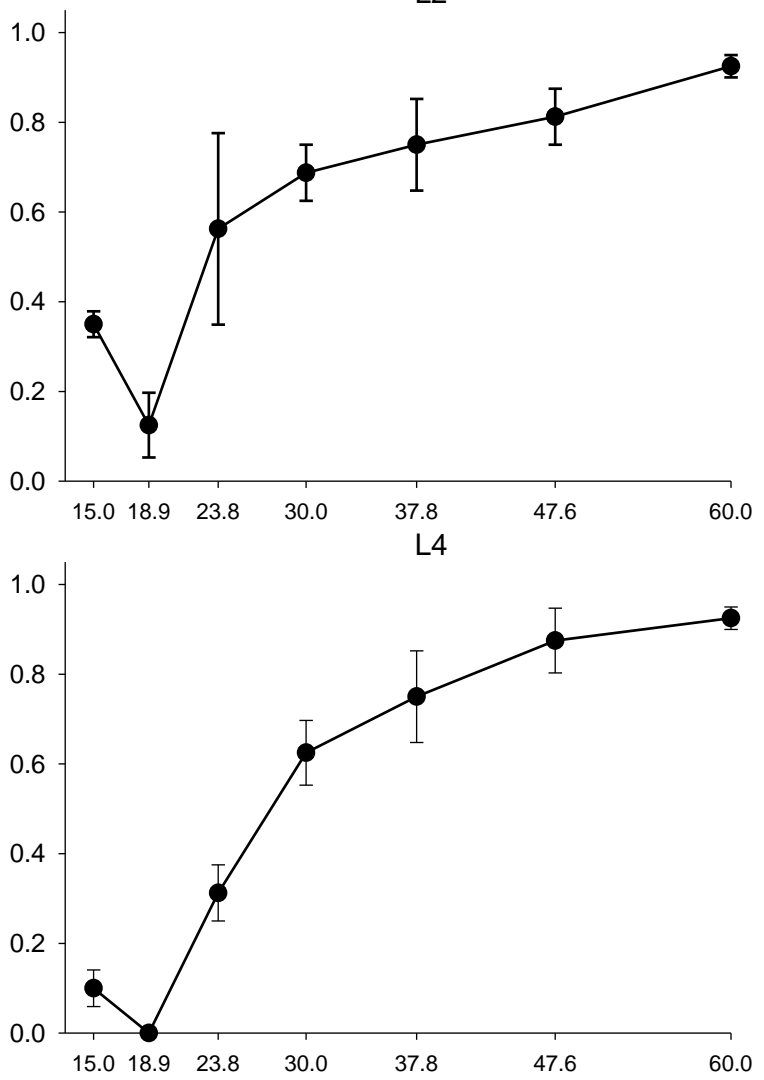

L6

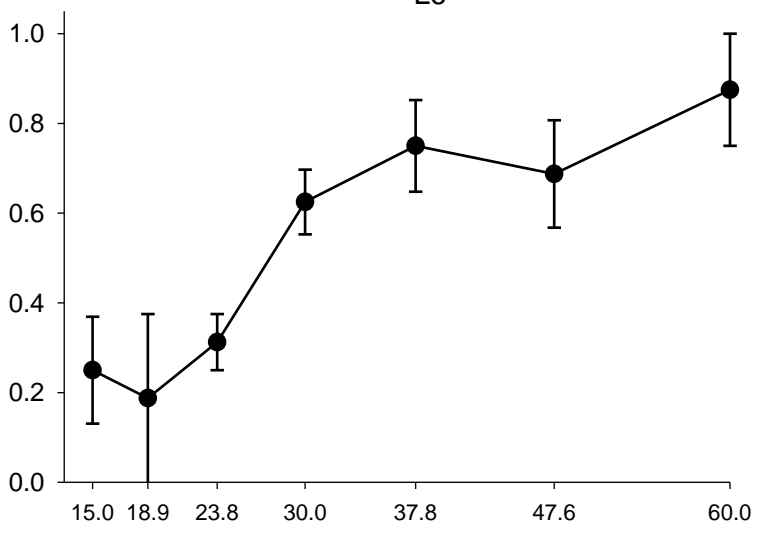

Duration (s)

Figure D8. Individual obtained functions averaged across sessions for LEW rats in the 15-s-vs.60-s series of the baseline phase. Error bars represent standard error of the mean. 


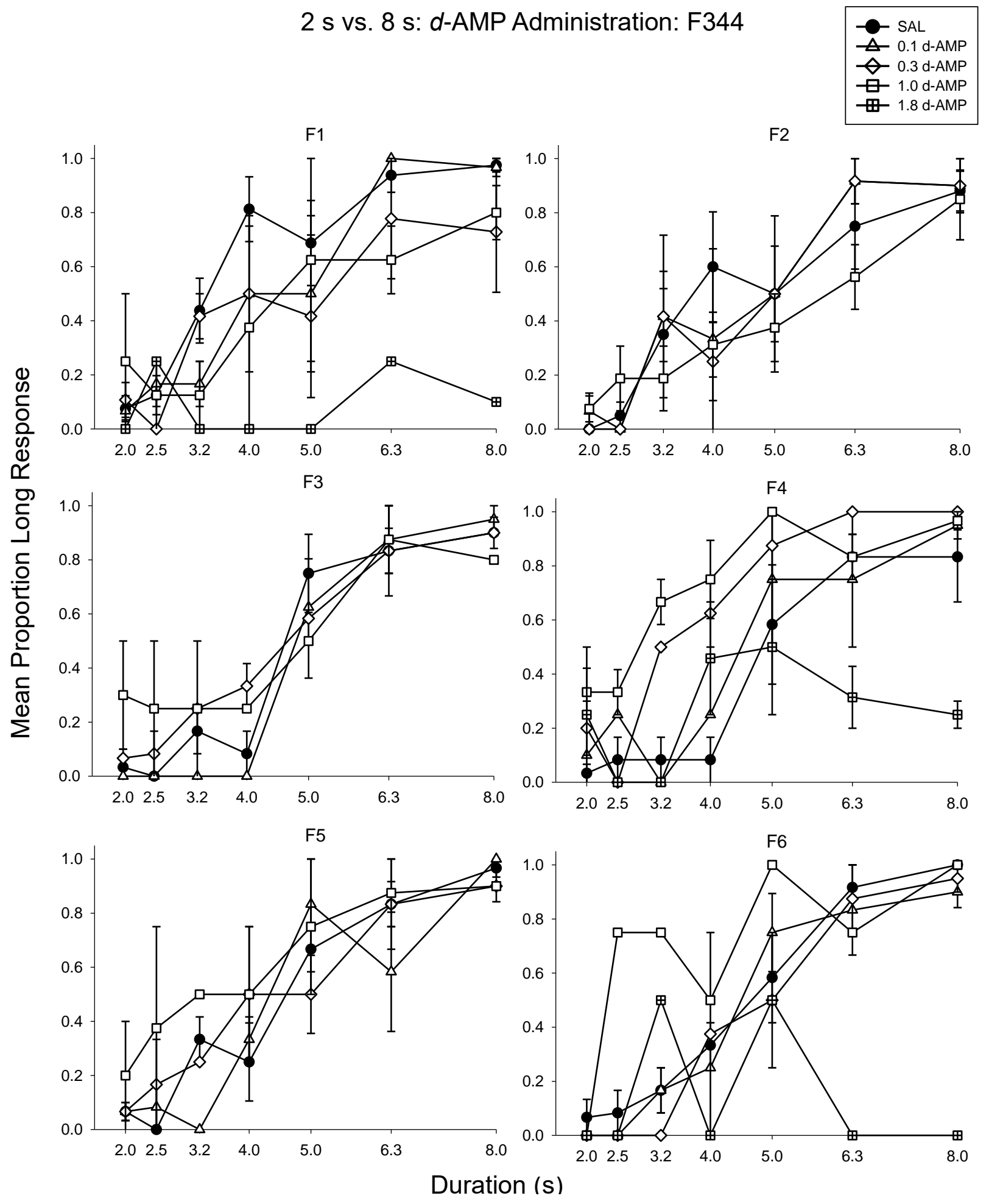

Figure D9. Individual obtained functions averaged across sessions for F344 rats in the 2-s-vs.-8-s series of the drug administration phase. Error bars represent standard error of the mean. 


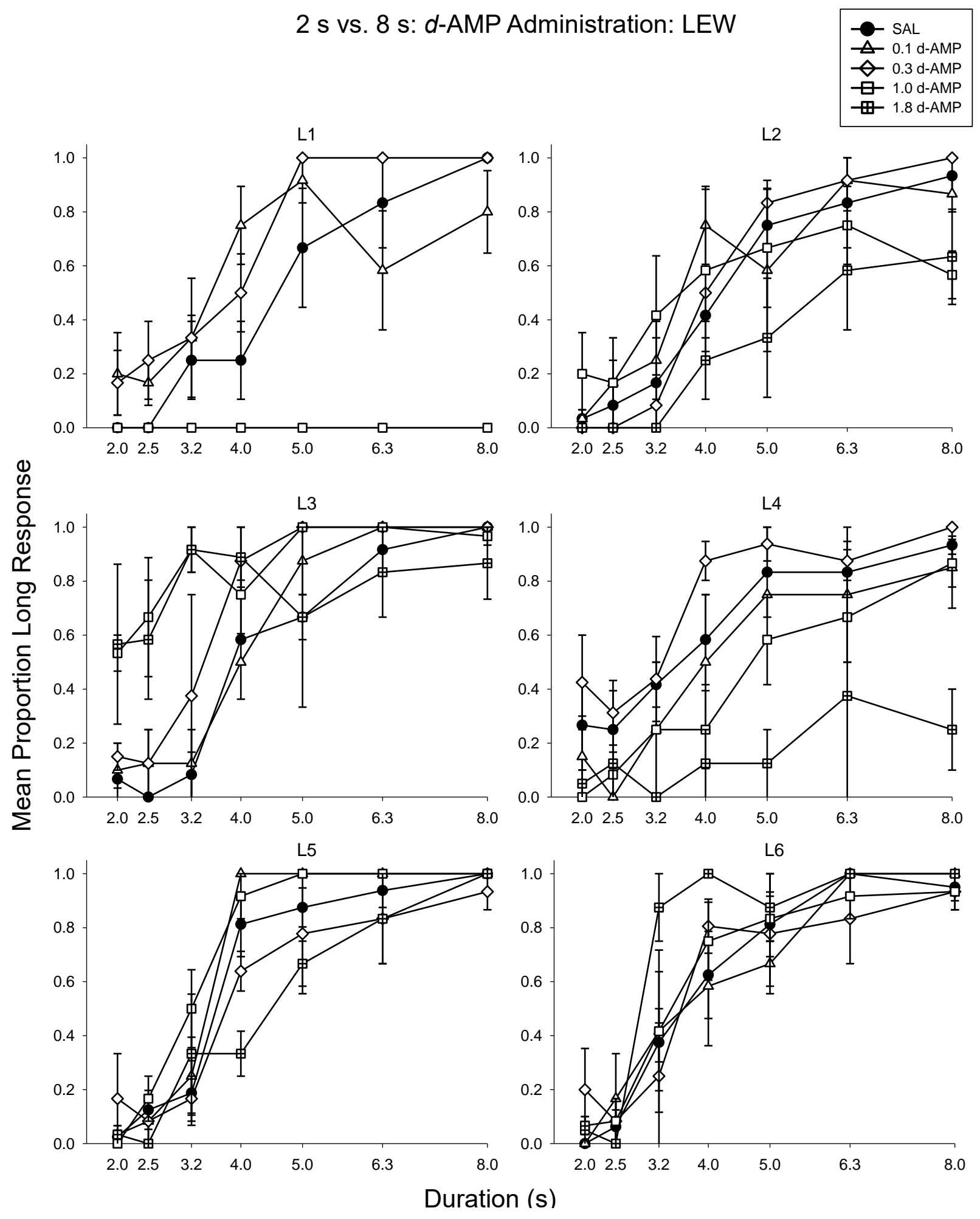

Figure D10. Individual obtained functions averaged across sessions for LEW rats in the 2-s-vs.8 -s series of the drug administration phase. Error bars represent standard error of the mean. 


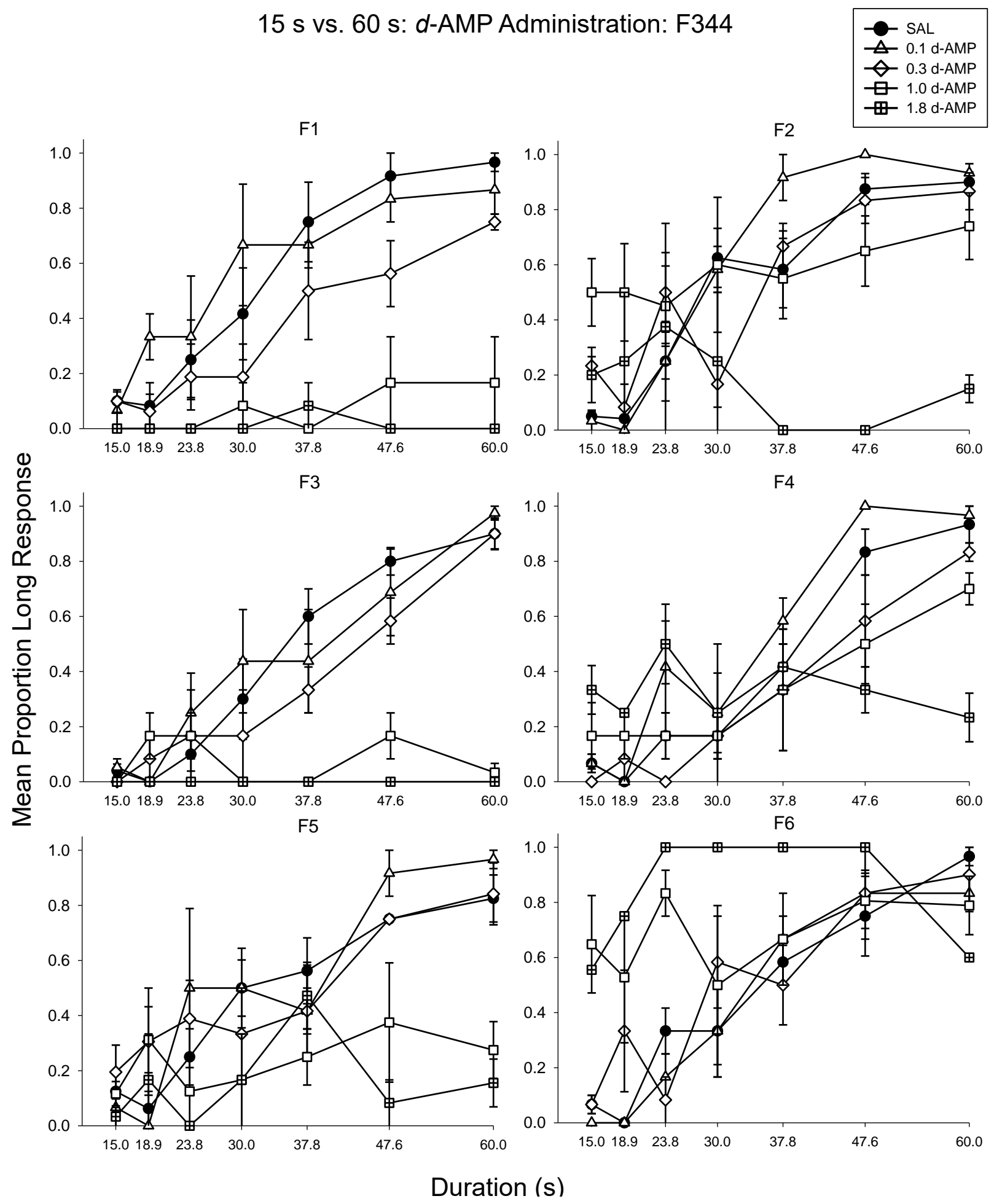

Figure D11. Individual obtained functions averaged across sessions for F344 rats in the 15-s-vs.60 -s series of the drug administration phase. Error bars represent standard error of the mean. 
$15 \mathrm{~s}$ vs. $60 \mathrm{~s}:$ d-AMP Administration: LEW

SAL

$\triangle 0.1 \mathrm{~d}-\mathrm{AMP}$

$\diamond 0.3 \mathrm{~d}-\mathrm{AMP}$

๑ $1.0 \mathrm{~d}-\mathrm{AMP}$

田 $1.8 \mathrm{~d}-\mathrm{AMP}$
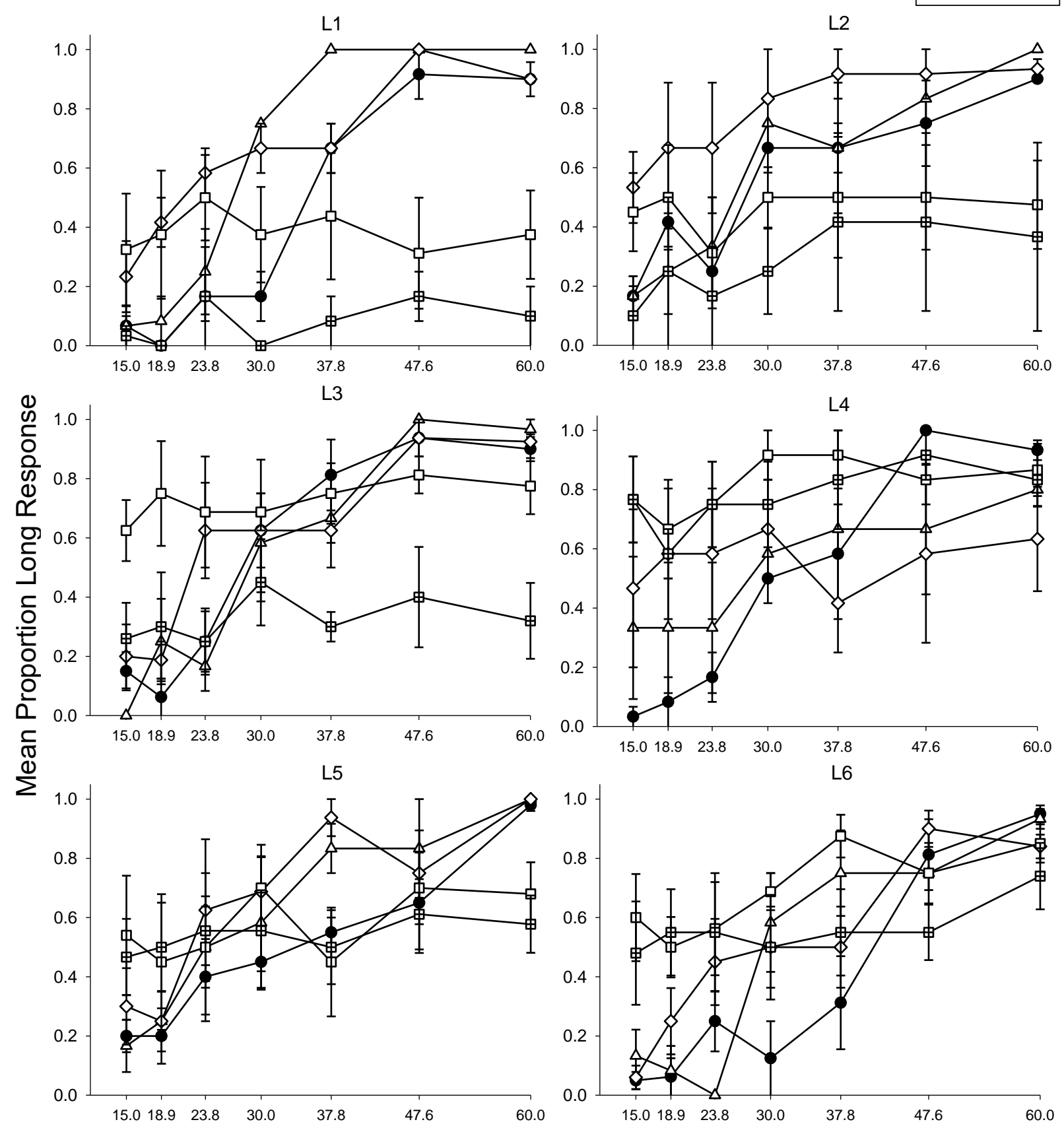

Duration (s)

Figure D12. Individual obtained functions averaged across sessions for LEW rats in the 15-s-vs.60 -s series of the drug administration phase. Error bars represent standard error of the mean. 
Appendix E: Log-Survivor Plots of Latencies
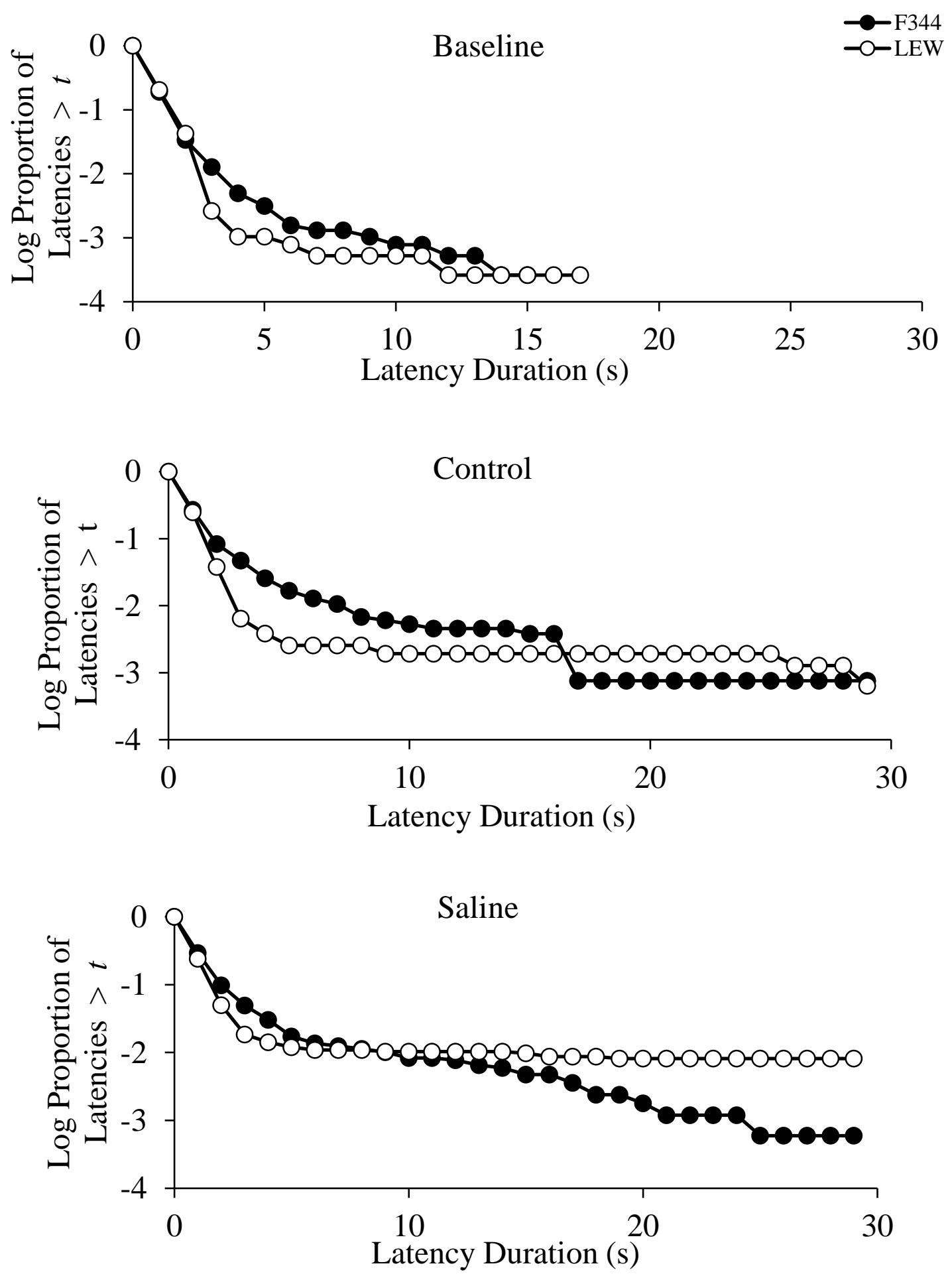

Figure E1. Log-survivor plots of latencies averaged across baseline, control, and saline sessions. 

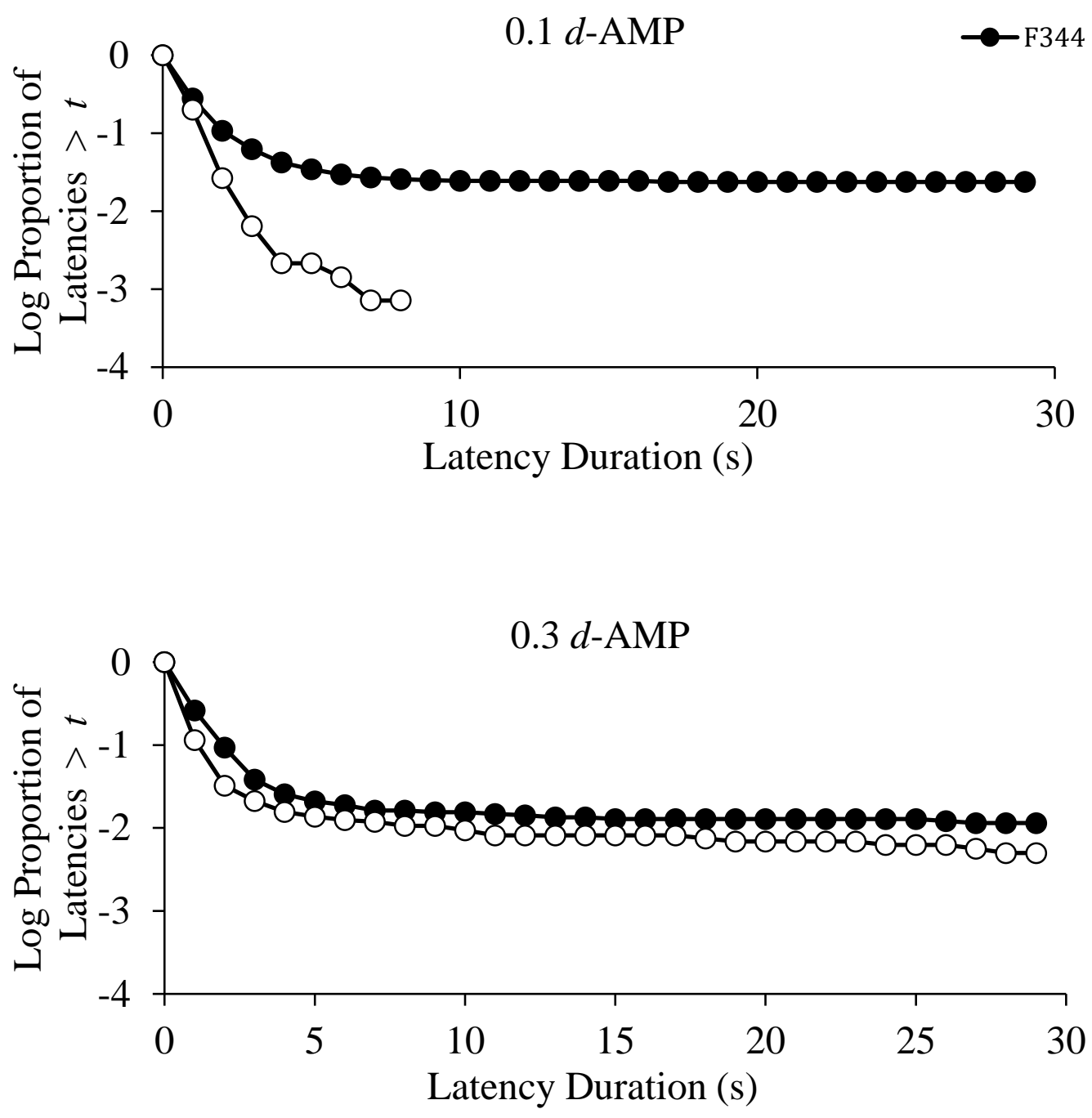

Figure E2. Log-survivor plots of latencies averaged across sessions with 0.1 and $0.3 \mathrm{mg} / \mathrm{kg} \mathrm{d}$ AMP administration. 

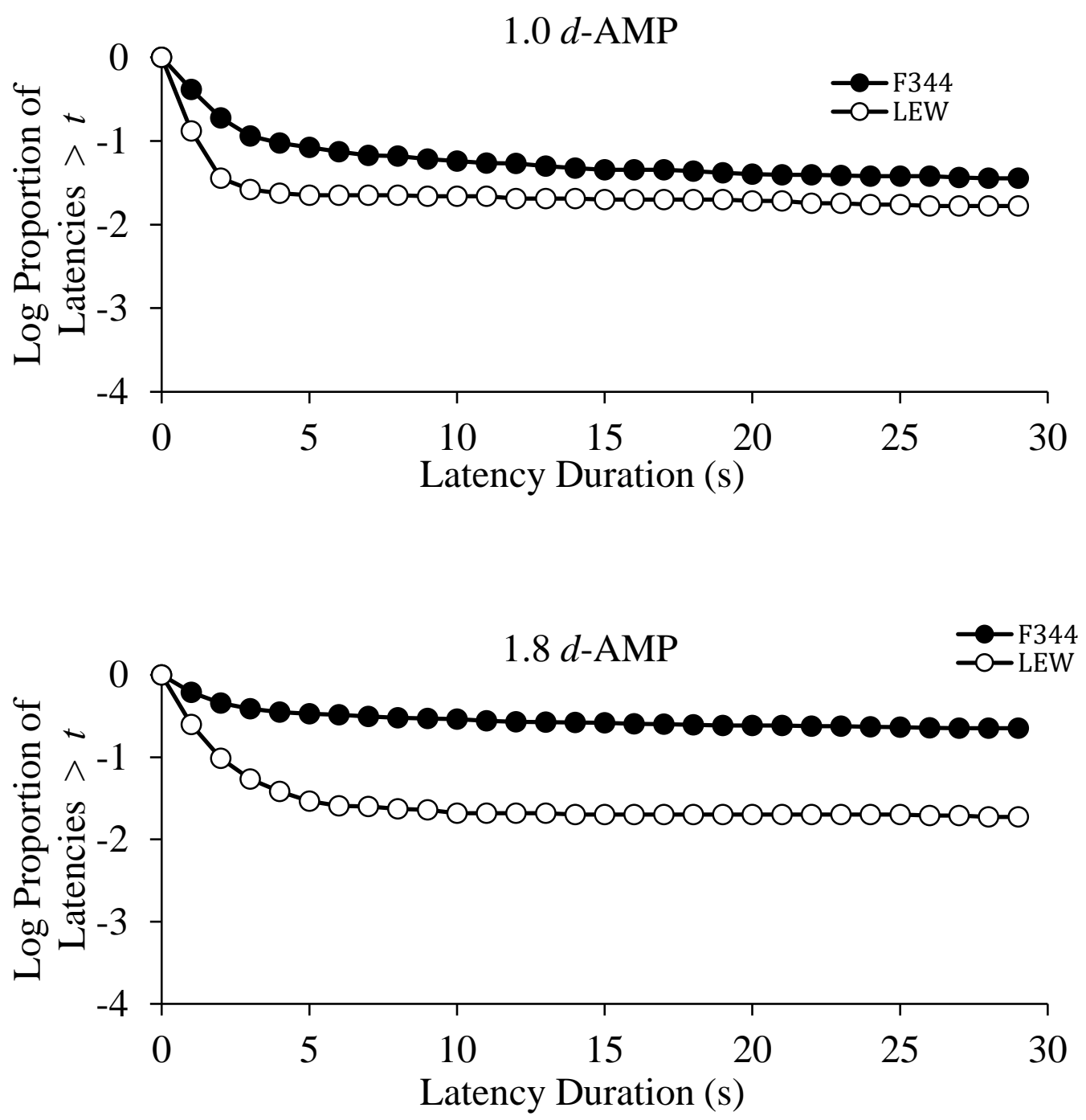

Figure E3. Log-survivor plots of latencies averaged across sessions with 1.0 and $1.8 \mathrm{mg} / \mathrm{kg} \mathrm{d}-$ AMP administration. 